\title{
WOMEN AND THEIR “FOOD TIME” \\ AN INVESTIGATION INTO FOOD PURCHASES, PREPARATION, AND CONSUMPTION ATMOSPHERE USING SMARTPHONE SURVEY TECHNOLOGY
}

\author{
A Thesis \\ presented to \\ the Faculty of California Polytechnic State University, \\ San Luis Obispo
}

\begin{abstract}
In Partial Fulfillment
of the Requirements for the Degree

Master of Science in Agribusiness
\end{abstract}

by

Garland Nell Jaeger

June 2013 
(C) 2013

Garland Nell Jaeger

ALL RIGHTS RESERVED 
COMMITTEE MEMBERSHIP

TITLE:

Women and Their "Food Time”

An Investigation into Food Purchases, Preparation, and

Consumption Atmosphere Using Smartphone Survey

Technology

AUTHOR: $\quad$ Garland Nell Jaeger

DATE SUBMITTED: June 2013

COMMITTEE CHAIR: Jennifer S. James, Ph.D., Professor, Agribusiness Department

COMMITEE MEMBER: Christiane Schroeter, Ph.D., Assistant Professor, Agribusiness Department

COMMITTEE MEMBER: $\quad$ Lisa M. Nicholson, Ph.D., R.D., Professor, Food Science and Nutrition Department 


\begin{abstract}
Women and Their "Food Time"
\end{abstract}

An Investigation into Food Purchases, Preparation, and Consumption Atmosphere Using

Smartphone Survey Technology

Garland Nell Jaeger

Women's food purchasing and eating habits have been studied in detail, but are still not entirely understood. Prior research has sought to segment the female food shopper market, but typically use only demographic characteristics. In this study, fifty females were recruited in San Luis Obispo, CA from March 2012 to May 2012 to keep an electronic food-time diary for one week. By collecting information through surveys distributed using a smartphone application, SurveySwipe, the study investigated the amount of time expended for each meal, as well as the manner in which the meal was prepared or purchased, and the context surrounding the eating situation, for a period of seven days. A segmentation of these female food consumers was then formed in order to demonstrate that by using attitudinal and behavioral data, a unique segmentation scheme may be achieved, different than would have resulted using only demographic information.

For the data analysis, four principal components analyses were conducted followed by subsequent cluster analyses, followed by ANOVA and Chi-Square tests. Study participants were segmented in four distinct sets of clusters, or consumer groups. Of the four sets of clusters formed, one was created using solely demographic variables, whereas the other three used "food time" variables comprised of behavioral and attitudinal information. It may be inferred from the results that the behavior of the participants within each cluster was similar regarding a particular variable being tested, while it differed from the behavior of participants in other clusters (regarding the same variable being tested). Specifically, an abundance of key, significant differences were found with the "food time" variables.

The study supports the use of variables related to "food time" allocation and the context of the eating situation as they relate to the purchase, preparation, and consumption of food, instead of only demographic attributes. The results will be useful for food marketers and product developers seeking to understand how food fits into the lives of female consumers with diverse roles and behaviors, in addition to being valuable for segmenting a select market or targeting a particular customer type.

Keywords: food marketing, market segmentation, attitudinal and behavioral variables, food context. 


\section{ACKNOWLEDGMENTS}

First and foremost I would like to thank Dr. Jennifer James, my thesis advisor, for her incredible contribution to this research. Without her encouragement and determination to achieve nothing but the best, I'm not sure I would have found the tenacity to finish this thesis. I am also very grateful for the time and evaluation provided by my committee. My fiancé, Jordan Perkins, was also integral as his unending support and advice provided

during my thesis was truly inspirational. I also want to recognize my amazing parents and grandparents, whose support in my attending grad school undoubtedly changed my life. Lastly, I would like to send a grand "thank you" to all of my family, friends, classmates, and professors who were a part of this project in any capacity. I am so grateful for your support. 
TABLE OF CONTENTS

Page

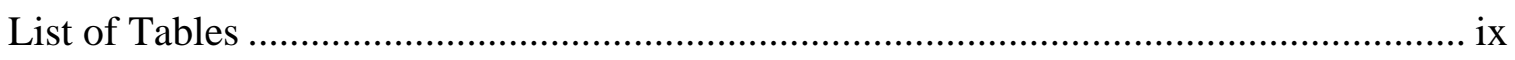

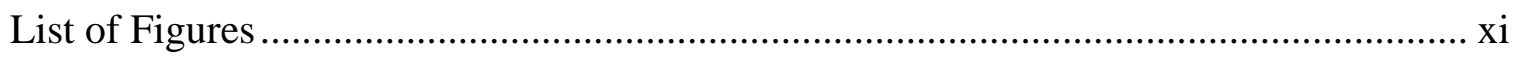

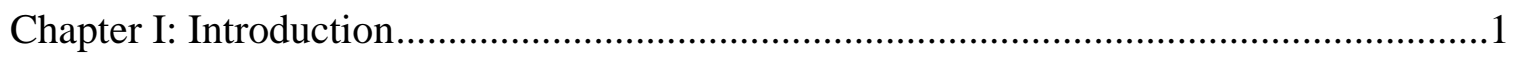

Background Information ....................................................................................

Problem Statement ..........................................................................................

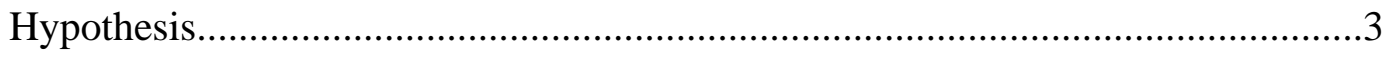

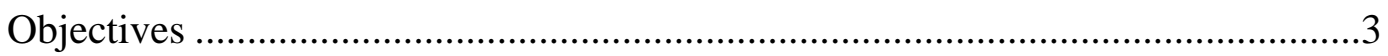

Justification of the Study .....................................................................................

Chapter II (Part A): Household Responsibilities, Education, and Labor Force

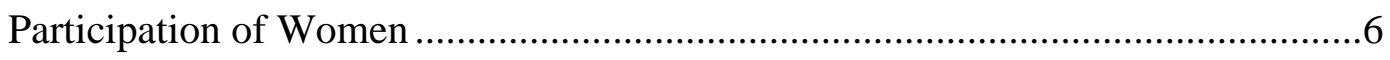

Increasing Educational Attainment....................................................................6

Participation in the Labor Force ..........................................................................

Distribution of Responsibilities in the Household ......................................................

Transferring the Task of Food Preparation .............................................................11

Trends in Food Preparation..................................................................................11

Grocery Shopping Trends ................................................................................14

Mobile Technology in the Food Industry ................................................................14

Chapter II (Part B): Previous Research of Food Context and Market Segmentation .........16

Interpretation of "Food Context" ...........................................................................17

Methods for Collecting Data................................................................................20

Application of Cluster Analysis and Segmenting the Food Consumer ..................26

Chapter III: Methodology ………………………………............................................

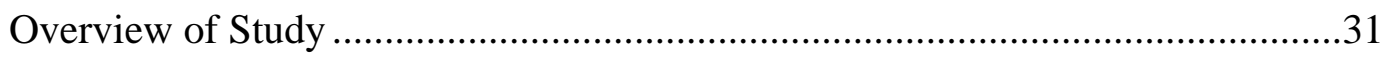




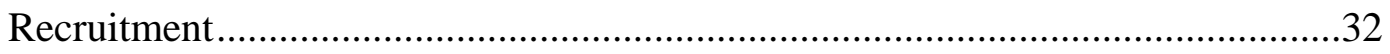

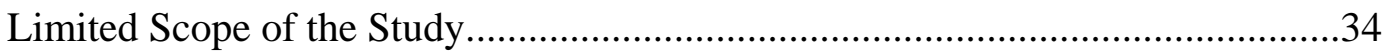

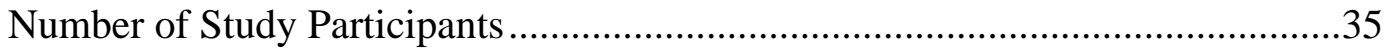

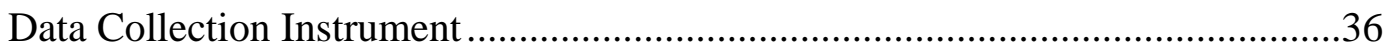

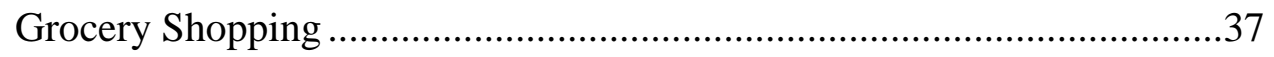

Meal Planning and Preparation..........................................................43

Food Choices ..........................................................................44

Consumption Atmosphere ............................................................45

Cooking Proclivity .......................................................................45

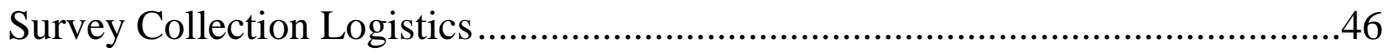

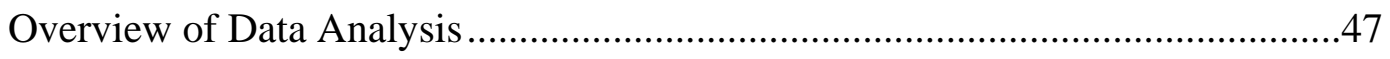

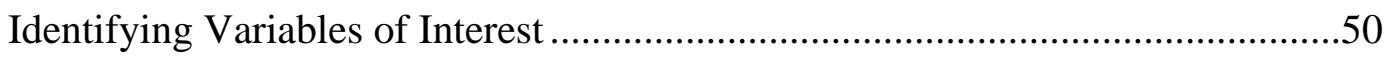

Principal Components Analysis ..............................................................51

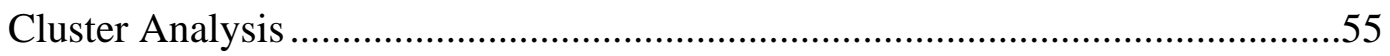

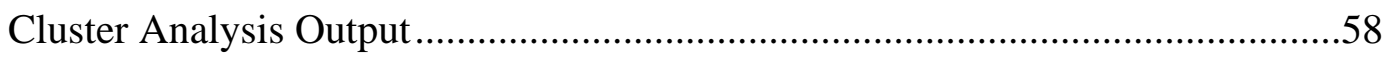

Validation of the Cluster Analysis: ANOVA and Chi-Square Tests ....................60

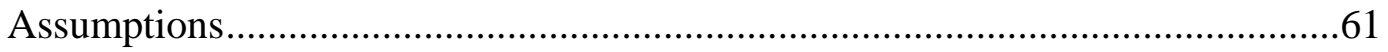

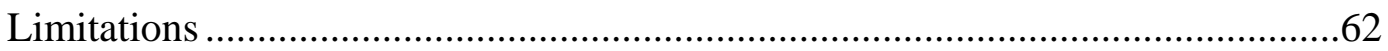

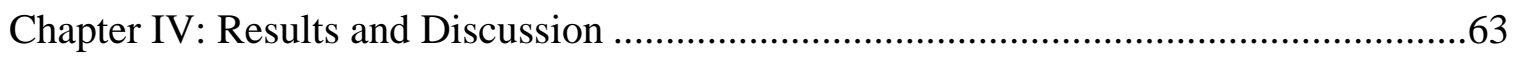

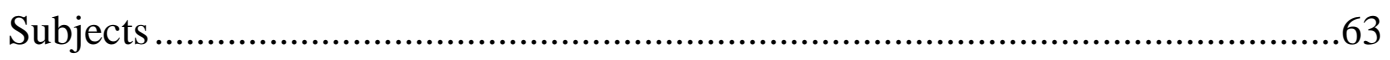

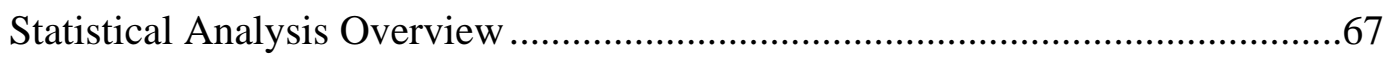

Principal Components Analysis: Methods and Results ...................................69

Principal Components Analysis \#1 ...................................................71

Principal Components Analysis \#2 ....................................................74

Principal Components Analysis \#3......................................................77 
Principal Components Analysis \#4 ...........................................................81

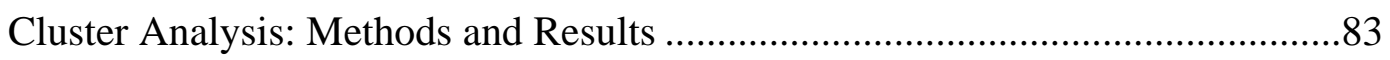

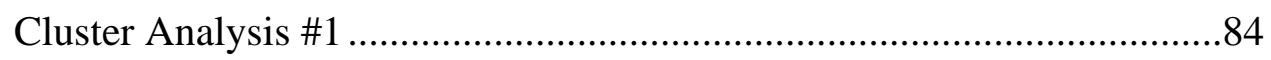

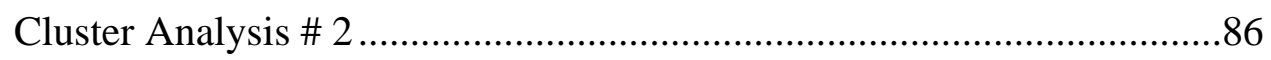

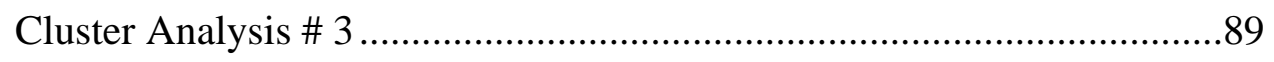

Cluster Analysis \# 4 ……………………………………………………....91

Choosing the Most Effective Analysis: Methods and Results.................................94

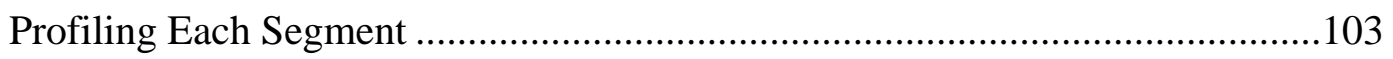

Cluster \#1: The Congenial Consumer.........................................................107

Cluster \#2: The Casual Consumerista.........................................................108

Cluster \#3: The Communal Consumer ....................................................110

Cluster \#4: The Contemporary Consumer ..................................................111

Targeted Marketing Promotions Using the Four Consumer Segments ................113

Cluster \#1: The Congenial Consumer........................................................113

Cluster \#2: The Casual Consumerista.........................................................114

Cluster \#3: The Communal Consumer .....................................................115

Cluster \#4: The Contemporary Consumer ..............................................116

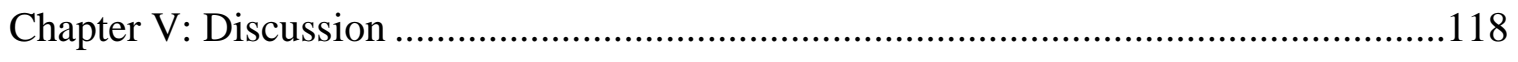

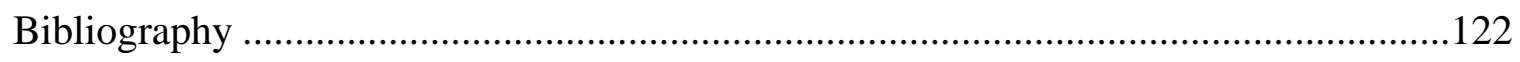

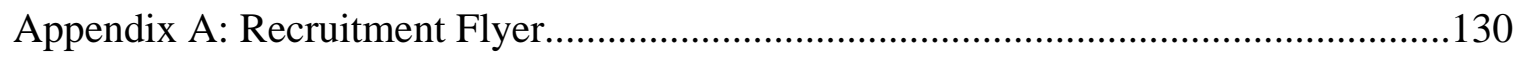

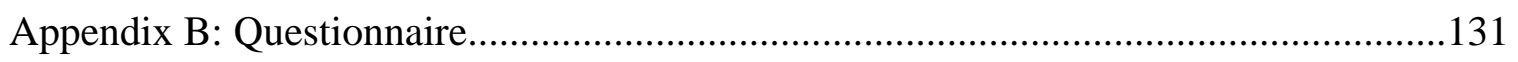

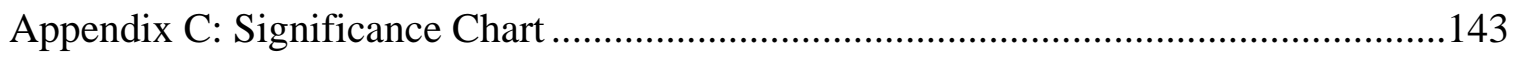

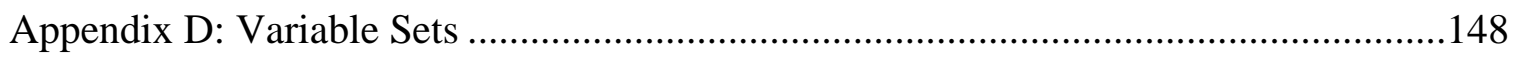




\section{LIST OF TABLES}

Chapter and Table Number $\quad$ Page

Chapter III: Methodology

3.1 Location and timing of recruitment efforts ..................................................33

3.2 Survey types and information obtained .......................................................37

3.3 Survey questions, variable names, and answer selections, by topic area ........38

Panel a Grocery shopping .................................................................38

Panel b Meal planning and preparation ................................................39

Panel c Food choices..........................................................................40

Panel d Consumption atmosphere....................................................41

Panel e Cooking proclivity...............................................................42

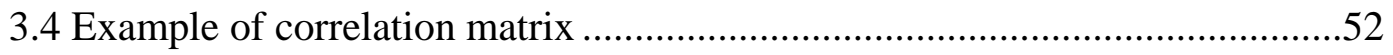

3.5 Example of the eigenequation output from SAS $\mathbb{C}$......................................53

3.6 Output example of eigenvalues of the correlation matrix...............................54

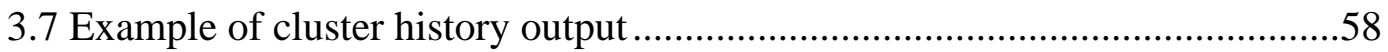

Chapter IV: Results and Discussion

4.1 Variables included in each principal components analysis...........................71

4.2 Eigenvalues of the correlation matrix for PCA \#1......................................72

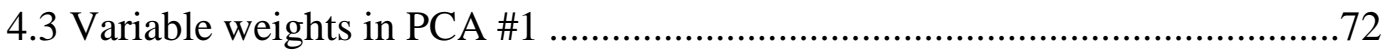

4.4 Correlation matrix for variables in PCA \#1 …...............................................73

4.5 Eigenvalues of the correlation matrix for PCA \#2.......................................75

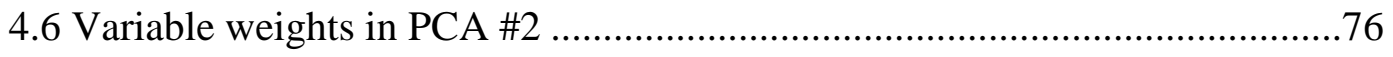

4.7 Correlation matrix for variables in PCA \#2 ...............................................76

4.8 Eigenvalues of the correlation matrix for PCA \#3......................................78

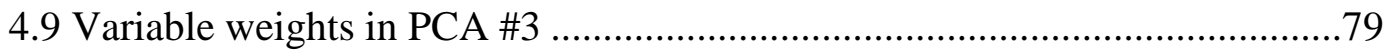

4.10 Correlation matrix for variables in PCA \#3 …...........................................79

4.11 Eigenvalues of the correlation matrix for PCA \#4....................................81 


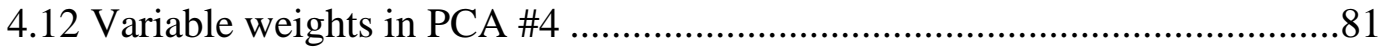

4.13 Correlation matrix for variables in PCA \#4 ................................................82

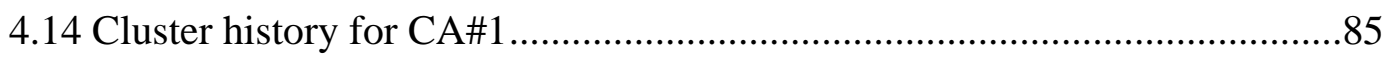

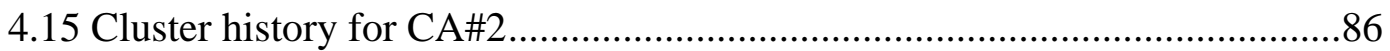

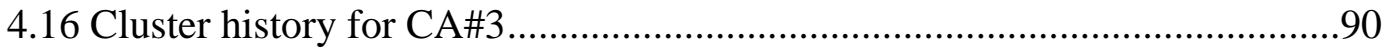

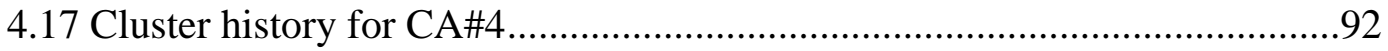

4.18 Number of significant differences found for each cluster analysis................95

4.19 Variables for which statistically significant differences were found in at least two cluster analyses ............................................................96

4.20 "Food time" variables with statistically significant differences for final model and demographic model......................................................99

Panel a Grocery shopping ................................................................99

Panel b Meal planning and preparation .............................................99

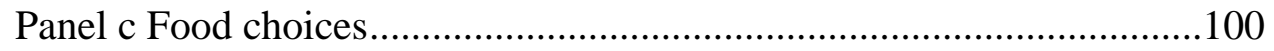

Panel d Consumption atmosphere ......................................................101

Panel e Cooking proclivity................................................................102 


\section{LIST OF FIGURES}

Chapter and Figure Number

Page

Chapter II (Part A): Household Responsibilities, Education, and Labor Force

Participation of Women

2.1 Percent of women ages 16+ in the labor force, 1950-2010

2.2 Average time spent in household activities, by women and men, 2003 versus 2010 .10

2.3 Annual per capita consumer food expenditures, 2005-2010

Chapter III: Methodology

3.1 SurveySwipe application on home screen of smartphone

3.2 Example of "push notification” sent to each panelist's smartphone within close proximity of mealtimes...............................................................32

3.3 Graphics used in recruitment flier..........................................................34

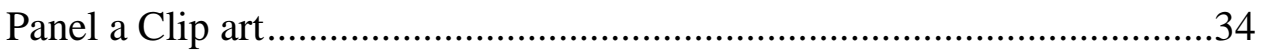

Panel b QR code.............................................................................34

3.4 Recruitment flyer including QR code and website link to download the SurveySwipe application ..............................................................46

3.5 "Push notification” of the most recent survey ...........................................47

3.6 Answer selections on the smartphone touch screen ..................................47

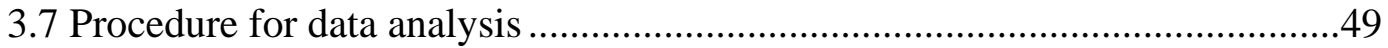

3.8 Cluster analysis: New cluster groupings are formed by combining two clusters whose centers are the closest in proximity ................................56

Chapter IV: Results and Discussion

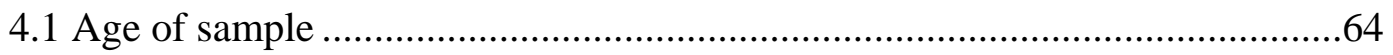

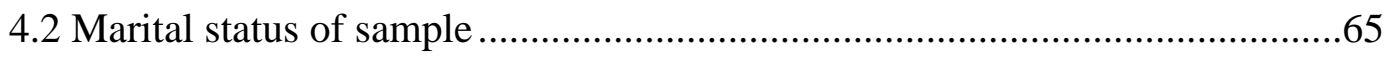

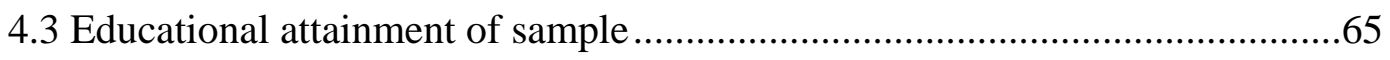

4.4 Annual household income of sample......................................................66

4.5 Employment status of sample ..........................................................67

4.6 Body Mass Indexes for sample ...........................................................67 
4.7 Visual representation of the statistical analysis process ...............................68

4.8 Scree plot from the SAS output for PCA\#1 ..............................................72

4.9 Scree plot from the SAS output for PCA\#2 .............................................75

4.10 Scree plot from the SAS output for PCA\#3 ................................................78

4.11 Scree plot from the SAS output for PCA\#4 ................................................82

4.12 Cubic Clustering Criterion (CCC) plot for CA \#1 ......................................86

4.13 Cubic Clustering Criterion (CCC) plot for CA \#2 .......................................87

4.14 Clustering of the sample: CA \#1, CA \#2, CA \#3, and CA \#4 ......................88

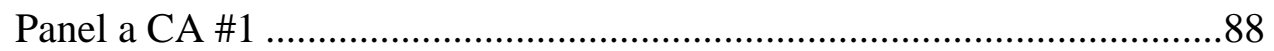

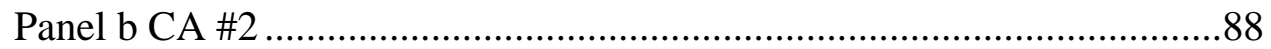

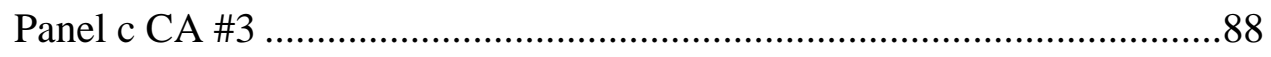

Panel d CA \#4 ...................................................................................8

4.15 Cubic Clustering Criterion (CCC) plot for CA \#3.......................................90

4.16 Cubic Clustering Criterion (CCC) plot for CA \#4 ......................................93

4.17 Demographic characteristics of entire sample, and by cluster....................104

4.18 Advertisement for grilling avocados.....................................................114

4.19 Advertisement for the multiple uses for avocados...................................115

4.20 Advertisement encouraging consumers to use avocados in taco dishes......116

4.21 Advertisement for eating an avocado raw or adding it to a salad ...............117

Chapter V: Discussion

5.1 Clustering of the sample: final model and demographic model ....................120

Panel a Final model......................................................................120

Panel b Demographic model ..........................................................120 


\section{Chapter I: Introduction}

\section{Background Information}

Traditionally, the woman has been the key individual responsible for food procurement and preparation in the household; however, the societal roles of women have changed dramatically since the 1950s. Women have obtained more education and increased their participation in the labor force (Solis and Hall, 2011). As a result, the context in which food is purchased, prepared, and consumed has changed as well. The amount of time allocated to grocery shopping has decreased (U.S. Bureau of Labor Statistics, 2010a), and the amount of time women spend preparing food has also been steadily declining throughout the past four decades (Zick and Stevens, 2009). Women now fulfill multiple roles in society, a course that will undoubtedly persist as a consequence of major demographic trends (Barnett, 2004), making their time increasingly limited. Despite time constraints, women remain the chief individual responsible for food procurement in the household (U.S. Bureau of Labor Statistics, 2010a), and women meet this responsibility using a variety of strategies. Because their food-related behaviors are so widespread, defining unique types of female food consumers is increasingly difficult.

Identifying different types of consumers is the basis of market segmentation, a widely used strategy in the food industry. This approach divides a consumer market into smaller, more identifiable sub-markets, or segments (Guthrie, Lin, and Frazao, 2002). Consumers within each segment are similar to one another but differ from individuals in other segments, thereby categorizing consumers into different groups based on their needs, tastes, and preferences as they relate to a particular product (Hunter, et al., 2010; Guthrie, Lin, and Frazao, 2002). 
In the past, demographic information such as household income, marital status, presence of children in household, employment status, and level of educational attainment, has often been used to segment the female consumer market (Kuruvilla and Joshi, 2010). However, this approach will no longer suffice, as women belonging to the same demographic segment can have extremely different habits and preferences regarding their food product demands. Segmenting food shoppers based on lifestyle characteristics can be informative in understanding what drives consumers to purchase certain types of food products (Buckley, Cowane, and McCarthy, 2007). The time allocated to different foodrelated activities is one lifestyle characteristic, but there is currently a lack of information concerning the relationship between the time allocation of the modern woman in America, the context of the eating situation, and the degree to which these factors influence her decisions about purchasing, preparing and consuming food.

In contrast to demographics-based marketing approaches, life-style marketing is a strategy in which a market is segmented based on consumers' habitual attitudes and behaviors, in particular the recurrent activities that eventually result in frequent purchases of a product. Promotional strategies may then be designed based on these patterns (Allen and Sachs, 2007). In this study, life-style market segmentation is employed, specifically in regards to the context of the food consumption, purchasing, and preparation made by a group of females. Ultimately the objective of market segmentation is to obtain a competitive advantage; by identifying particular segments to target, marketing and promotional tools may be specifically tailored to each segment (Hunter, et al., 2010), increasing the efficiency of marketing efforts. 
The "context” of food consumption can have many definitions. Some studies suggest that context is the amount of exposure or the degree of familiarity one has with a specific food or taste (Prescott and Bell, 1995). This explanation may be applicable to research that compares the perceptions of food(s) between different cultures. Context may also refer to the formation of an idea or interpretation, specifically in regards to food. For example, the definition of "healthy" may vary enormously between individuals, particularly as it relates to the nutritional value of food (Ronteltap, et al., 2012). Additionally, the context of food may be associated with the setting or atmosphere in which food is consumed (Blake, et al., 2007). For the study at hand, "food context” refers to: a) the social aspects of food choices (how many meals were eaten with others versus alone), b) the eating situation (if the meal was eaten in a restaurant, while sitting down, or on-the-go), c) the time spent eating each meal, and d) the manner in which the meal was prepared.

\section{Problem Statement}

Is "food context" as it relates to the purchase, preparation, and consumption of food, a valuable tool for segmenting the market of female food consumers?

\section{Hypothesis}

Using "food time" variables to create segments of female shoppers will generate more meaningful segments than when only demographic characteristics are used.

\section{Objectives}

1. To use surveys to collect information about women's eating habits, specifically:
A. The amount of time spent purchasing and preparing food
B. The amount of time spent eating meals
C. The eating location and atmosphere 
D. If meals were eaten alone or with others

E. Attitudes, behaviors, and preferences related to food choices, grocery shopping, and cooking

2. To conduct a principal components analysis and a successive cluster analysis using "food time" and "food context” variables created from survey responses.

3. To conduct a principal components analysis and a successive cluster analysis using solely demographic variables.

4. To assess the differences among the clusters that were formed using ANOVA and Chi-square tests.

5. To compare the results from segmentation using "food time" and "food context" to those from segmentation using only demographic characteristics.

\section{Justification of the Study}

Women's food purchasing and eating habits have been studied in detail, but are still not entirely understood. Most prior research has focused on the efforts of an intervention such as a cooking class or nutrition education on the types of food consumed (Glanz, Sorensen, and Farmer, 1996; Wrieden, et al., 2007). Some research has sought to segment the female food shopper market, but usually with demographic characteristics.

In this study a segmentation of female food consumers was formed using behavioral and attitudinal information. The examination is unique in regards to the inclusion of "food time," or the influence of study participants' perception of time (e.g., preferring not to cook a meal due to the amount of time and effort required to shop and prepare the food) and the actual amount of time expended related to food (e.g., grocery shopping, preparing meals, and eating meals). The results of the study will be useful for food companies, 
particularly marketers and product developers, in addition to organizations interested in obtaining a better understanding of the relationship between food context and the lives of female consumers with diverse roles and behaviors. 


\section{Chapter II (Part A): Household Responsibilities, Education, and Labor Force Participation of Women}

Throughout U.S. history, women have been responsible for feeding their families and preparing food to provide ample nutrients. Today this responsibility continues to be primarily held by the chief female of the household (U.S. Bureau of Labor Statistics, 2010a). In the latter half of the twentieth century, American women experienced a great deal of change with regards to the purchase, preparation, and distribution of food. New endeavors such as obtaining more education and entering the work force began to be integrated and the numerous roles women previously played in society were dramatically transformed (Solis and Hall, 2011). As a result, the manner in which women shop for food in today's marketplace and the subsequent preparation methods have evolved over recent decades. Currently, behavior as it relates to food differs greatly from a time when women's responsibility for cooking and food shopping remained a powerful norm across lines of class, race and ethnicity (Deutsch, 2010).

\section{Increasing Educational Attainment}

The number of women in the United States who attend college has been rapidly increasing during the past forty years. In 1970, 8.2 percent of females over the age of 25 obtained a bachelor's degree or higher and by 2011, this proportion climbed to 30.1 percent (National Center for Education Statistics, 2012). Furthermore, women are now more likely to obtain college degrees compared to men, a trend that began in 1992 (Taylor, et al., 2011). In 2010, 36 percent of women aged 25-29 had obtained a bachelor's degree versus 28 percent of their male counterparts. This difference in degree attainment by genders is the largest ever achieved (Taylor, et al., 2011) and it is likely to continue to rise. In fact, women are predicted to represent 60 percent of all students 
enrolled in college by 2016 (Hussar and Bailey, 2008). In addition, this shift in educational attainment has concurrently gradually transported women from the home to the workplace.

\section{Participation in the Labor Force}

In addition to their educational pursuit, the participation of women in the labor force has also been increasing throughout the latter half of the twentieth century. Women are increasingly seeking more prestigious positions and value having a career, which can often take priority over getting married, having children, and running a household. In 1950, 34 percent of females over the age of 16 were in the labor force; the proportion increased to 59 percent by 2010 (U.S. Bureau of Labor Statistics, 2011). See Figure 2.1. For women age 16 and over, the following percentages of each ethic group are employed: 54 percent of White females, 51.7 percent of Black or African American women, 53 percent of Asian women, and 49.6 percent of Hispanic or Latino females. Conversely, for women age 16 and over, the following percentages of each ethic group are unemployed: 7.7 percent of White females, 13.8 percent of Black or African American women, 7.1 percent of Asian women, and 12.3 percent of Hispanic or Latino females (U.S. Bureau of Labor Statistics, 2011). Women who are neither employed nor unemployed do not participate in the labor force. 


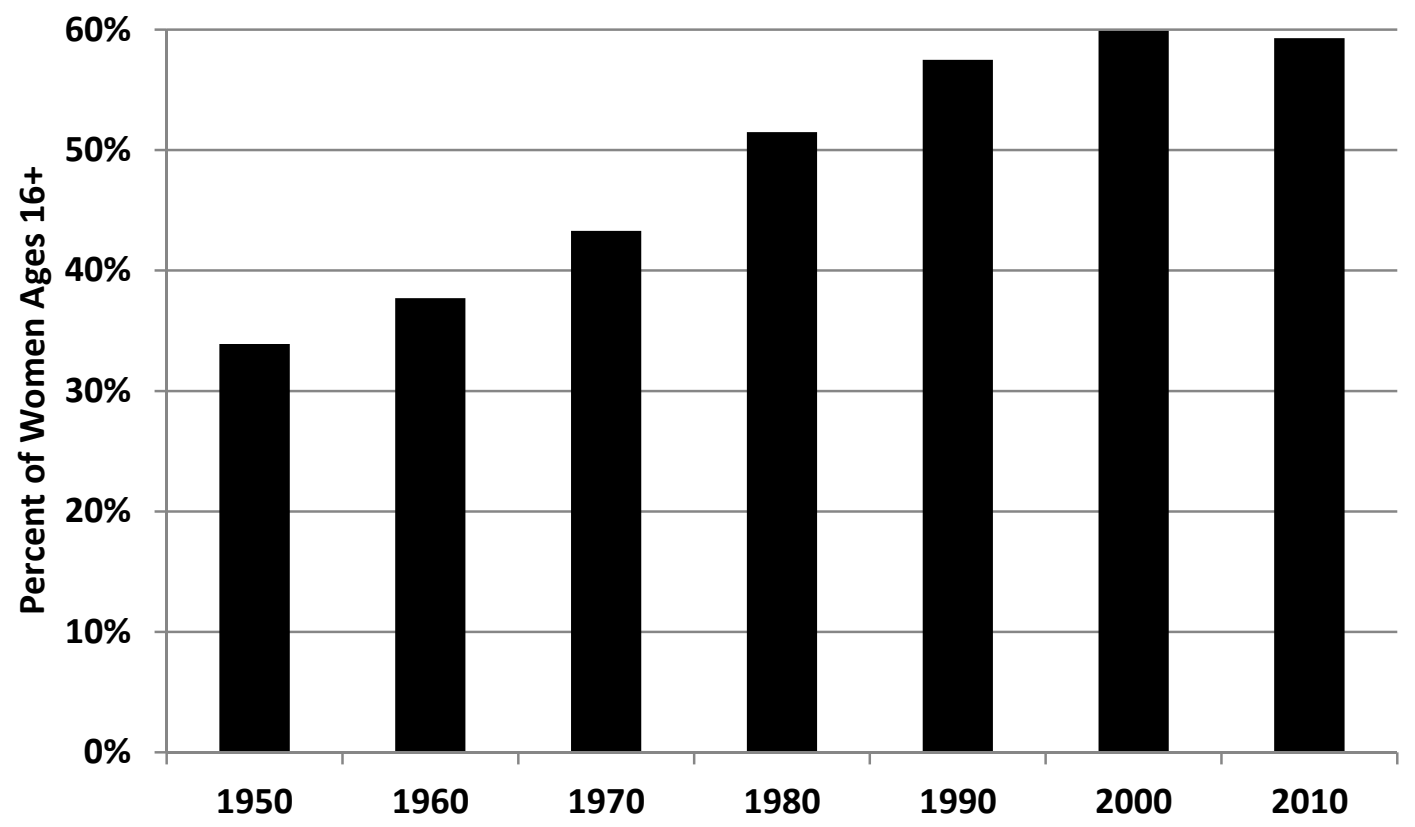

Figure 2.1 Percent of women ages 16+ in the labor force, 1950-2010

(Note: Percent is out of the total number of women in the civilian non-institutional population aged 16 and over)

Source: U.S. Bureau of Labor Statistics (2011)

Increased participation of women in the labor force is seen among many types of women. The proportion of college educated women in the labor force has increased dramatically, climbing from slightly over 11 percent in 1970 to 37 percent in 2011 (U.S. Bureau of Labor Statistics, 2011). In March 1975, 47.4 percent of women with children under 18 participated in the labor force, which rose to a peak of 72.9 percent in March 2000 (Solis and Hall, 2011). Unmarried women with children are more likely to participate in the workforce compared to married mothers. In 2010, 74.9 percent of unmarried mothers were in the labor force, compared with 69.7 percent of married mothers (U.S. Bureau of Labor Statistics, 2010b). Further, women are now waiting much longer to get married, 
with the estimated median age of females at first marriage increasing from 22 in 1979 to 26.5 in 2011 (U.S. Bureau of Labor Statistics, 2011).

With an increase in the amount of time committed to the workplace, it is increasingly difficult for women to devote time to food procurement, and as a result, the manner in which women provide food for their families has changed. Compared to their unemployed counterparts, women in the workforce devote less time to cooking and eating with their children (Zick and Stevens, 2009). Families with working mothers are also more likely to eat out and skip the evening meal, as well as consume more snacks (Beshara, Hutchinson, and Wilson, 2010). In addition, many women rely more on products that require little preparation. This is evidenced by employed women's perceived lack of time being particularly influential in shifting away from cooking meals and opting for convenience foods instead (Bava, Jaeger, and Park, 2008).

\section{Distribution of Responsibilities in the Household}

As a result of women's increased involvement in the work force, the composition of the managerial responsibilities in the household has transformed considerably. More women hold multiple jobs including part-time, evening, and weekend work, compared to men (Solis and Hall, 2011). Instead of transferring a portion of the household tasks to others, they still tend to do more household work than men (Mancino and Newman, 2007). Particularly with regards to kitchen duties, the authority is not distributed equally. For instance, 90 percent of female respondents in the U.S. Department of Agriculture's 1994 Continuing Survey of Food Intakes of Individuals (CSFII) claimed to be involved in the planning or preparation of family meals, compared to less than 30 percent of males (Harnack, et al., 1998). On average, women spend 7.8 minutes a day grocery shopping 
(compared to men who average 4.8 minutes per day) and more than double the amount of time spent in food preparation and clean-up activities compared to men (U.S. Bureau of Labor Statistics, 2010a). In 2010, women spent an average of 47.4 minutes per day in food preparation and clean-up activities versus men who spent 19.2 minutes per day, on average. Furthermore, women spent an average of 52 minutes per day engaging in housework, whereas men devoted an average of 16 minutes, to similar tasks (see Figure 2.2). "Housework” represents the following activities: interior cleaning, laundry, sewing, repairing, and maintaining textiles, and storing interior household items, including food (U.S. Bureau of Labor Statistics, 2010a). Finally, men spent around 69 minutes per day eating and drinking, and women were close behind at an average of 65 minutes (U.S. Bureau of Labor Statistics, 2010a). With time spent in these household activities, as well as tasks related to food procurement and consumption, it is plausible women are obtaining food from other methods besides self-preparation.

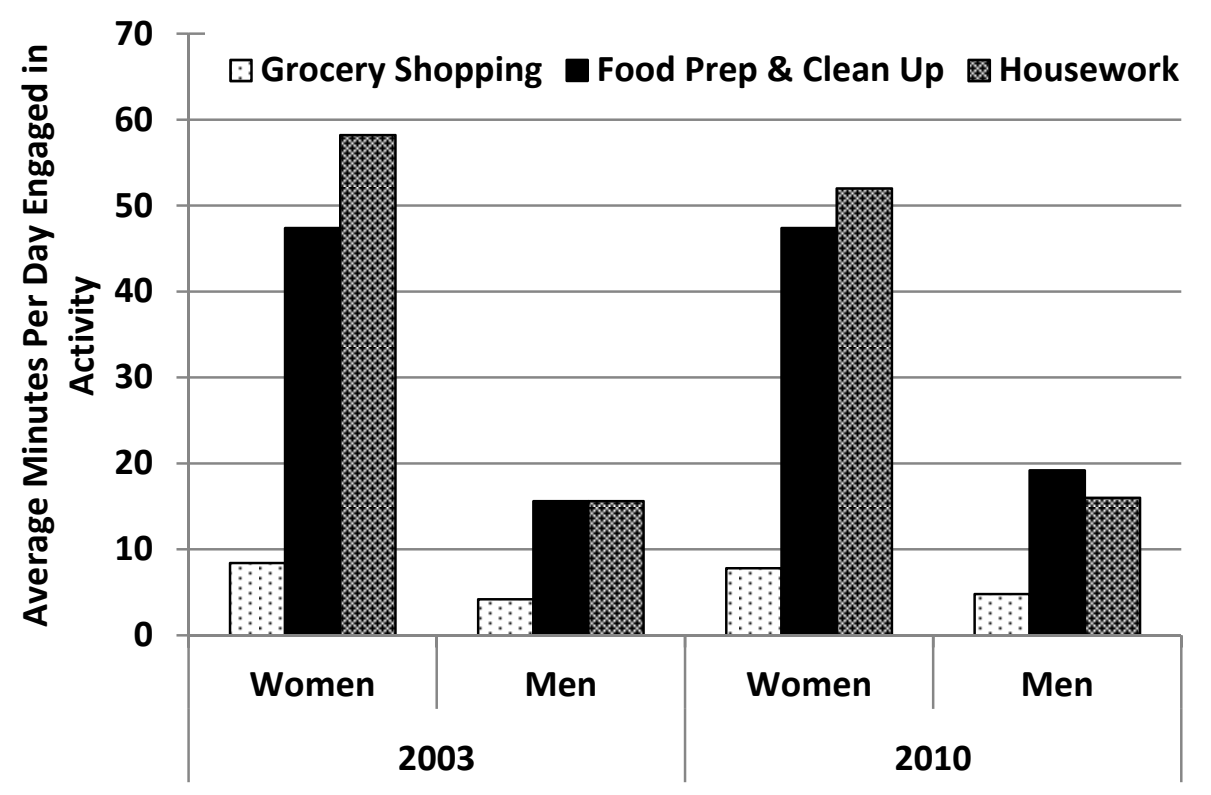

Figure 2.2 Average time spent in household activities, by women and men, 2003 versus 2010 Source: U.S. Bureau of Labor Statistics (2010a) 


\section{Transferring the Task of Food Preparation}

With women devoting more time to the work place and in turn increasing their household income, food shopping and preparation has decreased in recent years, not only with time distribution, but also in terms of prioritization. Households managed by time-constrained individuals with more education are more likely to purchase prepared meals, or those ready for rapid consumption, outside of the household, compared to cooking a meal at home (Harris and Shiptsova, 2007). In fact, those in charge of meal preparation who work over 30 hours per week are more inclined to purchase food products with convenience attributes compared to those who work less than 9 hours per week (Candel, 2001). Between 1975 and 2006, the time American women typically spent in food preparation declined by 40 minutes per day (Zick and Stevens, 2009), and by 2010 expenditures on food consumed outside of the home by households and businesses comprised 49 percent of all food spending in the U.S. compared to 35.8 percent in 1975 (USDA-ERS, 2011). By purchasing prepared foods, the responsibility of food preparation is transferred from the home to food processing companies, thus relieving countless women from the effort, time, and skills necessary to execute these tasks (Park and Capps, 1997). In the fall of 2010 alone, women between the ages 18 to 49 were 16 percent more likely to have purchased packaged dinners and side dishes, such as mixes or prepared foods, during a six-month time period, compared to all homemakers (MRI, 2010).

\section{Trends in Food Preparation}

The time-constrained circumstances of countless women's lives make preparing food at home difficult and many women rely on ready-to-eat meals or convenience food items (Bava, Jaeger, and Park, 2008). However, other situational factors have been influential 
in the opposite sense, enticing women to prepare meals in the household more frequently and placing a high priority on doing so themselves. For instance, the economic recession beginning in 2008 has affected meal preparation tendencies, encouraging women to prepare food more often in their household. For example, 75 percent of consumers claimed they prepared more meals on their own in 2011 compared to the previous year with the specific goal of saving money on food (FMI, 2011). Additionally, relative to 2009, over half of consumers cooked more meals at home in 2010 and 32 percent prepared more meals from scratch (FMI, 2011; Sloan, 2011). Shoppers also reported consuming an average of five home-cooked meals per week in 2011 (FMI, 2011). In many regards, preparing meals at home is less demanding now than in the past as a result of technological advances in the kitchen designed to make food preparation and clean-up more efficient (Bittman, Rice, and Wajcman, 2004). Electrical devices such as hot-plates and waffle irons developed in the 1930s, as well as popular appliances like microwaves and the Crock-Pot $\odot$ slow cooker from the 1970s (Lovegreen, 2005), made cooking meals increasingly manageable for women. These appliances changed the definition of "cooking a meal," ranging from assembling components "cooked" in a microwave as a meal versus heating a dish in a microwave that is a ready-to-eat meal. In either case, women were able to prepare a meal in a less amount of time. Interestingly, between 2003 and 2010, the percent of daily family meals consumed at home noticeably increased, from 52 percent to 73 percent (Moag-Stahlberg, 2011), perhaps a result of technological advances in the kitchen.

The amount of money spent on food in the U.S. has been increasing since the 1940s, except between 2008 and 2009, when both food at home and food away from home 
spending experienced a minor decrease during the recession (USDA-ERS, 2011). While expenditures have been escalating, average annual spending on food at home has remained higher than food away from home spending (USDA-ERS, 2011). See Figure 2.3 below. This trend implies consumers are still more inclined to prepare food at home compared to eating out, which is further supported by the fact that 90 percent of shoppers feel home-cooked meals are either "somewhat” or "much" healthier compared to food prepared by a restaurant (FMI, 2011).

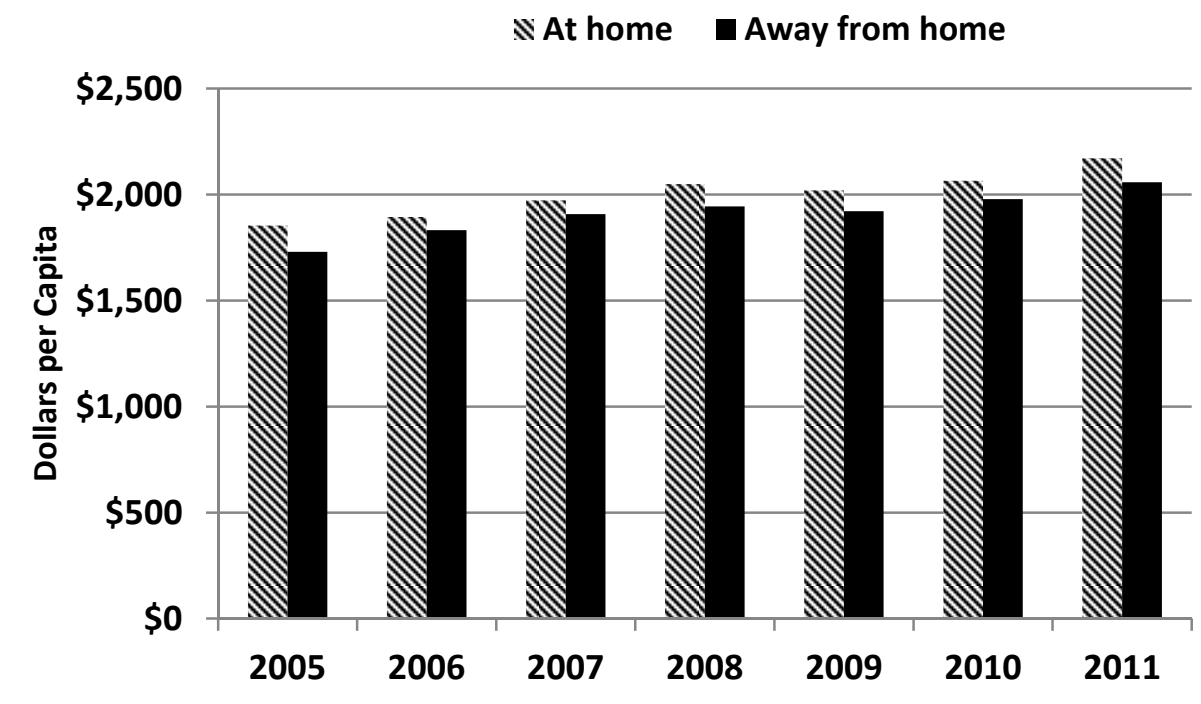

Figure 2.3 Annual per capita consumer food expenditures, 2005-2010 Source: USDA-ERS (2011)

Lastly, cooking has arguably become fashionable in modern-day American culture. Some even claim cooking and dining in the home has increased in its social status over recent decades (Moisio, Arnould, and Price, 2004). The rising popularity of celebrity chefs and media such as the Food Network $($, which is distributed to more than 96 million U.S. households, (Food Network, 2012) will likely propel this societal trend in the future. 


\section{Grocery Shopping Trends}

The manner in which women, and consumers shop for groceries has fluctuated in recent years. For example, low prices have now become the driving factor when it comes to shopper priorities, taking precedence over various store attributes that were customarily valued the most by customers in the past (FMI, 2011). Additionally, women believe it is more important for their primary grocery store to have a convenient location compared to men (Mortimer and Clarke, 2011). In regards to high-quality produce and meat, both genders believe having a good selection is "very important" in store selection.

Nevertheless, irrespective of store attributes, the number of trips to the grocery store has substantially decreased, dropping to an average of 1.7 times per week in 2011, down from 2.1 in 2006 (FMI, 2011).

Similar to being the key individual in charge of food procurement in the household, women are also doing the majority of grocery shopping (U.S. Bureau of Labor Statistics, 2010a). Whereas men are more inclined to make short trips to get a few select items, female shoppers tend to purchase numerous items when they buy groceries, with the intention of stocking the kitchen at home (FMI, 2011). However since 2003, the amount of time women spend grocery shopping has been declining (U.S. Bureau of Labor Statistics, 2010a). With a typical grocery store carrying an average of 38,000 different items, (FMI, 2011) marketing must be appropriately and precisely designed in order to entice female consumers to purchase specific food items.

\section{Mobile Technology in the Food Industry}

Technology has become a fundamental resource for communicating with consumers in the food industry. As of February 2012, the percentage of Americans who own a smart phone climbed to 46 percent, an increase from 35 percent in May 2011 (Zickuhr, 2012). 
This amount now exceeds the 41 percent of adults who own a mobile device that is not a smart phone (Zickuhr, 2012). The mobile app economy is rapidly expanding as a result of smart phone acquisition amongst consumers. Additionally, interest is reasonably high for apps related to grocery shopping and cooking, with functions such as searching for recipes, money-saving specials, and digital coupons, in addition to perusing product reviews, comparing prices, and finding retail locations (FMI, 2011). In fact, research conducted by AT\&T between March 2011 and March 2012 showed the number of scans of quick response (QR) codes in the food and grocery category was 36 percent, the most out of seven categories (RetailWire LLC, 2012).

Millennials (individuals born between 1980 and 2000) use smart phones on a more frequent basis compared to older generations (Mosaic Research Consulting, 2011), indicating that mobile technology usage will likely continue to rise in the future. While smart phone ownership is more prevalent among men, it is growing faster among women. The percentage of female ownership increased from 31 percent in May 2011 to 44 percent in February 2012. Conversely, the growth for men increased from 39 to 49 percent over the same time period (Zickuhr, 2012). By utilizing app-based technology, retailers can obtain real-time information specific to consumers' habits (FMI, 2011) and preferences, thus creating an opportunity to transmit marketing and advertising at the paramount time. 


\section{Chapter II (Part B): Previous Research of Food Context and Market Segmentation}

With women increasing their participation in the labor force and their increased educational attainment, and advancements in technology that enable consumers to prepare food rapidly or purchase meals that are ready-to-eat, research pertaining to female consumers' food-related behavior is even more imperative to gain a legitimate understanding of their needs and preferences. This is further complicated by the issuance of cooking being en vogue again for some individuals, or at least a high priority, and grocery shopping tendencies that are even more variable due to a plethora of circumstances.

Innumerable studies have been conducted pertaining to female food consumers. Aspects of those studies typically include the interpretation of "food context, methods for data collection, and procedures for analysis and market segmentation.” Because of the wide range of methods and approaches taken, the following three sections will describe previous studies with a similar focus to the study at hand, referred to as the "Women and Their Food Time” study or the "food time” study. While these studies are indeed different than the present study, understanding research that has been performed in the past is valuable so as to understand the conception of the "food time" study, in addition to its distinctiveness and contribution to the field. Doing so allows one to identify advantages and disadvantages of particular elements of a study design with the goal of making sound choices in the design of the current project.

The study at hand utilized surveys to collect information about women's eating habits including: (1) the amount of time spent purchasing and preparing food, (2) the amount of 
time spent eating meals, (3) the eating location and atmosphere, and (4) if meals were eaten alone or with others. Surveys were administered using a smartphone application. After an initial survey was completed, push notifications were sent at 2PM and 7PM each day for a week, prompting respondents to describe the source and eating context for their most recent meals. At the end of a week, a final survey was administered. Information regarding the participants' attitudes, behaviors, and preferences related to food choices, grocery shopping, and cooking was also collected. A principal components analysis and a successive cluster analysis were then conducted, using "food time” and "food context" variables created from survey responses. For comparison purposes, another analysis was conducted using demographic variables only. Lastly, ANOVA and Chi-square tests were used to assess the differences among the clusters that were formed. The value of each analysis is deliberated, namely the depth of information captured by the variables used in each analysis. Below, previous studies are described and comparisons will be drawn between the past studies and the one conducted for this thesis.

\section{Interpretation of "Food Context"}

The interpretation of the term "context” as it relates to food choices can differ between researchers, however; most interpretations are in accordance with the notion that food choice is an extremely misunderstood subject matter (Rozin and Fallon, 1980). Different aspects of context can include the influence of individuals' immediate environment when they purchase, prepare, and consume food, as well as their sensory perception of that environment. Cultural influences may also be referenced in contextual discussions, namely how one’s food environment is influenced by their ethnic background.

Sociological factors have also been found to influence the context of food: if the presence and/or behavior of another person affect food consumption or food purchases, for 
example. Likewise, occasions or events have been correlated with context, in that factors pertaining to these settings might play a part in the decision to partake in eating or buying particular food products.

In 2010, Oh, Choi, and Woo proposed a food recommendation system based on the assertion that "context-aware food recommendations" should "reflect personal needs in real time.” The data collected in the study included both "personal and situational contexts" of the study participants and their environment. "Context” included the profiles of subjects (e.g., gender or body figure), in addition to physiological characteristics (e.g., heart rate), and the sensory observation of their environment (e.g., noise level). The researchers concluded their food recommendation system based on personal information was more valuable versus a system where dietary advice was more generalized in nature.

Research related to the marketing environment of food and beverages targeted towards specific ethnicities has often associated the term "food environment” with context (Grier and Kunnanyika, 2008). Specifically, food environment is defined as "the totality of influences on how people acquire, choose, and consume foods and beverages as a distinct characteristic of this environmental context” (pg. 1616). Grier and Kunnanyika (2008) stated that while it is not possible to understand the preferences of individual consumers, segmenting shoppers into similar groups based on attributes such as "usage behavior, needs, wants, lifestyles, behavior, and values” (pg. 1617) will enable marketers to design promotional efforts that each segment will likely respond to. Sealy (2010) also studied the influence of culture as it relates to the context of food consumption, in which the culture of study participants was correlated with the ethnic context of their food choices. Influences included the types of food they ate during their childhood, which geographic 
location they were from, as well as the manner in which they learned to prepare food and continue to do so (Sealy, 2010). In addition, differences between different cultural groups were examined, such as having a limited amount of time available for grocery shopping and the tendency to prepare meals at home versus purchasing them.

Social influence has also been mentioned as being a part of the context in which food choices are made, particularly regarding the degree to which food consumption by an individual is affected by the behavior of another individual who is present (Pachucki, Jacques, and Christakis, 2011). Furst, et al. (1996) conducted interviews to investigate the social factors and the process of making food choices. Study participants answered questions regarding their decisions related to grocery shopping, specifically how they chose foods to purchase while shopping and their strategies for shopping. Particularly related to context, subjects reported which factors played a role in their choice to buy or consume particular food products during certain settings such as a birthday or special occasion, in addition to foods they typically consume at home and those they tend to eat when dining out. Food context was defined as the "environment for food choices that occur in specific behavior settings" and included the "physical surroundings and social climate of the choice setting” (pg. 256). Ultimately, the researchers concluded that contextual factors had a significant influence on the food choices of a number of study participants, while other participants' consumption decisions were less affected by these contextual factors.

The interpretations of "food context" used in the studies mentioned above are all capable of explaining consumer behavior from a unique and potentially more beneficial perspective compared to studies that omit these contextual factors. They reflect trends in 
the marketplace and provide valuable information for food companies for product development and positioning in the market (Onwezen, et al., 2012). It is likely the complexity of consumers' food-related behavior will continue to grow. With this in mind, the study at hand was designed to expand upon these studies and others that are similar, with the objective of making a valuable contribution to the body of knowledge.

\section{Methods for Collecting Data}

Many studies pertaining to food purchasing behavior, preparation methods, and consumption tendencies use food frequency questionnaires for collecting data (Brunner, van der Horst and Siegrist, 2010; Hopping, et al., 2010; Pliner et al., 2006), or dietary recalls (Shay, et al., 2012), in an attempt to document how often specific food items are consumed. Others use administered, face-to-face interviews (Turrell and Kavanagh, 2006). Often, socioeconomic and demographic attributes are utilized to distinguish consumption habits between groups of individuals who earn a similar household income or are of the same gender (Brunner, van der Horst and Siegrist 2010; Hopping, et al., 2010; Turrell and Kavanagh, 2006; Shay, et al., 2012). Research has also compared the efficacy of unconventional data collection methods such as digital food assessment tools (Vereecken, Covents, and Maes, 2010; Tomiyama, Mann, and Comer, 2009).

In 2010, research was conducted to examine the extent to which study participants saved time by cooking (or alternatively, the increase in the amount of time expended when opting to cook), the effort that went into meal preparation, and their knowledge of cooking and preparation methods (Brunner, van der Horst and Siegrist, 2010). They also investigated the cost associated with preparing food from scratch versus purchasing meals with convenience attributes. In a food frequency questionnaire distributed by mail, 
respondents were asked how often they consumed food items with convenience attributes out of a selection of 17 common convenience foods found in supermarkets. Based on that information, a 7-point scale was used to track how often various types of convenience food items were eaten, categorized into four groups of convenience products including highly processed food items, moderately processed food items, single components, and salads (Brunner, van der Horst and Siegrist, 2010). Their examination obtained information from subjects who were the primary shopper and preparer of food in their households.

Brunner, van der Horst and Siegrist (2010) found age to be the strongest predictor of convenience food consumption, with older respondents consuming less convenience food items. Additional consumption predictors included gender, working status, and having children in the household. Females in particular were less likely to eat convenience food items compared to men, and convenience food consumption decreased even further for women with children and those who worked full-time. Other unique consumption predictors were measured besides socio-demographic variables, including nutrition knowledge and cooking ability. Additionally, respondents were asked how much time each day they typically spent cooking, the degree to which they were concerned with the naturalness of the foods they ate, and their inclination to purchase foods based on their aversion to wasting food.

To some extent, Brunner, van der Horst and Siegrist’s (2010) work is analogous to the Initial and Final Surveys incorporated in the study "Women and Their Food Time," with questions pertaining to similar information such as the amount of time spent cooking and cooking proficiency. Both sought to obtain additional information from respondents 
along with socio-economic and demographic characteristics. Brunner, van der Horst and Siegrist's (2010) emphasis on real preparation is also similar to aspects of the current study. However his focus on individuals who are similar in regards to the proportion of food shopping they do for their household may allow for a more accurate comparison of different food purchasing behaviors. In the current study, female consumers of all types were included, and a broader range of foods and food attributes were covered. This approach is capacious in that it attempts to allow a more diverse set of consumers and food items to be measured.

The quality of the information collected in the food frequency questionnaire used by Brunner, van der Horst and Siegrist (2010) is somewhat uncertain, because study participants were required to remember details pertaining to their food purchases, consumption, and preparation methods after the fact. They completed the questionnaire in its entirety at once, rather than recording their conduct over a longer time period as consumption occurred. Alternatively, it may be preferable to record the occurrences instantaneously using digital devices such as the smart phones used in the current "food time” study. Furthermore, rather than collecting data on an undesignated day during the week (which may be a Saturday or Sunday). The "food time” study collected data on each subject for 7 days in order to gain an extensive record of food tendencies throughout the week.

It has been mentioned that socioeconomic factors are often used to distinguish different food related behaviors, and a 2006 study by Turrell and Kavanagh is an example of research within this arena (Turrell and Kavanagh, 2006). Face-to-face interviews were conducted with 1003 individuals in order to assess the association between educational 
attainment, household income and food purchasing behavior. The households tested were selected intentionally, premised upon the socioeconomic status of each district in Brisbane City, Australia, in conjunction with random sampling. Like the study by Brunner, van der Horst and Siegrist (2010), the population was narrowed by solely surveying the individual in the household primarily responsible for the food shopping. Questions assessed the respondents' dietary knowledge, concern about food costs, and food purchasing tendencies.

Akin to evaluating the food preferences and behaviors in the Initial Survey in the food time study, Turrell and Kavanagh (2006) measured the overall attitudes and knowledge of the sample population prior to conducting the experiment. In particular, the extent of dietary knowledge each participant possessed and its influence on their food purchasing behavior was examined, as well as their perspective on food, nutrition, and health, measured by a 20-item index. The process for analyzing the data entailed a Principal Components Analysis (PCA), a two-stage cluster design, and linear regression (used to evaluate associations between variables).

Not surprisingly, the results found significant correlations between education, household income, and food purchasing behavior. The subjects who were least likely to buy healthier foods also had obtained less education and came from low-income households. These results were alike those achieved in previous studies of this nature (Bihan, et al., 2010). With largely socio-demographic characteristics considered, instead of including additional unique factors apt to influencing food purchasing behavior (such as the "food time” variables used in the study at hand), it is understandable that novel findings were not attained. In order to gain new insight regarding the behavior of food consumers, 
variables that have not been measured previously are valuable for research endeavors seeking original findings.

The influence of circumstances encountered in everyday, routine atmospheres on food related tendencies was also investigated by Tomiyama, Mann, and Comer (2009). They examined the eating habits of 118 females who recorded their behavior on an hourly basis for two days and used electronic diaries to document possible triggers for hunger, as well as the actual eating that occurred. This alternative method for data collection enabled the study participants to be evaluated in their normal settings, compared to staged circumstances or laboratory atmospheres.

The authors tout the study’s use of electronic daily diaries, proclaiming that an examination of everyday food choices is more effective compared to collecting responses that were described retrospectively (Tomiyama, Mann, and Comer, 2009). Many results of the study were unique in comparison to results achieved from studies conducted in laboratory settings (Lattimore and Caswell, 2004), both in terms of measuring the influences of everyday scenarios and the use of electronic diaries. Specifically, “restrained eaters” have been found in laboratory settings to overeat in response to emotional states but not hunger, whereas unrestrained eaters only eat in response to hunger. Tomiyama, Mann, and Comer (2009) found that for “restrained eaters” (1) overeating was not a response to experiencing anxiety, (2) when in positive or negative moods they ate less, and (3) they ate more when they were hungry. These findings were opposite those found in laboratory settings, whereas the results of the "unrestrained eaters” were fairly similar to lab findings (Tomiyama, Mann, and Comer, 2009). Thus studies collecting data about participants’ routine environments using digital technologies 
may enable researchers to discover new information that would have otherwise been unattainable in settings orchestrated by the researchers (Tomiyama, Mann, and Comer, 2009).

Numerous data collection elements from Tomiyama, Mann, and Comer's (2009) study were particularly analogous to the current study, specifically by utilizing an electronic diary. For example, participants enrolled in Tomiyama, Mann, and Comer’s (2009) study through a web-based sign-up page and answered a baseline questionnaire to gather information about their overall attitudes and behaviors. Each subject also received a page on a Personal Digital Assistant (PDA) to enter their food intake, which is comparable to the push notifications in the "food time" study. However Tomiyama, Mann, and Comer’s (2009) study remains different in terms of the hourly reporting, instead of twice a day, and a data collection period of two days compared to one week.

Pliner, et al. (2006) looked at the influence atmosphere might have on food consumption. The researchers measured the amount of food ingested by study participants, and assessed if it was a consequence of the number of “coeaters” present (Pliner et al., 2006). One hundred thirty two individuals, both male and female, were recruited via telephone to eat a meal in a prearranged setting. Each participant was either examined alone or in groups, with the amount of time allocated for eating based upon the number of people in the examination group. The researchers investigated the effects of eating on mood, testing participants in groups of two, four, or by themselves. Two specific time increments, 12 or 36 minutes, were allocated for the subjects to eat a meal. Afterwards a post experimental questionnaire was completed in a different room where the same food items provided for the meal were again present. The size of the group was not found to be significant. The 
authors concluded their findings support the notion that previous studies who did find group size had an effect on food intake were actually influenced by meal duration instead of group size (Pliner et al., 2006).

The procedure by Pliner, et al. (2006) is markedly different than the "Women and Their Food Time” study, in which data was collected from study participants on an individual basis. Furthermore, the food consumed in Pliner et al.'s study was chosen by the researchers and the data was collected during a specific eating occurrence. In the post experimental questionnaire gender, group size, and meal duration were measured, as well as the amount of food consumed during the main meal. Participants recorded their information on a single, post-experiment questionnaire, rather than providing information on all meals consumed for a time period spanning multiple days. It is plausible this tactic for data collection lacks accuracy due to the fact it is unknown if identical behavior would have occurred in environments that were not prearranged.

\section{Application of Cluster Analysis and Segmenting the Food Consumer}

Along with the interpretation of "food context" and methods for collecting data, bases for segmentation concerning the food market have varied a great deal in the past (Honkanen and Frewer, 2009). Many used demographic characteristics (Hopping, et al., 2010) or geographic data (Quinn, Hines, and Bennison, 2007), while others used character traits and attitudinal factors, which became popular bases for segmentation in the 1980s (Quinn, Hines, and Bennison, 2007). Shopping habits and preferences followed in the next decade (Gehrt and Shim, 1998) and in recent years, lifestyle characteristics have gained more attention (Buckley, Cowane, and McCarthy, 2007). This is supported by the notion that consumers are increasingly multi-faceted and thus, require unconventional 
segmentation techniques in order to better understand the underlying motives of their food behavior (Ares and Gámbaro, 2007). The study at hand was conceived with this idea in mind.

Cluster analyses are often used in conjunction with market segmentation research in order to obtain a better understanding of consumer tendencies, as well as the drivers for particular behaviors (Onwezen and Bartels, 2011; Ares and Gámbaro, 2007). The outcome of studies in this realm can be widespread, depending on the basis for segmentation. For example, Ares and Gámbaro (2007) studied the preferences of 200 consumers in regards to their food selection, utilizing a cluster analysis. Data was collected using a survey and participants were recruited at shopping areas, universities and public places. "Functional food” items were presented to each subject. "Functional food” items were designated as those that contained one or more of the following ingredients: honey, yogurt, vegetable cream soup, sweetened condensed milk and marmalade, as well as containing one of the following enrichments: fiber, calcium, antioxidant extracts and iron. Respondents were asked to rate the degree to which they perceived the item as healthy, as well as their willingness to try it. Three consumer groups were outlined based on their patterns for food-related decisions and demographic factors, in addition to their willingness to try functional foods. The authors suggested the allure of product attributes such as sensory appeal, nutritional value, price, and convenience vary depending on the type of consumer. Furthermore, the authors encouraged food producers to conduct consumer research prior to launching a new product in order to have a better understanding of shoppers’ perceptions of the product. Ultimately they concluded that functional foods should be designed with a specific 
consumer group in mind, rather than targeting the entire marketplace. This is in-line with the "food time" study, which aims to utilize a targeted marketing approach for each consumer group that is created within the sample.

Similar research was conducted a few years later by Onwezen and Bartels (2011), on innovation occurring in the European fresh fruit market. Data was collected using an online panel survey and a cluster analysis was employed for data evaluation. Three cluster groupings were profiled, distinguished by the importance ratings of an array of product attributes and willingness to purchase novel fresh fruit items. The researchers praised the utilization of a cluster analysis, stating it can produce improved, tailored marketing strategies (Onwezen and Bartels, 2011).

In addition to obtaining a better understanding of the underlying motives for consumer behavior, market segmentation is also frequently used to predict how consumers will react to products in the future (e.g., Onwezen, et al., 2012). Using cluster groupings based on consumers' previous actions, marketers can forecast which shoppers will be more attracted to particular food items. They can also use this information when launching new products by targeting consumers who have a higher likelihood of trying novel items. As an example, Onwezen et al. (2012) used a cluster analysis to identify consumer groups based on the level of importance placed on food benefits including health and convenience. The segments were examined to see if the level of importance subjects placed on food benefits could be used to predict food intake during different consumption occurrences. The examination in the "food time" study was slightly different, as it did not measure participants’ opinions of the benefits of food items in particular. Instead the approach to buying, preparing, and eating food was studied. Additionally, Onwezen, et al. 
(2012) examined whether the segments themselves could be used to predict the perception a consumer will likely have in regards to the benefits of specific food items.

The results indicated the segments (differentiated by their importance rankings of food benefits) did indeed have different perceptions of food products, namely if they were considered healthy or unhealthy. The authors concluded that consumers' decisions are not generalized, rather they are dependent upon the nature of food products and the type of context, or situation, in which the food products are encountered (Onwezen, et al., 2012). Likewise, other studies have drawn similar conclusions including the claim that different eating occurrences, such as breakfast and dinner (King et al., 2004) and the atmosphere of the consumption situation, such as dining in the household or eating out (Meiselman et al., 2000), affect individuals' food choices and reception of food products. For the future, Onwezen, et al. (2012) promoted a segmentation scheme based on perceptions of food products and claimed it would equip marketers with valuable information for positioning products in the marketplace, as food companies deal with consumption motives and incidences that vary a great deal. Furthermore, it was argued that it is inefficient for companies to highlight product attributes that do not differ much in terms of importance between consumers. Instead, product characteristics that differ in importance among consumers should be promoted to particular segments, for a targeted approach.

Only recently have segmentation studies considered many food-choice motives simultaneously with factors like demographic characteristics as the basis for segmentation (Ares and Gámbaro, 2007; Kornelis, Van Herpen, Van der Lans, and Aramyan, 2010; Onwezen, et al., 2012). Due to the fact that understanding consumer 
demand is not as simple as examining demographic factors, the lifestyles of different consumer types, and the catalysts responsible for these changing lifestyles must be identified (Buckley, Cowan, and McCarthy, 2007).

Utilizing the simultaneous, many food-choice motives approach, Buckley, Cowan, and McCarthy (2007) examined 1000 consumers and their "convenience food lifestyle (CFL)”. The authors describe the CFL concept as the extent to which an individual is oriented towards convenience, opting to save time and energy when it comes to foodrelated activities. A questionnaire was used for data collection and it included questions regarding meal preparation tendencies, how often study participants dine out, purchase carry out meals to eat at home or on-the-go, and cook meals from scratch, among others. These same topic areas were the basis for several questions in the "food time study." Buckley, Cowan, and McCarthy (2007) conducted a principal components analysis and cluster analysis that resulted in four CFL segments, based on 20 convenience lifestyle factors. This method was referred to as a "lifestyle segmentation procedure" by the authors, who claimed this type of in-depth understanding of consumers' motivations enables food companies to develop improved and targeted marketing tools for product development and communication strategies. 


\section{Chapter III: Methodology}

\section{Overview of Study}

Fifty females were recruited in San Luis Obispo, CA from March 2012 to May 2012 to keep an electronic food-time diary for one week. Members of the convenience sample were recruited using several tactics. In an effort to discover if variables corresponding to women's "food time," may be used to segment the female consumer, the study examined (for each meal), the amount of time expended, as well as the manner in which the meal was prepared or purchased, and the context surrounding the eating situation, for a period of seven days. Surveys included an Initial Survey, a Final Survey, and two surveys sent on a daily basis, a $2 P M$ and a $7 P M$ Survey. Prior food-related studies often use a handwritten diary to administer food frequency questionnaires (Rockett, et al., 1997; Hennessy, et al., 2010). In contrast, this study utilized a smartphone application, SurveySwipe, designed as an electronic diary.

SurveySwipe is a smartphone survey system which allows surveys to be created and distributed across numerous mobile platforms. Each participant was required to own a smartphone. This method was selected based on ease of entry as well as timeliness of record keeping. Using a smartphone, subjects had access to their food-time diary on a consistent basis throughout the day. The food diary application was stored on the home screen of each participant's smartphone, providing effortless accessibility (e.g., see Figure 3.1). Participants were reminded to record their information twice each day via "push notifications" sent to their smartphones within close proximity of mealtimes (e.g., see Figure 3.2). The $2 P M$ and a $7 P M$ Surveys were designed to be completed in approximately 50 seconds, which enabled participants to input their information quickly. Regardless of whether previous surveys had been skipped by a participant, push 
notification alerts were sent every day throughout the study in effort to encourage ample participation.

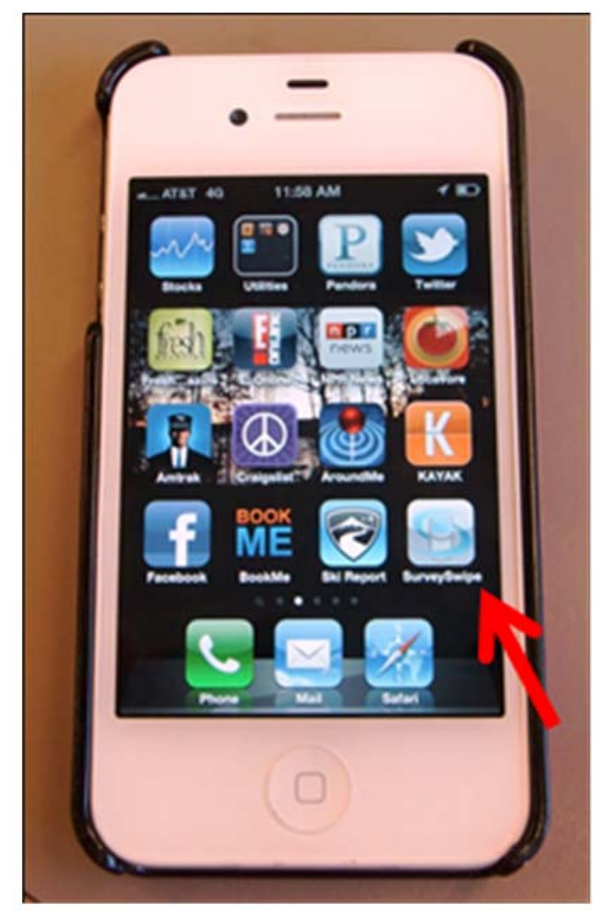

Figure 3.1 SurveySwipe application on home screen of smartphone

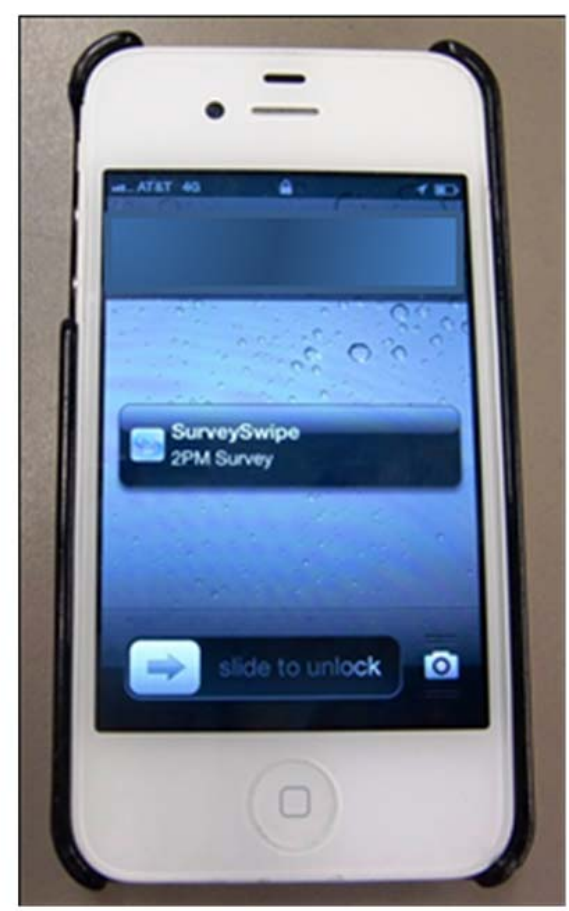

Figure 3.2 Example of "push notification" sent to each panelist's smartphone within close proximity of mealtimes

\section{Recruitment}

Due to the time commitment required to complete the surveys and the novelty of the data collection method, recruiting female subjects required vigorous effort. Table 3.1 displays a list of the locations used throughout the recruitment process.

Creative promotional tools were also used to entice women to participate in the study.

Fliers were distributed at each recruitment site and were designed to persuade women to take part by captivating their attention with colorful and eye-catching graphics (see Panel a of Figure 3.3). Furthermore, a Quick Response (QR) code was displayed on the flier 
which enabled participants to scan the image with a QR code reader on their smartphone (see Panel b of Figure 3.3). The QR code took them directly to a website where they could download the SurveySwipe application. If individuals preferred not to use a QR code reader, a link to the study's website with instructions on downloading the application was also displayed on the flier (a copy of the flier is included in Appendix A).

Table 3.1 Location and timing of recruitment efforts

\begin{tabular}{|c|c|}
\hline $\begin{array}{l}\text { Date of } \\
\text { Recruitment } \\
\text { (all in 2012) }\end{array}$ & Organization/Event \\
\hline $\begin{array}{l}\text { Ongoing March } \\
\text {-Mav }\end{array}$ & Equilibrium Fitness for Women \\
\hline & $\begin{array}{l}\text { New Frontiers Natural Marketplace } \\
\text { Daycares, churches, retail stores in San Luis Obispo } \\
\text { Restaurants in the downtown district of San Luis Obispo }\end{array}$ \\
\hline Ongoing March & After school car pick-up lines \\
\hline $\begin{array}{l}\text { March 8, 15, } 29 \\
\text { April 5, 12, } 19\end{array}$ & Thursday Farmers' Market downtown San Luis Obispo \\
\hline $\begin{array}{l}\text { March } 31 \\
\text { April } 21\end{array}$ & Saturday Farmers' Market Madonna Road San Luis Obispo \\
\hline March & Food Systems Coalition Alliance \\
\hline March 9 & Administration offices at California Polytechnic University \\
\hline March 30 & "Story time” SLO Children’s Museum \\
\hline April 21 & Cal Poly Compost Tour \\
\hline April 22 & Cal Poly Earth Day Festival \\
\hline April 5-18 & Advertisement in New Times newspaper \\
\hline $\begin{array}{l}\text { Ongoing March } \\
\text {-April }\end{array}$ & $\begin{array}{l}\text { Advertisement in organizational newsletters: Equilibrium Fitness } \\
\text { for Women, American Association of University Women (AAUW), } \\
\text { SLO Newcomers Club, and the California Women for Agriculture } \\
\text { (CWA) Central Coast Chapter }\end{array}$ \\
\hline
\end{tabular}




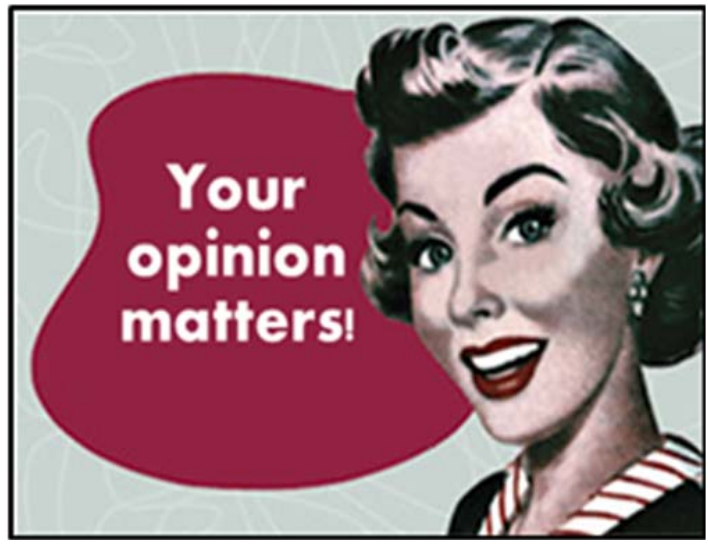

Panel a Clip art

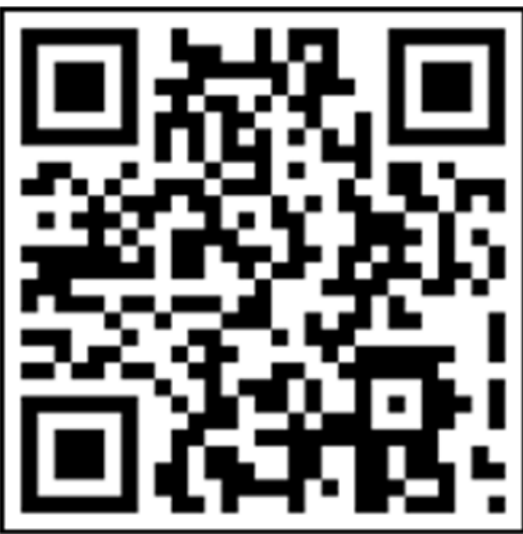

Panel b QR code

Figure 3.3 Graphics used in recruitment flier

\section{Limited Scope of the Study}

The scope of the project was intentionally narrow, prioritizing depth over breadth of information. More specifically, rather than striving for a large number of study participants who would provide information that is more general in nature, the study opted to acquire an extensive amount of detailed information from a smaller group of participants. Additionally, by incorporating attitudinal and behavioral factors, as well as investigating daily conduct, the process for data collection was complex. A larger sample might have exacerbated this complexity.

However, various extensions to the study were considered initially. For example, online forums related to food, such as "mommy blogs" and websites listing recipes were approached with requests to contact their subscribers in regards to participating in the study. The websites who responded merely offered to advertise the study on their webpage and a fee was required for the promotion. Additionally, conducting the study simultaneously in different cities and eventually comparing the results between different geographic locations was deliberated. The in-depth nature of the study would have made it exceptionally difficult to compare subjects from different regions; the variation in 
responses would likely have been very widespread without a large enough sample size to estimate geographic effects. Finally, the study was limited to examining solely females, as opposed to both genders. This was a result of food being historically entrusted to the woman's realm in the household (Messer, 2002), a convention that still persists today. Throughout the recruitment process, females under the age of 22 were omitted, in order to avoid housing situations such as living in university dormitories (Soliah, Walter, and Antosh, 2006) where women do not have much involvement or control in food-related decisions.

\section{Number of Study Participants}

In San Luis Obispo, CA, there are 16,251 women aged 21 and over (U.S. Census Bureau, 2010). An adequate sample size to represent this population (with the exception of 21year-olds) was estimated using a confidence interval approach (Malhotra, 2010). This approach is used to determine an interval around the sample mean that, when repeated, will include the population mean 90 percent of the time (for a 10\% level of significance). The formula relating the sample size to the precision of resulting estimates is derived by first normalizing the variable: $z=(\bar{X}-\mu) / \sigma_{\bar{X}}$. Next, the numerator may be replaced with a level of precision, $D=(\bar{X}-\mu)$, which is the maximum permissible difference between the sample mean and the population mean. Since $\sigma_{\bar{X}}=\sigma / \sqrt{n}$, the equation simplifies to $n=\sigma^{2} z^{2} / D^{2}$.

Specification of values for components of the equation reveals the relationship between sample size and precision. Using a 90 percent confidence level, the associated $z$ value is 1.645. Since the exact standard deviation of the population variable is unknown, it is estimated by dividing the range of the data by 6 . Most variables of interest range from 0 
to 1 , therefore the standard deviation is estimated by $1 / 6$. The final equation with these values $n=\left(\frac{1}{6}\right)^{2} 1.645^{2} / D^{2}$ which results in a 0.04 level of precision for a sample size of 50. This indicates a sample size of 50 study participants amounted to a sample mean that was within 0.04 of the population mean. A sample size of 50 was deemed sufficient to represent the study population.

\section{Data Collection Instrument}

All data was collected using a smartphone survey application, SurveySwipe, through which four types of surveys were distributed during the seven days of the study. An Initial Survey was sent to each participant on the first day of the study and a Final Survey was sent on the last day of the study. Additionally, two daily surveys were sent to each participant including a $2 P M$ Survey with questions regarding breakfast and lunch and a 7PM Survey inquiring about the dinner meal and grocery shopping (if the respondent indicated that she went grocery shopping on that particular day). The information acquired from each survey is listed in Table 3.2 below and a copy of each survey is included in Appendix B.

Questions were grouped into five topic areas: grocery shopping, meal planning and preparation, food choices, consumption atmosphere, and cooking proclivity. Table 3.3 lists the specific questions within each survey that are associated with each of the five topic areas. Variable names were created based on the survey in which they were included or the aspect of food time they measured. For example, the variable “I01GrShare” was the first question that appeared in the Initial Survey and it asked about the share of grocery shopping the participant did for her household. Variables that represented questions in the $2 P M$ and $7 P M$ Surveys were typically named using specific 
survey responses. For example, "PreparBfast $\sim$ ” represented the survey response that indicated the participant prepared breakfast that day. Additionally, new variables were created to relay information gleaned from the $2 P M$ and $7 P M$ Surveys as a group and quantified each participant's behavior throughout the seven-day study. For example, PurchBfast indicates the percent of days that the respondent purchased breakfast. These variables are also included in Table 3.3 .

Table 3.2 Survey types and information obtained

\begin{tabular}{|c|c|}
\hline Survey Type & Information Obtained from Survey \\
\hline \multirow[t]{3}{*}{ Initial Survey } & $\begin{array}{l}\text { Overall opinion of, and interest in, food and food procurement, } \\
\text { including. }\end{array}$ \\
\hline & $\begin{array}{l}\text { Attitudes, behaviors, and decisions pertaining to the purchase, } \\
\text { preparation, and consumption of food }\end{array}$ \\
\hline & Grocery shopping tendencies and preferences \\
\hline 2PM Survey & That day's breakfast and lunch meals \\
\hline 7PM Survey & That day’s dinner meal and grocery shopping (if applicable) \\
\hline \multirow[t]{4}{*}{ Final Survey } & $\begin{array}{l}\text { The extent to which the week was typical for the respondent in terms } \\
\text { of: }\end{array}$ \\
\hline & $\begin{array}{l}\text { Money spent grocery shopping, the number of meals prepared, } \\
\text { eaten out, eaten alone, or eaten with others, and the effort that } \\
\text { went into shopping and preparing food }\end{array}$ \\
\hline & Demographic information, including: \\
\hline & $\begin{array}{l}\text { Household income, educational attainment, employment status, } \\
\text { household characteristics, and Body Mass Index (BMI) }\end{array}$ \\
\hline
\end{tabular}

Grocery Shopping

Questions pertaining to grocery shopping strived to determine if correlations exist between shopping tendencies and food preparation and consumption. The share of grocery shopping done in the household, frequency of shopping, enjoyment level, as well as preferred store attributes were queried. Questions about general grocery shopping habits and preferences were included in the Initial Survey, and more detailed questions were included in the 7PM Survey if the panelist went grocery shopping that day. 
Table 3.3 Survey questions, variable names, and answer selections, by topic area

Table 3.3, Panel a Grocery shopping

\section{Survey and Question Initial Survey \\ 1. About what share of grocery shopping I01GrShare would you say you do for your household?}

2. How many times a week, on average, I02GrNum would you say you go to the grocery store?

3. Please finish the phrase: "I find grocery shopping...”

5. For each of the factors listed, please indicate how important it is to you when deciding where to shop for groceries.
a. Convenient location
b. Quality fresh fruits \& vegetables
c. Quality meat \& seafood
d. Prepared food
e. Wide selection of products
f. Frequent money-saving specials
g. Selection of organic \& green products

7PM Survey

12. Did you go grocery shopping today?

13. Did you bring a shopping list?

14. How long, would you say, it took you to grocery shop from beginning to end (in minutes)?

16. Was anyone else with you while you were shopping (Select all that apply)?

Final Survey

1. Please indicate how typical this week was for you in terms of the following: a. Money spent on groceries
I03GrPleasant

I05aConvLoc

I05bFrVeg

I05cMeatSea

I05dPrepFood

I05eSelection

I05fMoneySav

I05gGreenSel

GroceryShop

BringList

GrocShopHowLAvg

(n)

GrocShopChild

GrocShopPart

GrocShopFriend

GrocShopFam

GrocShopAlone

F01a\$Gr
Answer Selections (and Codes)

All or nearly all

More than half

Less than half

Almost none

$1,2,3,4,5^{+}$

Very Unpleasant

Somewhat Unpleasant

Neither Pleasant or Unpleasant

Somewhat Pleasant

Very Pleasant

Not at All Important

Not Important

Neutral

Somewhat Important

Very Important

Yes/No

Yes/No

1-60 in single minute increments, or

1 hour 5 minutes

1 hour 10 minutes

1 hour 15 minutes

More than 1 hour 15 minutes

Child

Domestic Partner

Friend

Family member other than a partner or child

No one else was with me while I was

shopping

Other

Not typical at all

Somewhat not typical

Neutral

Somewhat typical

Very typical 
Table 3.3, Panel b Meal planning and preparation

\section{Initial Survey}

4. About what share of meal planning and preparation would you say you do for your household?

7. How much, would you say, the following factors influence the purchase and preparation of the foods you eat?
a. Health
I07aHealth
b. Time
I07bTime
c. Cost
I07cCost
d. Effort of planning and shopping
I07dEffort

2PM Survey

2. Did everyone in your household eat the same breakfast dish?

3. Did you purchase breakfast this morning or did you prepare breakfast?

4. Please indicate which statement(s) correctly describe the way you prepared breakfast. (Select all that apply)

D02BrEatSame

PreparBfast PurchBfast SOElsePreparBfast

BrPrepSc BrPrepPremade

BrPrepMic

5. How many ingredients did you use? PrepScAvgBrIng

7. Please select the phrases below that BrFroz best describe the pre-made and/or BrProc on-the-go parts of your breakfast. (Select all that apply)

14. Did you prepare lunch today or purchase lunch?

BrLitPrep $\mathrm{BrHH} \sim$

FreshFr

PrepLu

PurchLu

SOPrepLu

15. Please indicate which statement(s) correctly describe the way your lunch was prepared.

LuPrepSc LuPrepPremade LuPrepMic

16. How many ingredients did you use? PrepScAvgLuIng 7PM Survey

4. Did you prepare dinner this evening PrepareDinner or did you purchase it?

PurchasedDinner SomeElsePrepDin

5. Please indicate which statement(s) correctly describe the way you prepared dinner. (Select all that apply)

UseCookBk

PrepDinFrScratch

PrepWPremadePor

PrepWMicro

6. How many ingredients did you use? DinAverNumIngr

7. Please select the statement(s) below FrozDinner

Almost none

Less than half

More than half

Almost or nearly all

Never

Rarely

Sometimes

Often

Very Often

Yes/No

I prepared breakfast

I purchased breakfast

Someone else prepared breakfast for me

I made breakfast from scratch

A portion of the breakfast I prepared was premade

I prepared my breakfast with a microwave

Other

$1,2,3,4,5^{+}$

It was a frozen meal

It was processed Not part of the meal was made fresh

It required little preparation

It was a hand-held food item

It was a fresh fruit item

I prepared lunch

I purchased lunch

Someone else prepared lunch for me The lunch was prepared from scratch A portion of the lunch was premade A portion of the lunch was prepared using a microwave

Other

$1,2,3,4,5^{+}$

I prepared dinner

I purchased dinner

Someone else prepared dinner for me

I used a cookbook

I made dinner from scratch

Some of the dinner I prepared was premade

I prepared dinner with a microwave

Other

$1,2,3,4,5^{+}$

It was a frozen meal 
that best describe the portion of your ItemWLitPrep dinner that was pre-made. (Select all that apply)

UsedProcItemBox UsedProcItemCan UsedProcItemJar UsedProcItemBag

Final Survey

1. Please indicate how typical this week was for you in terms of the following:

b. Number of meals prepared c. Number of meals purchased

F01bMealPrep F01cMealPurch
It was a frozen item that required little preparation

It was a processed food item in a box It was a processed food item in a can It was a processed food item in a jar It was a processed food item in a bag

Not typical at all

Somewhat not typical

Neutral

Somewhat typical

Very typical

\section{Table 3.3, Panel c Food choices}

\section{Initial Survey}

6. Please indicate how important each of the following attributes are when choosing the food you purchase and eat:

a. Taste

b. Nutrition

c. Price

d. Packaging

e. Ease of preparation

2PM Survey

9. Please indicate which phrases below BrDontL best describe the reason you did not BrNotH eat breakfast this morning. (Select all that apply)

13. Please indicate which phrases below best describe the reason you did not NoLuNotHun*

eat lunch today. (Select all that NoLuTime* apply)

7PM Survey

2. Please select the phrase below that best describes the reason you did not eat dinner.

9. How well would you say the following phrases describe the meal you had for dinner?
a. Made from fresh ingredients
b. Nutritious
c. Inexpensive
d. Tasty
e. Made from new recipe or ingredient
f. Easy-to-prepare

\section{I06aTaste \\ I06aNut \\ I06cPrice \\ I06dPack \\ I06ePrep}

DidNotEatNotH*

DidNotEatNoTime*

DinWFreshIngAvg

DinNutriAvg

DinInexAvg

DinTastyAvg

DinRecNewFAvg

DinEasToPrepAvg
Not at All Important

Not Important

Neutral

Somewhat Important

Very Important

I don't like to eat breakfast

I wasn't hungry

I didn't have time

I am trying to lose weight

Other

I don't like to eat lunch

I wasn't hungry

I didn't have time

I am trying to lose weight

Other

I don't like to eat dinner

I wasn't hungry

I didn't have time

I am trying to lose weight

Other

Describes Not Well At All

Does Not Describe Well

Neutral

Describes Somewhat Well

Describes Very Well 
Table 3.3, Panel d Consumption atmosphere

\section{Initial}

9. Please indicate whether you agree or disagree with each statement below related to cooking, cooking tendencies or knowledge?

b. Usually eat meals with others. I09bEatMeal 2PM Survey

1. Did you eat your breakfast by yourself or with others this morning?

8. Did you eat breakfast on-the-go this BrOTG morning?

10. While eating breakfast, were any activities occurring at the same time? (select all)
DidNotEatBfast

AteBfastAlone

BfastwHH

BfastwNotinHH
Strongly Disagree

Somewhat Disagree

Neither Agree nor Disagree

Somewhat Agree

Strongly Agree

I did not eat breakfast this morning

I ate by myself

I ate with others in my household

I ate breakfast with others not in my household

Yes/No

Talking on phone

Watching television

Reading

Listening to music

Using a computer or another digital

device (iPad, etc.)

Driving a car

BrDrive

BrPubTrans

BrReady

BrHelp

BrChild

BrNoOther

11. How long, would you say, did it take BrHowLong you to eat breakfast from beginning to end, in minutes, (excluding prep time)?

12. Did you eat lunch by yourself or with others today?

DidNotEatLu

AteLuAlone

AteLuOthers

Riding public transportation

Getting ready for work

Helping other HH members get ready

Childcare tasks

No other

$1-40+$ in single minute increments

18. Please select a statement below that

LuPurchPrepFoodsGroc best describes the food establishment you purchased your lunch from.

$\sim$

LuPurchVendor

LuPurchSitDown

LuPurchFastFood

LuPurchCarryO

19. While eating lunch, were any other activities occurring at the same time? (Select all activities that occurred)

LuPhone

LuTV

LuRead

LuMusic
LuComp

LuDrive

LuDesk

LuNoOth

20. How long, would you say, did it take AvgLuHowLong you to eat lunch from beginning to end (in minutes
I did not eat lunch today

I ate lunch by myself

I ate lunch with others

\section{storel}

Street side vendor/caterer

Sit-down restaurant setting

Fast food establishment

Carry-out establishment

Talking on the phone

Watching television

Reading

Listening to music

Using a computer or another digital

device (iPad, etc.)

Driving a car

Riding public transportation

Sitting at a desk, engaged in work-

related tasks

No other activities

Other

1-59 in single minute increments, or 1 hour 10 minutes

1 hour 15 minutes 
7PM Survey

1. Did you eat dinner by yourself or with others this evening?

3. Did everyone in your household eat the same dish?

10. While eating dinner, were any other activities occurring at the same time? (Select all activities that occurred)
DidNotEatDin

AteDinAlone

AteDinHHMem

AteDinOthers

DinSameD

DinNotSameD

DinOthActPhone

DinOthActTV

DinOthActRead

DinOthActMusic

DinOthActComp

DinOthActDrive

DinOthActWork

DinOthActFriend

DinOthActHHMem

DinOthActNone

11. How long, would you say, did it take DinHowLongAvg you to eat dinner from beginning to end (in minutes)?

Final Survey

1. Please indicate how typical this week was for you in terms of the following:

d. Frequency of meals eaten with F01dMealOth others

Table 3.3, Panel e Cooking proclivity

\section{Initial Survey}

9. Please indicate whether you agree or disagree with each statement below related to cooking, cooking tendencies or knowledge?
a. Enjoy experience of cooking
b. Usually eat meals with others.
c. Knowledgeable about cooking
d. Mother taught me how to cook
e. Typically plan meals in advance f. Cook a lot throughout week
g. Enjoy entertainment related to cooking

11. Please indicate whether you agree or disagree with the following phrases about preparing a homemade meal. "Preparing a homemade meal..."
a. is something I enjoy
b. requires a lot of time and effort
c. is expensive
d. makes me feel healthier

1 hour 30 minutes

More than 1 hour 30 minutes

I did not eat dinner this evening

I ate dinner by myself

I ate dinner with others in my household I ate dinner with others not in my household

Yes

No

Talking on the phone

Watching television

Reading

Listening to music

Using a computer or another digital device (iPad, etc.)

Driving a car

Engaged in work-related tasks

Visiting with friends

Visiting with household members

No other activities

Other

1-75 in single minute increments, or

More than 1 hour 15 minutes

Not typical at all

Somewhat not typical

Neutral

Somewhat typical

Very typical
I09aCookEnjoy

I09bEatMeal

I09cKnowCook

I09dMomCook

I90ePlanMeal

I09fCookLots

I09gCookEnt
Strongly Disagree

Somewhat Disagree

Neither Agree nor Disagree

Somewhat Agree

Strongly Agree
Strongly Disagree

Somewhat Disagree

Neither Agree nor Disagree

Somewhat Agree

Strongly Agree
I11aPrepEnjoy

I11bPrepEffort

I11cPrepExp

I11dPrepHealth 
e. I prefer less to purchasing

f. I like to share with others

2PM Survey

6. What is the most important reason

why you purchased breakfast this morning?

17. What is the most important reason you purchased lunch today?

8. What is the most important reason why you purchased dinner?

Final Survey

1. Please indicate how typical this week was for you in terms of the following:

e. Effort that went into cooking and F01eEffort shopping

14. How well do the following phrases describe your perception of preparing a homemade meal compared to purchasing one?
a. Is something I enjoy
F14aPrepEnjoy
b. Requires lots of effort and time.
c. Is important to me.
d. Is necessary.
e. I would like to do more.
F14bPrepEffort
F14cPrepImp
F14dPrepNec
F14ePrepMore

I11ePrepLess

I11fPrepShare

BrPurchTime

BrPurchAvoid

BrPurchEnjoy

LuPurchTime

LuPurchAvoid

LuPurchEnjoy

LuPurchReq

PurchDinTime

PurchDinAvoid PurchDinEnjoyTaste
To save time

To save money

To avoid shopping and/or cooking

I enjoy the taste of the breakfast I

purchase

Other

To save time

To save money

To avoid shopping and/or cooking

I enjoy the taste of the lunch I purchase I ate lunch with others which required me to purchase my meal

Other

To save time

To save money

To avoid shopping and/or cooking

I enjoy the taste of the dinner I purchase Other

Not typical at all

Somewhat not typical

Neutral

Somewhat typical

Very typical

Describes not well at all

Does not describe well

Neutral

Describes somewhat well

Describes very well

\section{Meal Planning and Preparation}

Information regarding the share of meal planning and preparation the participant

performed in the household was collected in the Initial Survey. Questions investigated the

effort that goes into planning and shopping for food, along with the motives for doing so

(e.g., health, time, and cost). Food preparation behaviors were also assessed throughout

the week, such as the time spent planning meals and purchasing food, along with the

frequency of cooking meals from scratch. 
Meal planning and preparation questions corresponding to specific meals were included in the $2 P M$ and $7 P M$ Surveys. For example, if a particular meal was prepared at home, the respondent was asked if it was prepared by someone else, or if she prepared it. Follow-up questions were linked to the preparation method used. For example, if the subject prepared a meal from scratch, succeeding questions inquired about the number of ingredients used to make the meal and if she referenced a cookbook. For meals in which a premade portion was incorporated, related questions asked if the premade component included a frozen food item, a hand-held item (e.g., granola bar), if a microwave was required, or if little preparation was needed. If processed items were included, questions were in reference to the packaging of the food product: if it was packaged in a box, can, jar, or bag. If the panelist did not prepare a meal, they provided the primary reason for opting to purchase it instead.

\section{Food Choices}

Questions concerning general food choices and food-related behavior were included in the Initial Survey. Factors such as taste, nutrition, price, saving time or money, and functional product packaging (e.g. storability, ease of eating on-the-go, little preparation required) were rated in terms of their importance in the purchase and preparation of foods consumed by each participant. Responses ranged from (1) Not At All Important to (5) Very Important. In the $2 P M$ and $7 P M$ Surveys, the panelist's conduct specific to each meal was accounted for as it related to food choices and associated behavior throughout the day. For example, panelists’ responses indicated if they ate a particular meal on-thego, if they purchased a meal in order to save time, or the rationale for not eating if they skipped a meal. 


\section{Consumption Atmosphere}

The eating situation, its effect on the type of food consumed, and the amount of time spent eating a meal was examined. Survey questions included the frequency of eating meals with others versus the tendency to eat alone. The majority of questions concerning the consumption atmosphere were incorporated into the $2 P M$ and $7 P M$ Surveys, with a few additional questions included in the Initial Survey. For meals shared with household members, panelists reported if different types of food were eaten by household members or if all individuals ate the same dish. The amount of time spent eating a meal, excluding prep time, was reported in minutes. Various aspects of the consumption atmosphere were also investigated such as eating a meal on-the-go compared to dining in a sit-down setting, as well as any other activities occurring while eating (e.g. watching television, driving, etc.).

\section{Cooking Proclivity}

Each panelist responded to questions regarding their affinity for cooking, a self-reported knowledge level of cooking, frequency of cooking meals, and the factors related to the manner in which they prepare food. Respondents ranked their affinity for cooking and knowledge level of cooking in the Initial Survey through Likert-scale questions, by selecting the extent to which they agreed with various statements. The likelihood of cooking a homemade meal versus purchasing it was also measured by ranking the degree to which this choice was influenced by the following: health (perceiving a homemade meal to be healthier than eating out), belief that it takes a great deal of time, money, and effort to cook a meal versus purchasing it, or if preparing a homemade meal is an activity they like to share with others. Lastly, their cooking proclivity was examined on a daily basis in the $2 P M$ and $7 P M$ Surveys with questions about the manner in which food was 
prepared for each meal such as cooking from scratch or using a processed component, or their motivation for opting to purchase a meal out instead.

\section{Survey Collection Logistics}

Smartphone surveying technology was used in the study to collect responses from participants through the SurveySwipe smartphone application, a survey collection tool used to create and distribute surveys to platforms including iPhone, iPad, HTML5, iOS, Android, BlackBerry and Windows Media (SurveySwipe, 2012). By scanning the QR code on the flier for the study (see Figure 3.4) or visiting the website link also displayed
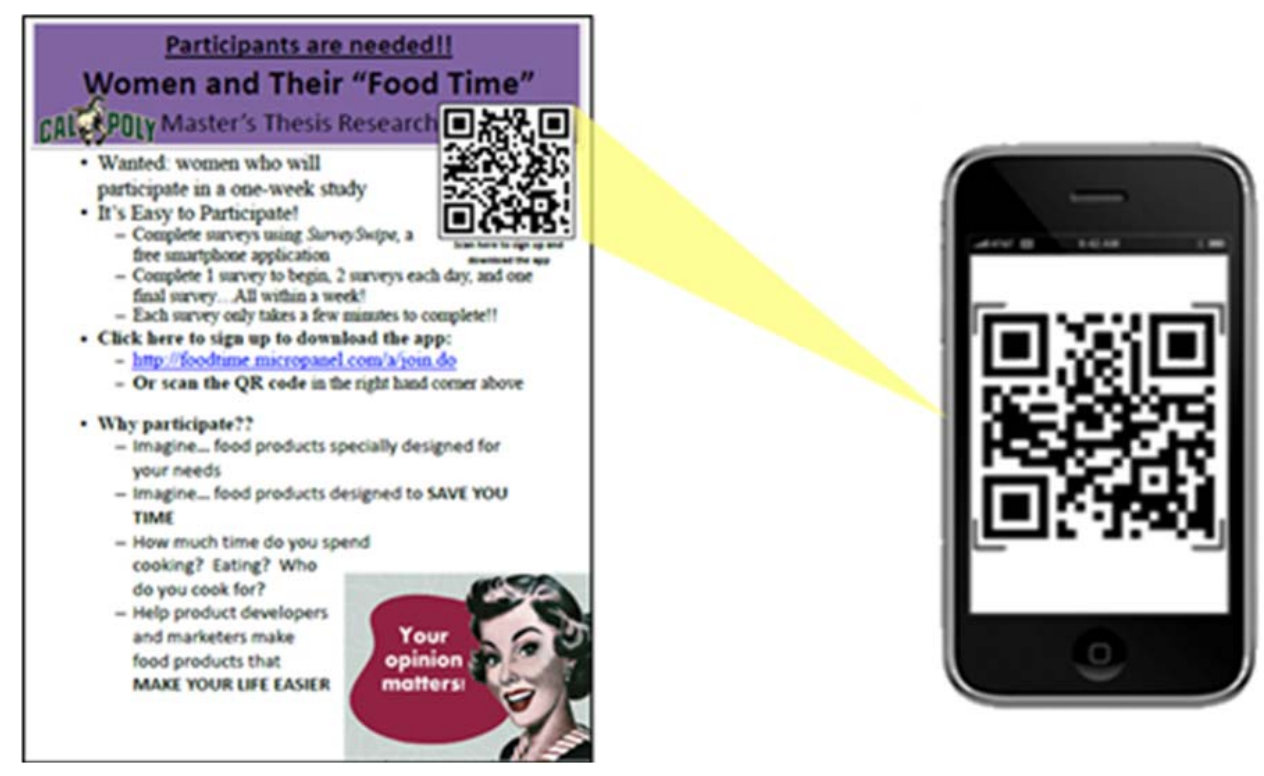

Figure 3.4 Recruitment flyer including QR code and website link to download the SurveySwipe application

on the flier, participants downloaded the SurveySwipe application onto their smartphone.

After providing an email address and password and successfully downloading the application, surveys began to be sent to the participant. 
Surveys were sent to each panelist via a "push notification.” Survey notifications appeared on each user's smartphone alerting them a survey was waiting to be completed in the SurveySwipe application on their phone. Participants would then go into their application and the most recent survey would immediately open (Figure 3.5). Thereafter, they responded to each question by selecting their answers using the touch screen on their smartphone (e.g., see Figure 3.6).

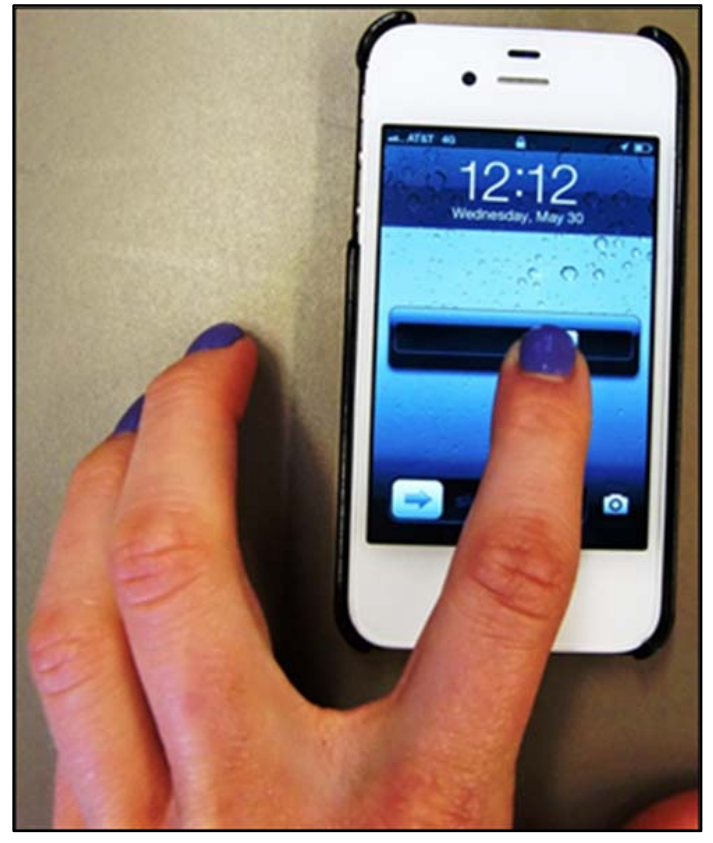

Figure 3.5 "Push notification" of the most recent survey

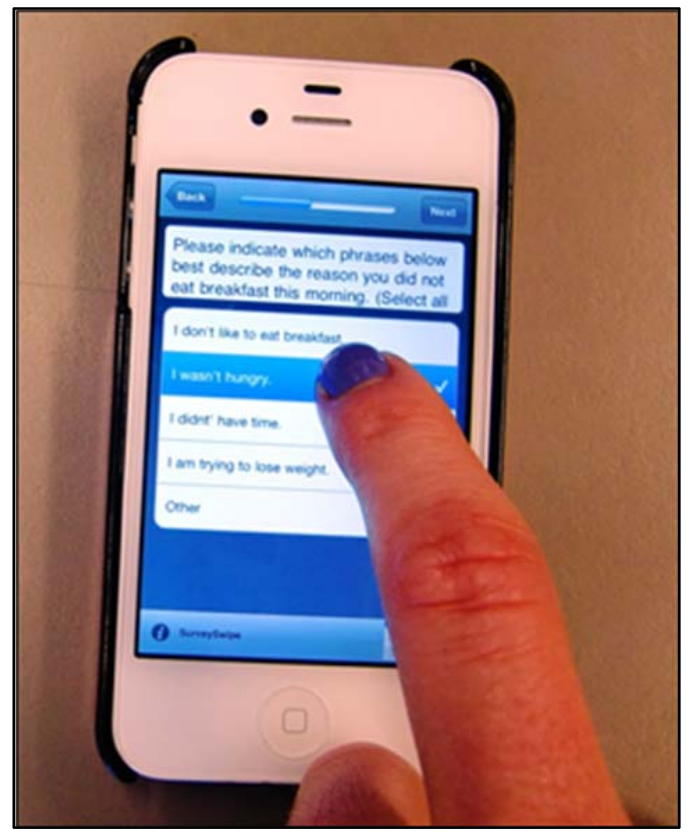

Figure 3.6 Answer selections on the smartphone touch screen

\section{Overview of Data Analysis}

Due to the complexity of the data set, the procedure for analyzing the data consisted of a five-stage process. First, the raw data was entered into Microsoft Excel@ . The term "raw data” refers to the complete set of individual survey responses collected from each study participant. Next, additional variables were created, using the raw data, and these values were added to the data set. Four principal components analyses were then conducted in 
SAS (C) using the augmented data set. Each individual set of components generated through the four principal components analyses were used in four subsequent cluster analyses. ANOVA and Chi-Squared tests were then conducted for each cluster analysis. See Figure 3.7 for a visual representation of this process. 


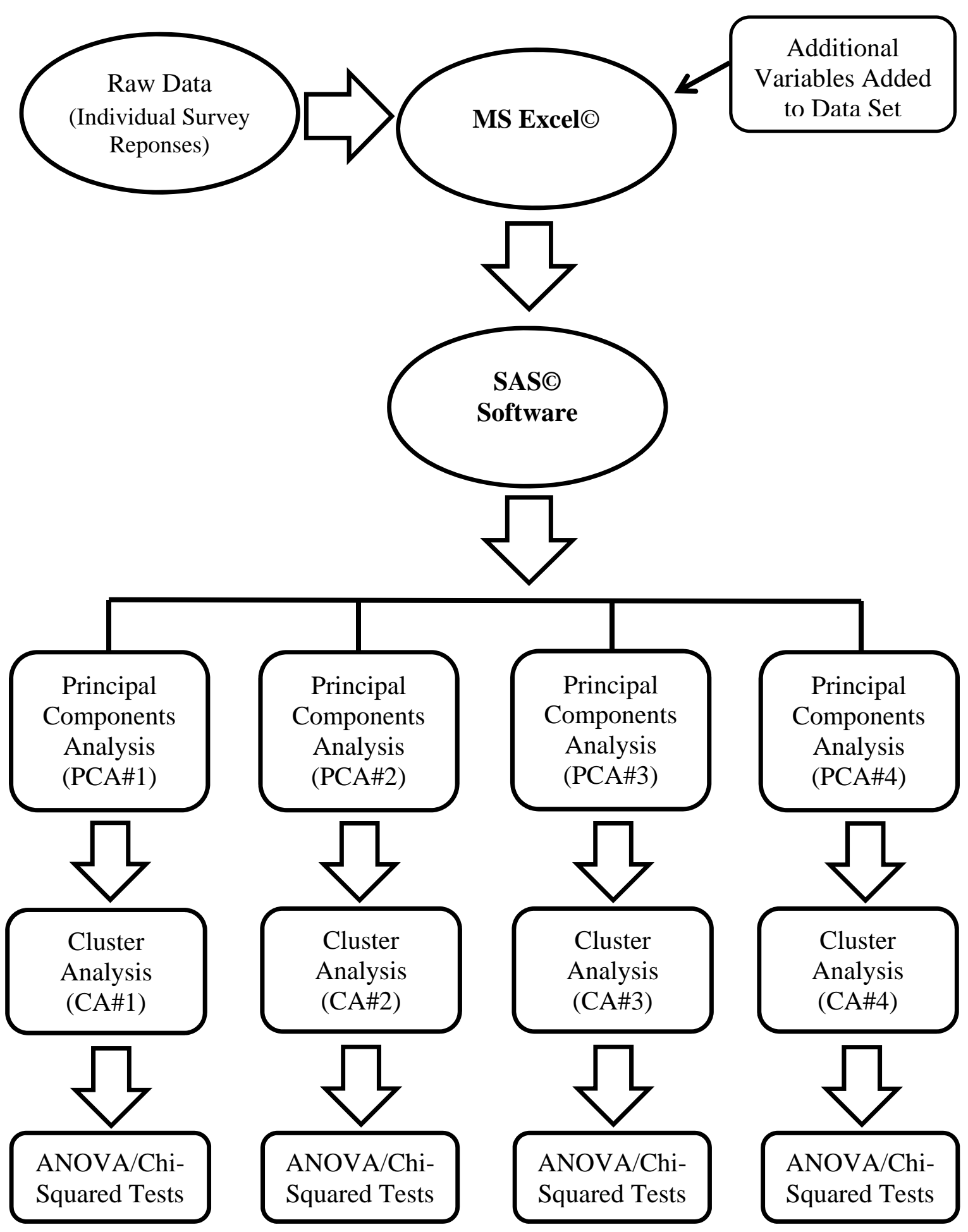

Figure 3.7 Procedure for data analysis 


\section{Identifying Variables of Interest}

Throughout the duration of the study, all survey data was digitally stored in an account using the website of Survey Analytics, the software platform of SurveySwipe (SurveySwipe, 2012). Data was accessed with a username and password to ensure confidentiality. When the data collection was complete, the survey data was downloaded into Microsoft Excel@C. An initial analysis was then conducted using descriptive statistics in Microsoft Excel $($ with the purpose of characterizing the sample and detecting themes in the data using frequency tables for nominal and ordinal variables and averages for interval and ratio variables. Next, new variables were created to summarize panelists’ responses to each question over the $2 P M$ and $7 P M$ Surveys completed. The objective was to formulate a ratio representative of the tendencies of each participant during the oneweek time period related to specific variables; for example, the percent of days a participant ate breakfast alone, prepared dinner, or went to the grocery store during the week.

Each new variable was then examined further, calculating the number of respondents who exhibited the behavior 100 percent of the time, and the number of respondents who did not exhibit the behavior at all. This supplementary calculation was used to identify variables that indicate distinct patterns in participants’ habits. For instance, a participant who used a computer while eating lunch during every lunch meal they ate throughout the seven-day time period would be distinguished from a panelist who never engaged in this activity during the study. Variables corresponding to behaviors in which a large number of respondents either always or never exhibited a behavior were identified as potential variables to use in the principal components analysis. These variables were likely to be 
valuable in identifying and profiling different types of female food consumers within the sample.

\section{Principal Components Analysis}

A principal components (PCA) analysis was conducted in order to generate variables to be used as a basis for a successive cluster analysis (CA). A CA depends entirely on the specified variables used in the procedure (Freeman and Poulin, 2000), but the number of potentially useful variables is often too large to be used in a CA. A PCA is a variable reduction procedure (Stanton, 1971) often implemented when using cluster techniques in market segmentation (Hwang, Yang, and Takane, 2005). It uses raw data as the input, from which an output data set with fewer variables is created (Allen and Sachs, 2007). For data sets that contain a large number of variables, a PCA will discover if there is any redundancy among the variables, such as variables correlated with one another, and perhaps measuring the same paradigm. As a result of these correlations, or linear relationships, the original variables may be reduced to a smaller number of principal components (Stanton, 1971), which are linear functions of the underlying variables. PCA ultimately decreases the dimensionality of the data by reducing the number of variables (SAS Institute Inc., 2011).

The purpose of a principal component analysis is to identify the most meaningful basis from which the original data may be expressed in a different way, with the objective of revealing a hidden structure underlying the data set (Shlens, 2009). This re-expression is a linear transformation of the original data which results in a smaller number of variables. Because the principal components are linear functions of the original data, they retain as much of the information from the original variables as possible, in addition to accounting 
for a majority of the variance in the original variables (Rao, 1964; Allen and Sachs, 2007; SAS Institute Inc., 2008). A PCA is used to provide a set of criterion variables that are more appropriate for further analysis (a cluster analysis, for example), compared to using the variables in their initial form. For the purposes of this study, the principal components analysis was conducted using the PRINCOMP procedure in SASC.

To begin the PCA, specific variables are selected from the data set to be used in the computation of the principal components. The PCA linearly transforms the information from the original variables, denoted with the expression $\mathrm{PX}=\mathrm{Y}$, where $\mathrm{P}$ symbolizes the principal components that transform X into Y (Shlens, 2009). A correlation matrix is generated by SASC, in which the correlations between the variables used in the PCA are summarized (see Table 3.4 for an example). The degree of the linear relationships between the variables is displayed in the matrix (SAS Institute Inc., 2008). A large positive value shows the data is positively correlated, whereas a large negative value signifies the data is negatively correlated. The degree of redundancy is measured by the absolute magnitude of these linear relationships between the variables (Shlens, 2009).

Table 3.4 Example of correlation matrix

\begin{tabular}{|c|c|c|c|c|}
\hline & Variable \#1 & Variable \#2 & Variable \#3 & Variable \#4 \\
\hline Variable \#1 & 1 & 0.3758 & -0.2500 & 0.0229 \\
\hline Variable \#2 & 0.3758 & 1 & -0.0432 & -0.0987 \\
\hline Variable \#3 & -0.2500 & -0.0432 & 1 & 0.5225 \\
\hline Variable \#4 & 0.0229 & -0.0987 & 0.5225 & 1 \\
\hline
\end{tabular}

For example, the intersection of Variable \#2 and Variable \#1, indicated by value 0.3758 , represents a moderate, positive relationship between these two variables. Similarly, a value of 1 is located at each intersection between identical variables, because the same 
variable is entirely correlated to itself. The correlation matrix shows to what extent each variable is related to another and how they are able to be combined to create principal components, due to representing similar trends in the data set (Stanton, 1971).

An eigenequation is also included in the PCA output, which produces eigenvalues, or scores, that are the optimal weights accounting for the maximum amount of variance in the original data set (Stanton, 1971). These eigenvectors, or weights, are orthogonal and demonstrate how each principal component is a linear combination of the original variables. This is shown by the comparative weight of each variable as it relates to each principal component displayed in the output (see Table 3.5).

Table 3.5 Example of the eigenequation output from SAS৫

\begin{tabular}{ccccc}
\hline Variable & \multicolumn{4}{c}{ Principal Component Number } \\
\cline { 2 - 5 } Number & 1 & 2 & 3 & 4 \\
\hline 1 & -0.4213 & 0.2007 & 0.4615 & -0.2895 \\
2 & -0.3155 & 0.2464 & 0.4433 & 0.6844 \\
3 & 0.5403 & 0.3876 & 0.0081 & 0.2436 \\
4 & 0.4201 & 0.4858 & 0.1212 & -0.3322 \\
5 & 0.4644 & -0.3138 & 0.3757 & 0.3454 \\
6 & 0.1258 & -0.0690 & 0.6397 & -0.3938 \\
7 & -0.1512 & 0.6398 & -0.1591 & 0.0588 \\
\hline
\end{tabular}

Note: Each number represents the coefficient on the variable in that row in the expression for the principal component in that column.

The combinations of the variables' weights, which are either positive or negative, provide a means for profiling each component's attributes, reflecting various themes in the data (SAS Institute Inc., 2011). For example, in Table 3.5, variable 6 is negatively related to the $2^{\text {nd }}$ and $4^{\text {th }}$ principal components, and positively related to the $1^{\text {st }}$ and $3^{\text {rd }}$ principal components, indicating the components are different and represent unique characteristics present in the data set. 
The eigenvectors are beneficial for deciding which principal components to use in successive analyses. With the purpose of providing a sufficient summary of the data, the least number of components that explain the largest amount of variance in the original data set is desirable. The number of components produced from a PCA is equal to the total number of variables being analyzed. However, typically the first few principal components generated account for the majority of the variance (Stanton, 1971) and are therefore the only variables used in the cluster analysis.

The explanatory power of individual principal components is presented in a table of eigenvalues, also included in the output. All components are arranged by descending eigenvalues, which are equal to the components’ variances (SAS Institute Inc., 2011). Table 3.6 includes an example of SAS $\subset$ output, which shows each principal component, its eigenvalue, or scaling factor, and the percent of variation accounted for by each, as well as the cumulative percent of variability explained by multiple principal components (SAS Institute Inc., 2011). As a criterion for deciding on the number of principal components to use in later analyses, it is common to choose only those components with eigenvalues greater than one (Cliff, 1988).

Table 3.6 Output example of eigenvalues of the correlation matrix

\begin{tabular}{crccc}
\hline $\begin{array}{c}\text { Principal } \\
\text { Component }\end{array}$ & Eigenvalue & Difference & Proportion & Cumulative \\
\hline 1 & 1.7950 & 0.2273 & 0.2564 & 0.2564 \\
2 & 1.5677 & 0.1652 & 0.2240 & 0.4804 \\
3 & 1.4024 & 0.5707 & 0.2004 & 0.6807 \\
4 & 0.8316 & & 0.1188 & 0.7996 \\
\hline
\end{tabular}


The primary impetus for conducting a principle components analysis is to reduce the number of variables used to classify individuals. There are crucial decisions associated with selecting variables to be used in a cluster analysis and a small number of variables are preferable (Punj and Stewart, 1983). Numeric variables are selected from the data set to generate a principal components analysis. Variables that contain observations with missing values are excluded from the analysis (SAS Institute Inc., 2011), therefore it is advantageous to solely use variables which do not contain missing values when creating principal components. It is logical to select variables that produce a small number of principal components with eigenvalues greater than one but still manage to explain an adequate proportion of the total variance, as seen in the eigenvalues of the correlation matrix. As such, several combinations of variables may be tested before a specific set of variables is chosen for producing the principal components. Finally, the number of principal components to be used in the cluster analysis is chosen based on the output.

\section{Cluster Analysis}

A cluster analysis (CA) was employed to classify study participants, as well as to empirically categorize observations, or consumers, into similar groups (Okazaki, 2006;

Ketchen and Shook, 1996). A key feature of a cluster analysis is its partitioning ability, or its aptitude for capturing the multidimensionality of a data set containing numerous, distinctly different variables, as opposed to using a small number of variables (Ketchen and Shook, 1996). Specifically, the analysis divides a sample into a number of homogeneous groups (Freeman and Poulin, 2000) such that the variance among the observations grouped together (within each cluster) is minimized, and the variance between the groups is maximized (Ketchen and Shook, 1996). Each cluster represents a set of observations that share a common profile, defined by variables that are different 
from one another conceptually (Meyer, Tsui, and Hinings, 1993). Each individual cluster is distinguishably different from other clusters (Freeman and Poulin, 2000).

This analysis is particularly useful for market segmentation by forming groups according to the connections between their demographic and/or attitudinal variables (Okazaki, 2006) and aims to describe natural groupings within the sample population (Smith and Albaum, 2005). In order to classify observations into similar groups, a specific clustering algorithm must be selected. This algorithm simplifies the data, describing a large number of points by a new, smaller number of groups (clusters). Individual cases, or study participants, whose centers are within the closest proximity of one another, are sequentially combined to create new cluster groupings (Khattree and Naik, 2000). See Figure 3.8 for a visual representation of a cluster analysis.
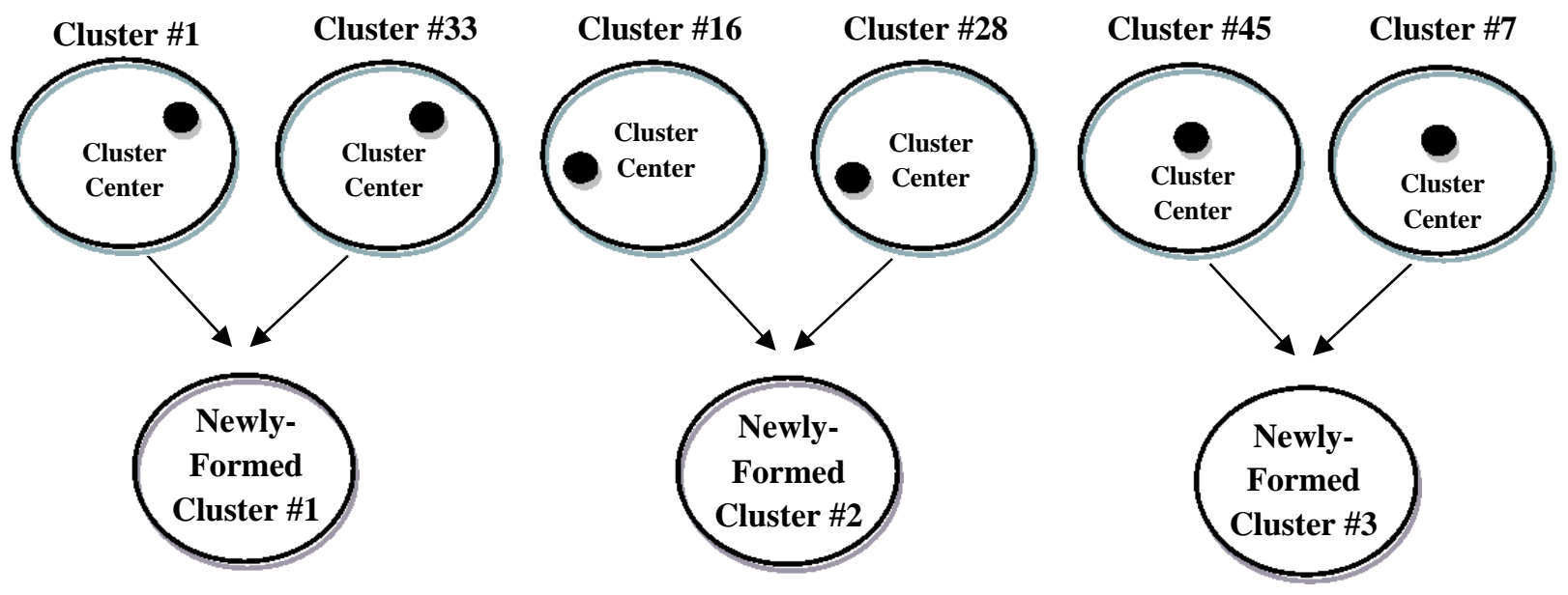

Figure 3.8 Cluster analysis: New cluster groupings are formed by combining two clusters whose centers are the closest in proximity

The center point within each cluster is of particular importance, as different methods for clustering are unique with respect to the computation of the distance between two clusters 
(SAS Institute Inc., 2011). The distance between each point is measured relative to the center of each cluster. A respondent is represented by a point. This distance is minimized at each agglomeration. The key distinguishing feature of each clustering method is the measuring of the mathematical distance between individual multi-dimensional observations (Finch, 2005). Many methods that identify the distance between two clusters as being represented by a center point within each cluster are referred to as geometric methods (Stanton, 1971). When two clusters are merged into a new cluster, the dissimilarities between the new cluster and other clusters are redefined, based on the center of each cluster (Stanton, 1971). These newly-created clusters represent a set of observations that share a common pattern of attributes (Finch, 2005). Merging of clusters is repeated until only one cluster remains (Stanton, 1971).

Using the CLUSTER procedure in SAS $@$, Ward’s minimum variance method was chosen as the clustering algorithm to be utilized in the analysis. This method defines the distance between two clusters as the "ANOVA sum of squares between the two clusters added up over all the variables” (SAS Institute Inc., 2011, pg. 1848). At each level of cluster groupings, “the within-cluster sum of squares is minimized over all partitions obtainable by merging two clusters from the previous generation” (SAS Institute Inc., 2011, pg. 1848). At each generation, the two clusters whose merging results in the smallest increase in the total within-cluster variance are joined.

All clustering techniques in SASC, including Ward's minimum variance method, are based on the agglomerative hierarchical clustering procedure, in which all study observations begin as a single cluster (SAS Institute Inc., 2011). Thereafter a tree-like structure is formed, called a dendrogram, which is a visual representation of the new 
cluster creations. It displays the process of each respondent beginning as a solitary cluster and each successive cluster being formed by two previously separate clusters whose points are within the closest proximity to one another (SAS Institute, 2011). New clusters are created, replacing the old (by merging the two closest clusters based on their centers), ultimately creating one solitary cluster. This method minimizes the variance within each cluster, decreasing the pooled within-cluster sum of squares (Punj and Stewart, 1983).

\section{Cluster Analysis Output}

In order to choose a sufficient number of clusters for describing the data set, several useful statistics generated from the CLUSTER procedure were analyzed. To understand this procedure, a description of the cluster analysis output from SAS $\subset$ is provided. The Cluster History table, featured in Table 3.7 below, lists the diagnostic statistics for each set of clusters.

Table 3.7 Example of cluster history output

\begin{tabular}{cccccccccc}
\hline $\begin{array}{c}\text { \# of } \\
\text { Clusters }\end{array}$ & $\begin{array}{c}\text { Clusters } \\
\text { Joined }\end{array}$ & Freq & $\begin{array}{c}\text { Semipartial } \\
\text { R-Square }\end{array}$ & $\begin{array}{c}\text { R- } \\
\text { Square }\end{array}$ & $\begin{array}{c}\text { Approx. } \\
\text { Exp'd R- } \\
\text { Sq }\end{array}$ & $\begin{array}{c}\text { Cubic } \\
\text { Clust } \\
\text { Criterion }\end{array}$ & $\begin{array}{c}\text { Pseudo F } \\
\text { Statistic }\end{array}$ & $\begin{array}{c}\text { Pseudo } \\
\text { t-Sqd }\end{array}$ \\
\hline $\mathbf{1 2}$ & CL28 & CL17 & 10 & 0.0160 & 0.864 &. &. & 19.6 & 5.7 \\
$\mathbf{1 1}$ & $\mathbf{7}$ & 48 & 2 & 0.0202 & 0.844 &. &. & 18.9 &. \\
$\mathbf{1 0}$ & $\mathrm{CL13}$ & $\mathrm{CL15}$ & 11 & 0.0265 & 0.817 &. &. & 17.9 & 5.9 \\
$\mathbf{9}$ & $\mathrm{CL14}$ & $\mathrm{CL20}$ & 6 & 0.0322 & 0.785 & 0.774 & 0.64 & 16.9 & 4.6 \\
$\mathbf{8}$ & $\mathrm{CL24}$ & $\mathrm{CL18}$ & 12 & 0.0322 & 0.753 & 0.747 & 0.31 & 16.5 & 18.1 \\
$\mathbf{7}$ & $\mathrm{CL16}$ & $\mathrm{CL27}$ & 4 & 0.0339 & 0.719 & 0.715 & 0.21 & 16.6 & 5.9 \\
$\mathbf{6}$ & $\mathrm{CL7}$ & 46 & 5 & 0.0488 & 0.67 & 0.676 & -0.25 & 16.3 & 3.2 \\
$\mathbf{5}$ & $\mathrm{CL9}$ & $\mathrm{CL11}$ & 8 & 0.0783 & 0.592 & 0.626 & -1.5 & 14.9 & 5.8 \\
$\mathbf{4}$ & $\mathrm{CL8}$ & $\mathrm{CL12}$ & 22 & 0.0963 & 0.496 & 0.52 & -0.92 & 13.8 & 21.8 \\
$\mathbf{3}$ & $\mathrm{CL4}$ & $\mathrm{CL10}$ & 33 & 0.1301 & 0.365 & 0.39 & -0.82 & 12.4 & 16 \\
$\mathbf{2}$ & $\mathrm{CL3}$ & $\mathrm{CL6}$ & 38 & 0.1744 & 0.191 & 0.226 & -1.2 & 10.4 & 13.2 \\
$\mathbf{1}$ & $\mathrm{CL2}$ & $\mathrm{CL5}$ & 46 & 0.1910 & 0 & 0 & 0 &. & 10.4 \\
\hline
\end{tabular}

In the first column, the number of clusters is displayed, with the following two columns listing the clusters that were combined during that particular cluster generation. For 
example, cluster grouping 6 in Table 3.7, when going from 7 to 6 cluster groupings, cluster 7 (CL7) was merged with observation 46. The notation "CL” indicates this was a cluster previously established through a preceding cluster generation whereas a numerical value (e.g. observation 46) represents a single participant that still exists in a cluster by itself. The Freq column indicates the number of observations that exist within the newlyformed cluster. So, there are 5 observations in cluster 6 .

The next column, displaying the semipartial R-square, signifies the loss of homogeneity due to merging two clusters to form a new cluster grouping (Sharma and Kumar, 2005), or the decrease in the proportion of variance accounted for by joining the two clusters (SAS Institute Inc, 2011). Smaller values for the semipartial R-square for a specific cluster grouping indicate the newly-formed cluster was formed by joining two very homogenous clusters. Conversely, large values of semipartial R-square imply the cluster grouping was created by merging two heterogeneous clusters (Sharma and Kumar, 2005).

Continuing to the right, the R-square value listed in each row is used as a criterion for selecting an ideal number of clusters to segment the data set. It represents the proportion of variation explained by the new set of cluster groupings (SAS Institute Inc, 2011). For example, in the second-to-last row of Table 3.7, cluster CL3 was merged with CL6, so there were only two clusters. This cluster grouping explains $19 \%$ of the variation in the data set. The Cubic Clustering Criterion (CCC) is also used to as a criterion for selecting an ideal number of clusters to segment the data set. Peaks in the plot of the CCC indicate a sufficient number of cluster groups, while large negative values in the CCC plot can be used to identify outliers (SAS Institute Inc., 2011). Furthermore, if all values of the CCC are negative and decreasing for 2 or more clusters, the distribution of the data is most 
likely unimodal (SAS Institute Inc., 1983), indicating that all observations are fairly homogenous in terms of the variables specified. For the example above, several CCC values are negative suggesting the data may be unimodal.

The final two columns, the pseudo $F$-statistic and pseudo t-squared, may also be used to determine the number of clusters to use, identified with larger values. However, neither of these criterions was included in the analysis for this study, as it has been stated that the pseudo $F$-statistic is not effective for deciphering the differences between clusters (SAS Institute Inc., 2009), and pseudo t-squared statistic can only serve as noise when interpreting a cluster analysis (Eshghi et al., 2011). By examining the results of the output, an ideal number of clusters is chosen.

\section{Validation of the Cluster Analysis: ANOVA and Chi-Square Tests}

An analysis of variance (ANOVA) test is a statistical method used to assess the variation in a response variable in relationship to specific circumstances defined by "classification variables" (Larson, 2008). ANOVA tests are utilized to test the null hypothesis of equal means among different groups, more specifically, the variance between the groups and inside each group (Larson, 2008).

A Chi-Square test is a similar statistical test for categorical variables. It is used to compare the "observed data," or the data collected during a study, with the expected data under a particular hypothesis, referred to as the null hypothesis (Fisher and Yates, 1963). The null hypothesis assumes there is no statistically significant difference between the results of the data collected in the study and the expected data results (Fisher and Yates, 1963). If the null hypothesis appears to be incorrect, then one can assume the alternative 
hypothesis is most likely true. In essence, it is likely there was at least one significant difference between the observed data and the expected data, and/or at least one significant difference between the groups.

ANOVA and Chi-Squared tests may be executed to validate the cluster analysis generated using the variables used in the principal components analysis. Once the clusters are formed, ANOVA and Chi-Squared tests reveal which variables differ significantly among the clusters (Michaelidou, 2012), particularly, external variables that were not used in defining the clusters (Ketchen and Shook, 1996). Due to the fact the clusters were derived using principal components, variables that were used in the PCA do not validate the cluster analysis if proved significantly different using an ANOVA test. Instead, variables other than those used to generate the principal components should be tested, with a greater amount of significant results indicating a more reliable cluster analysis for the data set. This tactic for validation also elucidates the attributes of each cluster, particularly for variables where statistically significant differences are found among clusters. For marketing segmentation purposes, the attributes of each cluster must be sufficiently distinct from other clusters. Individuals who fall into a specific segment will often respond similarly to the other people in that segment and consequently, it is beneficial to identify traits that differentiate a specific cluster relative to the group in order to direct marketing efforts appropriately.

\section{Assumptions}

It is assumed all survey questions were fully understood by study participants, and that they responded truthfully. Therefore all responses were considered true and reflective of their actual attitudes and behaviors. 


\section{Limitations}

The budget available for the study was fairly modest ( $\$ 1,000$ in total), all of which was used to purchase the SurveySwipe software in order to construct the electronic food-time diary. Monetary incentives could not be offered in exchange for individuals’ participation, despite their positive influence response rates found in previous studies (Griffin, et al., 2011). Additionally, a short amount of time was allotted for the study’s duration, with both exploratory and physical research executed in less than one year. The data were gathered over a three-month time period from 50 females recruited in San Luis Obispo, California (refer back to sections Overview of Study and Sample Size in Chapter III for more information on the sample and methods for recruiting participants). It is acknowledged the data would likely have been different had it been collected over a longer period of time or from multiple geographic locations. Finally, the study uses selfreported data. While the accuracy of the responses is assumed, previous studies have found that often self-reporting is not accurate, specifically by subjects underreporting their food intake (Abbot, et al., 2008). 


\section{Chapter IV: Results and Discussion}

All data for the study was collected from March to May 2012. Each participant was required to take part for seven consecutive days, during the three-month time period. Rather than gathering information for all study participants throughout the same time frame, data was accumulated over unique seven-day increments, corresponding with each participant. Hence, the study was designed to capture the attitudes and behaviors of each subject during a typical week, not throughout the course of an identical time period.

\section{Subjects}

Subjects were recruited in San Luis Obispo, as described in Chapter III, and were not chosen based on predetermined qualifications other than gender and minimum age. Ideally the study would have evaluated several types of female consumer segments. However, due to constraints discussed in Chapter III, the sample reflects a few select consumer groups, many of which are valuable for a marketing analysis based on various demographic characteristics. For instance, the population is comprised solely of females, approximately half of whom earn over $\$ 75,000$ per year. It has been stated that females are gatekeepers for the food consumed in their household (Allen and Sachs, 2007) and studies have found women with household incomes over $\$ 75,000$ spend more on food each week on average (Mendes, 2012).

The total number of women who enrolled in the study was 99 but in order to qualify as a legitimate panelist for the study, participation was required for a seven-day time period, in addition to completing an Initial and Final Survey. The Initial Survey covered attitudinal information, and the $2 P M$ and $7 P M$ Surveys recorded daily conduct. The Final Survey was imperative due to the fact its questions obtained the demographic information, which was essential for providing a basis of comparison amongst panelists. 
As a result, the final sample amounted to 50 women who completed the study sufficiently.

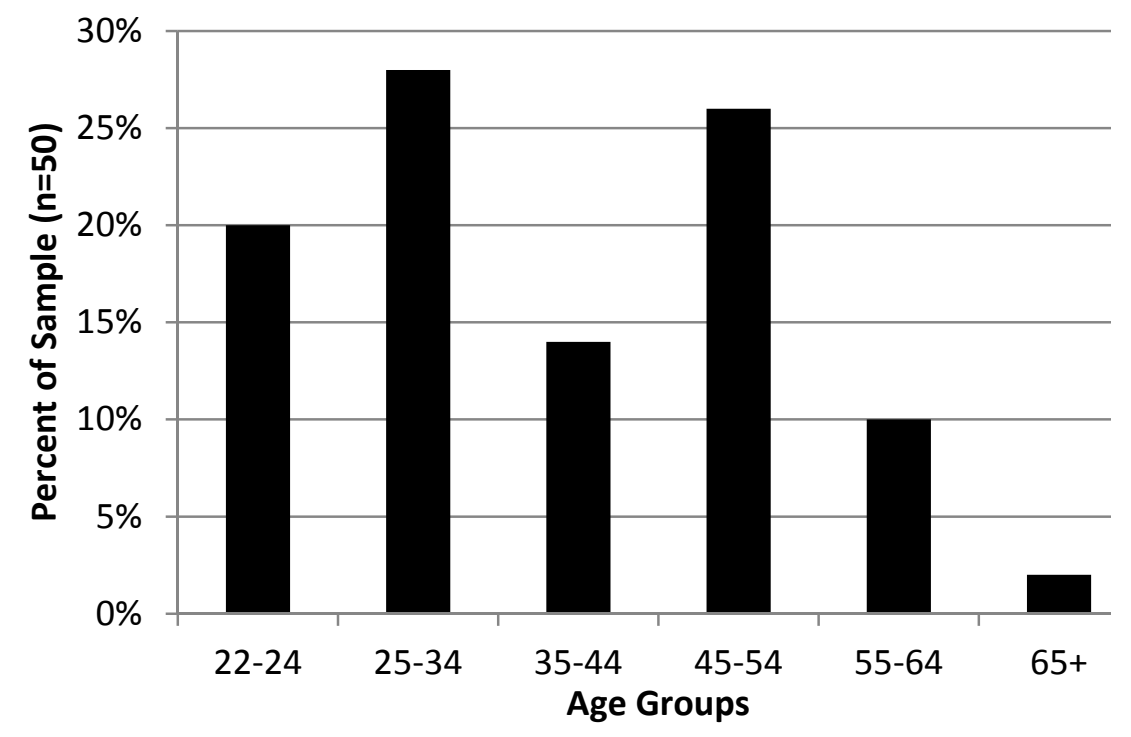

Figure 4.1 Age of sample

Distribution amongst adult age groups was fairly evenly distributed across the sample, with $88 \%$ of the sample between the ages 22-54 (see Figure 4.1). Half of the participants were married, with the remainder divided between women who had never been married, 32\%, and those who were divorced, $14 \%$ (see Figure 4.2). The ethnicity of the sample was not very diverse, with approximately $92 \%$ of subjects being white. Additionally, the majority of the participants were very well-educated, with $48 \%$ of the women responding they had obtained additional education after college and the remaining 50\% were either a college graduate or currently attend college (see Figure 4.3). 


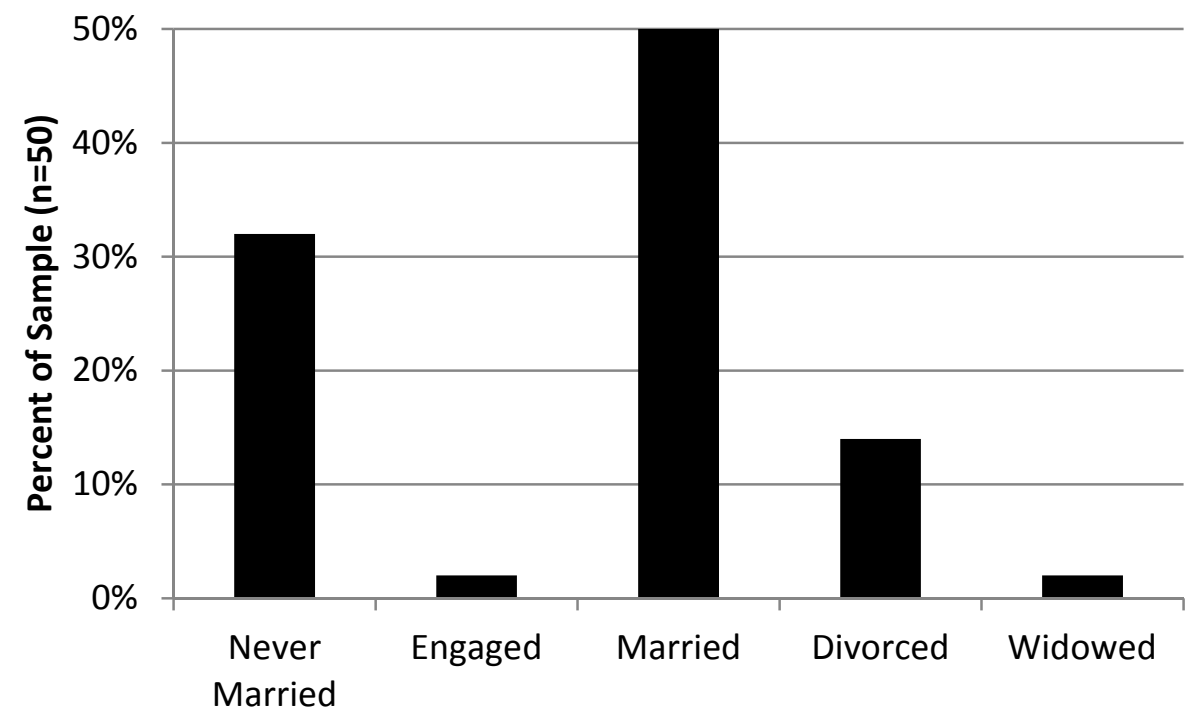

Figure 4.2 Marital status of sample

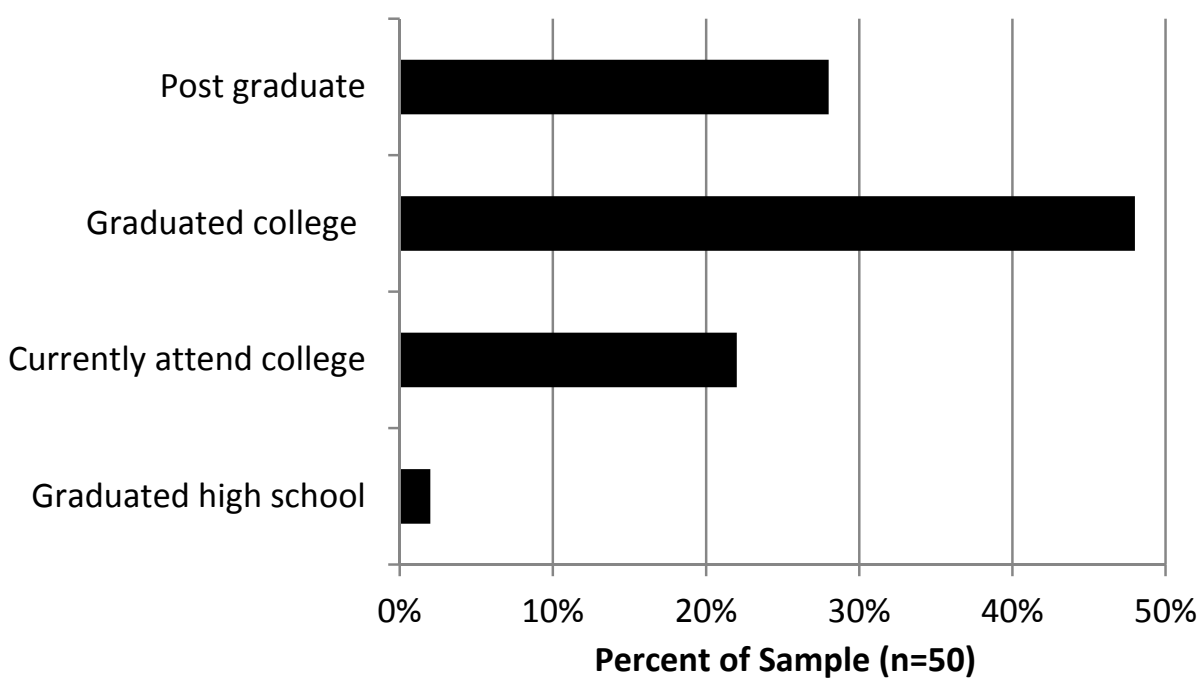

Figure 4.3 Educational attainment of sample 
In regards to annual household income, a substantial percentage of panelists (40\%) reported earning between $\$ 75,000$ - $\$ 149,000$ per year. The rest of the sample was moderately apportioned amongst other income brackets (see Figure 4.4).

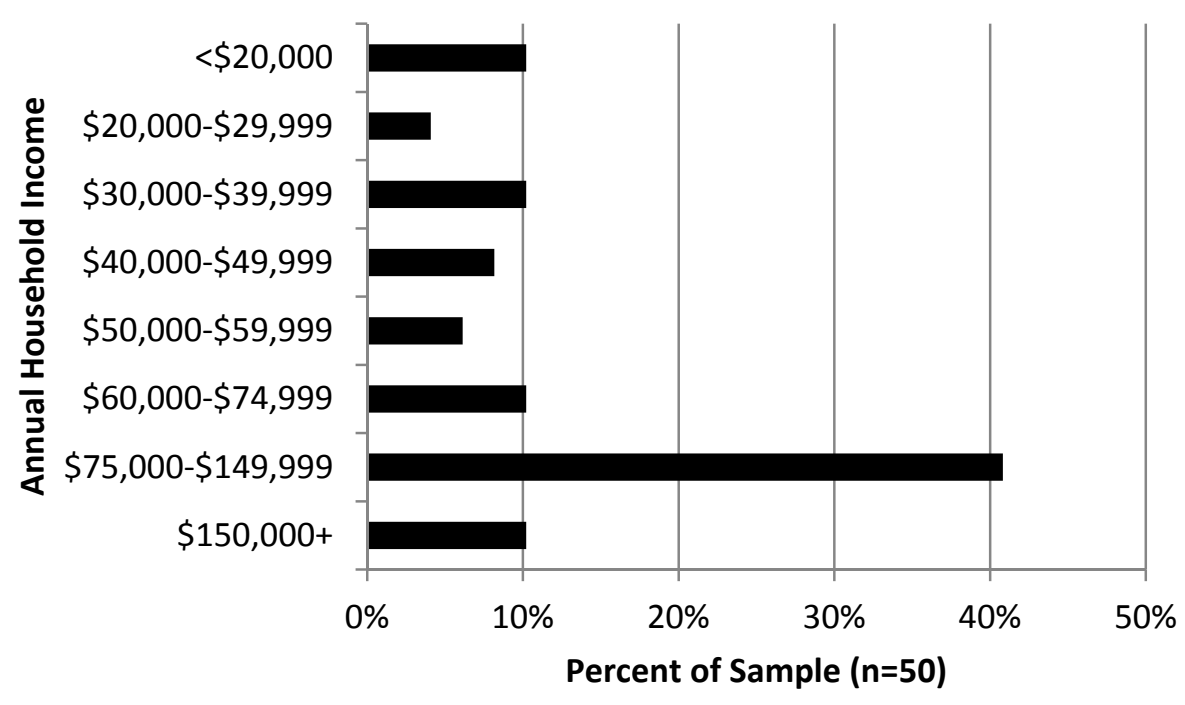

Figure 4.4 Annual household income of sample

The sample was comprised predominately of working women, with $65 \%$ being employed full-time and $18 \%$ who stated they were part-time employees (see Figure 4.5). Forty percent of the sample came from a household with 2 people, with the rest living in households with 1, 3 and 4 members. Sixty-two percent did not live in a household with children and for the subjects who did, most resided with 1 or 2 children.

The body mass index (BMI) was calculated for each subject using their reported height and weight. As shown in Figure 4.6, these ranged from 16.95 to 40.35, of which 63\% within the normal BMI range as specified by the Center for Disease Control (CDC, 2011). In the past, women's self-reported height has been overestimated and their selfreported weight has been underestimated (Engstrom, et al., 2003). Therefore it is likely a portion of the self-reported BMIs in this study are lower than the true measures. 


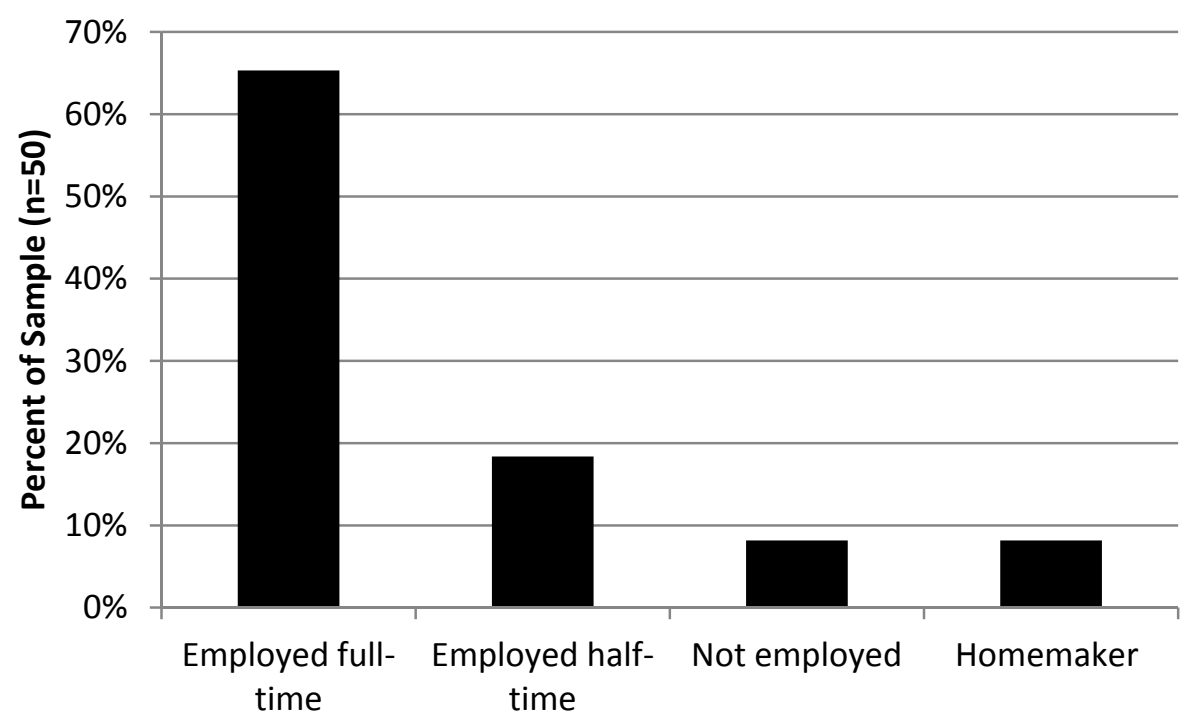

Figure 4.5 Employment status of sample

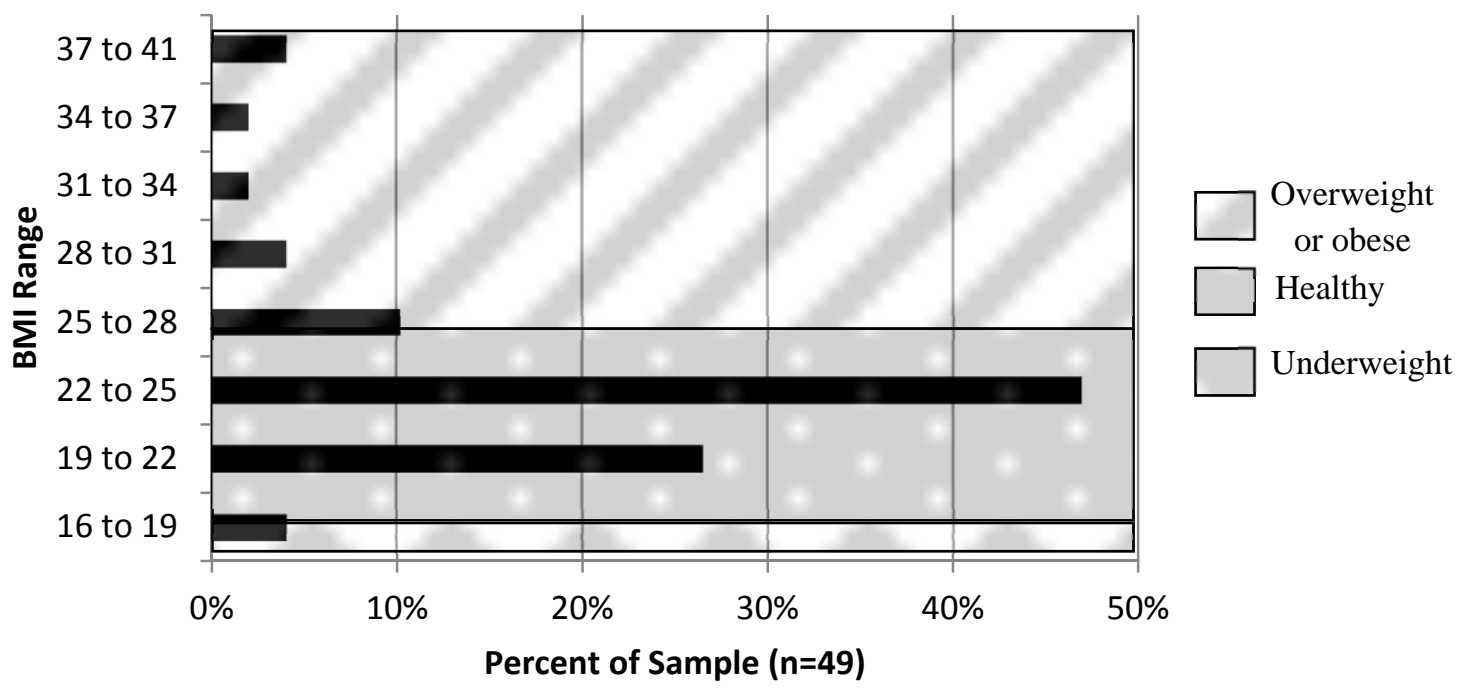

Figure 4.6 Body Mass Indexes for sample

\section{Statistical Analysis Overview}

Four sets of principal components were created using unique combinations of variables from the data set, three of which consisted of attitudinal and behavioral variables.

Conversely, the fourth set of principal components was created using only demographic 
variables. Four cluster analyses were then conducted using the four groups of principal components. Next, the validity of each set of clusters was assessed through ANOVA and Chi-Square tests. Finally, a particular set of clusters was selected in order to compare and contrast its results with the clusters formed using demographic variables only. See Figure 4.7 below for a visual representation of the statistical analysis process.

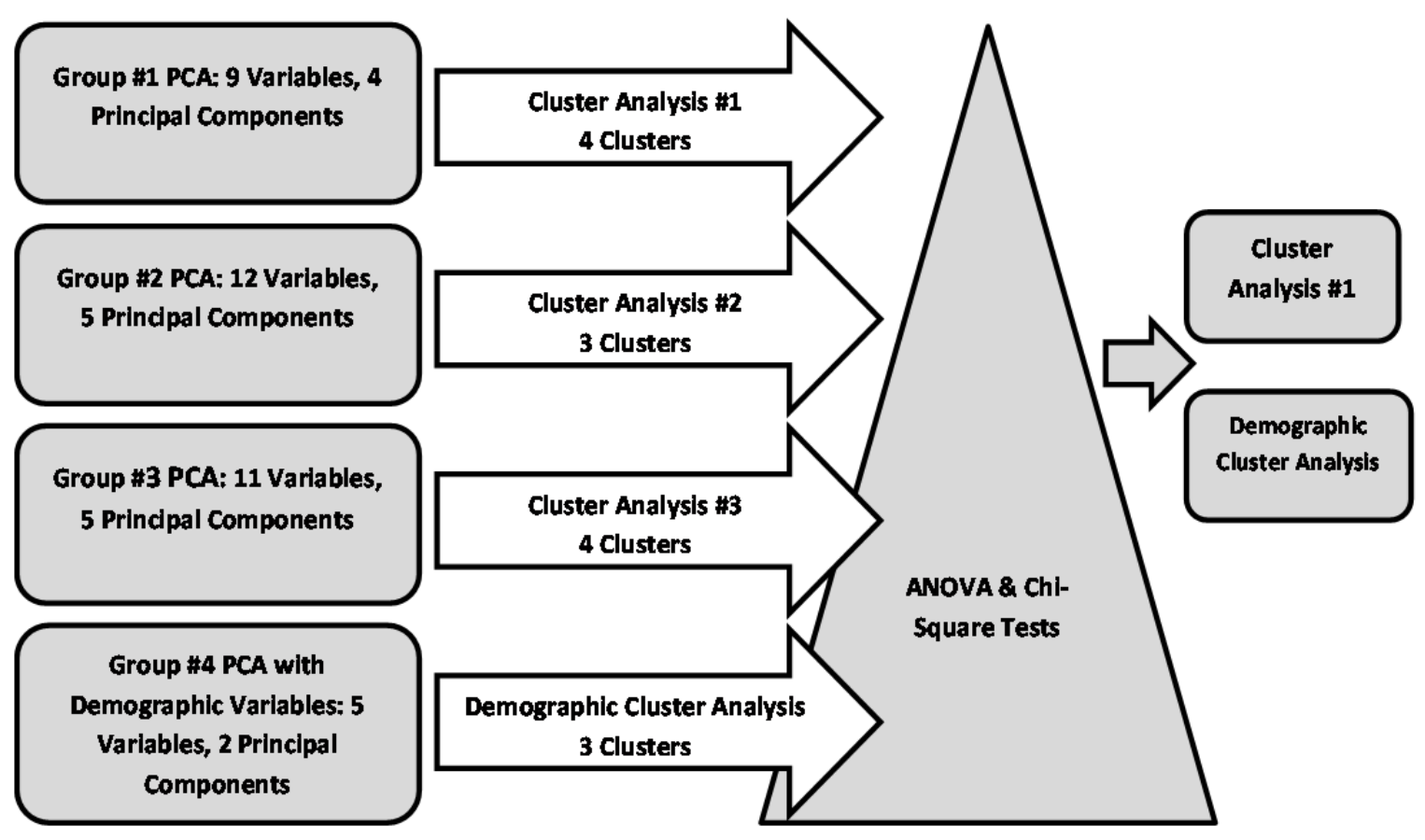

Figure 4.7 Visual representation of the statistical analysis process

To be used in any principal components analysis, a variable must not contain any missing observations (Freeman and Poulin, 2000). This was necessary, as the SAS@ statistical program procedure omits variables with missing values when generating a principal components analysis (SAS Institute, 2011). 


\section{Principal Components Analysis: Methods and Results}

A principal components analysis is used as a means of extracting pertinent information efficiently from complex data sets using a particular set of variables, in order to expose underlying structures or trends (Shlens, 2009). Determining which variables to use or to omit in a PCA is very important and can be quite difficult, as themes in the data may be challenging to decipher. For the four principal components analyses, variables were not chosen arbitrarily. Instead, unique variables were identified and their contribution to the PCA, if any, was evaluated.

In the first three arrangements each individual variable pertained to daily conduct, based on information obtained from the $2 P M$ and $7 P M$ Surveys (as opposed to demographic variables used in the fourth PCA). The first three analyses were performed in an effort to find the set of variables pertaining to conduct that resulted in the most descriptive group of principal components. In addition, as recommended by Ravindra and Naik (2000), each variable was associated with prominent behavioral variables (such as if the participant went grocery shopping during the week of study) as opposed to variables related to supplementary information (such as whether having a convenient location is an important factor for the panelist when choosing where she purchases groceries).

To some extent, variables were selected based on the degree to which they might reduce the dimensionality of the data set. The ultimate objective was to show that alternative variables (other than those pertaining to demographic information) result in a different segmentation scheme. Consequently, employing unique variables was imperative in order to demonstrate this. Unique variables were selected as those that reflected behaviors most participants engaged in extremely often or almost never. Variables that appeared to be 
highly related to one another were closely examined to ensure they were not redundant; if so, one or both of them were excluded from the PCA. The degree to which variables related to one another was assessed using the correlation matrix, included in the PCA output, with redundancy discernible by very large positive or negative values. Table 4.1 displays each set of variables used for the four principal components analyses.

The remainder of the output for each PCA was also compared, specifically the eigenvalues of the correlation, the proportion of variance explained by each eigenvalue, and the cumulative proportion of variance explained by multiple eigenvalues together (refer to Chapter III for more detailed information). The amount of variation explained by the eigenvalues is displayed in the scree and variance plots in the output. The eigenvalues, scree plots, and eigenvector matrices for each group of principal components are pictured below. As noted in Chapter III (Principal Components Analysis, page 54), eigenvalues equivalent to one or greater are preferred. 
Table 4.1 Variables included in each principal components analysis

\begin{tabular}{|c|c|c|c|c|}
\hline \multirow{2}{*}{ Attitude \& Behavioral Variables } & \multicolumn{3}{|c|}{ Included in Variable Set Noted? } & \multirow{2}{*}{$\begin{array}{c}\text { Demographic Variable Se } \\
(\# 4)\end{array}$} \\
\hline & $\# 1$ & $\# 2$ & $\# 3$ & \\
\hline Did Not Eat Breakfast & & $\mathrm{Y}$ & & Age \\
\hline Ate Breakfast Alone & $\mathrm{Y}$ & $\mathrm{Y}$ & $\mathrm{Y}$ & Marital Status \\
\hline Ate Breakfast with Household & $\mathrm{Y}$ & $\mathrm{Y}$ & $\mathrm{Y}$ & Ethnicity \\
\hline Did Not Eat Lunch & & $\mathrm{Y}$ & & Educational Attainment \\
\hline Ate Lunch with Others & $\mathrm{Y}$ & $\mathrm{Y}$ & $\mathrm{Y}$ & Household Size \\
\hline Prepared Lunch & $\mathrm{Y}$ & $\mathrm{Y}$ & $\mathrm{Y}$ & \\
\hline $\begin{array}{l}\text { Used a Computer While Eating } \\
\text { Lunch }\end{array}$ & $\mathrm{Y}$ & $\mathrm{Y}$ & $\mathrm{Y}$ & \\
\hline $\begin{array}{l}\text { Used a Computer While Eating } \\
\text { Lunch }\end{array}$ & & & $\mathrm{Y}$ & \\
\hline Did Not Eat Dinner & & $\mathrm{Y}$ & & \\
\hline Ate Dinner with Household & $\mathrm{Y}$ & $\mathrm{Y}$ & $\mathrm{Y}$ & \\
\hline $\begin{array}{l}\text { No Other Activities Were Occurring } \\
\text { During Dinner }\end{array}$ & $\mathrm{Y}$ & $\mathrm{Y}$ & & \\
\hline Purchased Dinner & & & $\mathrm{Y}$ & \\
\hline Someone else Prepared Dinner & & & & \\
\hline Ate Dinner Alone & $\mathrm{Y}$ & $\mathrm{Y}$ & & \\
\hline Grocery Shopping & $\mathrm{Y}$ & $\mathrm{Y}$ & $\mathrm{Y}$ & \\
\hline
\end{tabular}

*Each variable in Variable Sets \#1, \#2, and \#3 represents the proportion of time that the behavior occurred over the seven days.

Note: Appendix D displays the variables in Variable Sets \#1, \#2, and \#3, their corresponding variable names from Table 3.3, as well as the survey in which each question was included

Principal Components Analysis \#1

Nine variables were used to generate Group \#1 of principal components. In Group \#1, four principal components have an eigenvalue of one or more and combined, they explain around $75 \%$ of the variance (see Table 4.2) and were thus the only components used in the subsequent cluster analysis (CA\#1). The proportion of variance explained by each eigenvalue and the cumulative proportion of variance explained by four principal components is evidenced by the scree plot (Figure 4.8). Table 4.3 shows each variable used in PCA\#1 and its weight, or influence, on each specific principal component. Additionally, the correlation matrix (Table 4.4) displays the amount of correlation between the variables included in the analysis. Because the correlations are the bases of 
the principal components, they are included for the sake of reference and completeness but discussion of these results is limited.

Table 4.2 Eigenvalues of the correlation matrix for PCA \#1

\begin{tabular}{ccccc}
\hline $\begin{array}{c}\text { Principal } \\
\text { Component }\end{array}$ & Eigenvalue & Difference & Proportion & Cumulative \\
\hline 1 & 2.7255 & 0.9903 & 0.3028 & 0.3028 \\
2 & 1.7353 & 0.5177 & 0.1928 & 0.4956 \\
3 & 1.2176 & 0.1563 & 0.1353 & 0.6309 \\
4 & 1.0613 & & 0.1179 & $\mathbf{0 . 7 4 8 9}$ \\
\hline
\end{tabular}

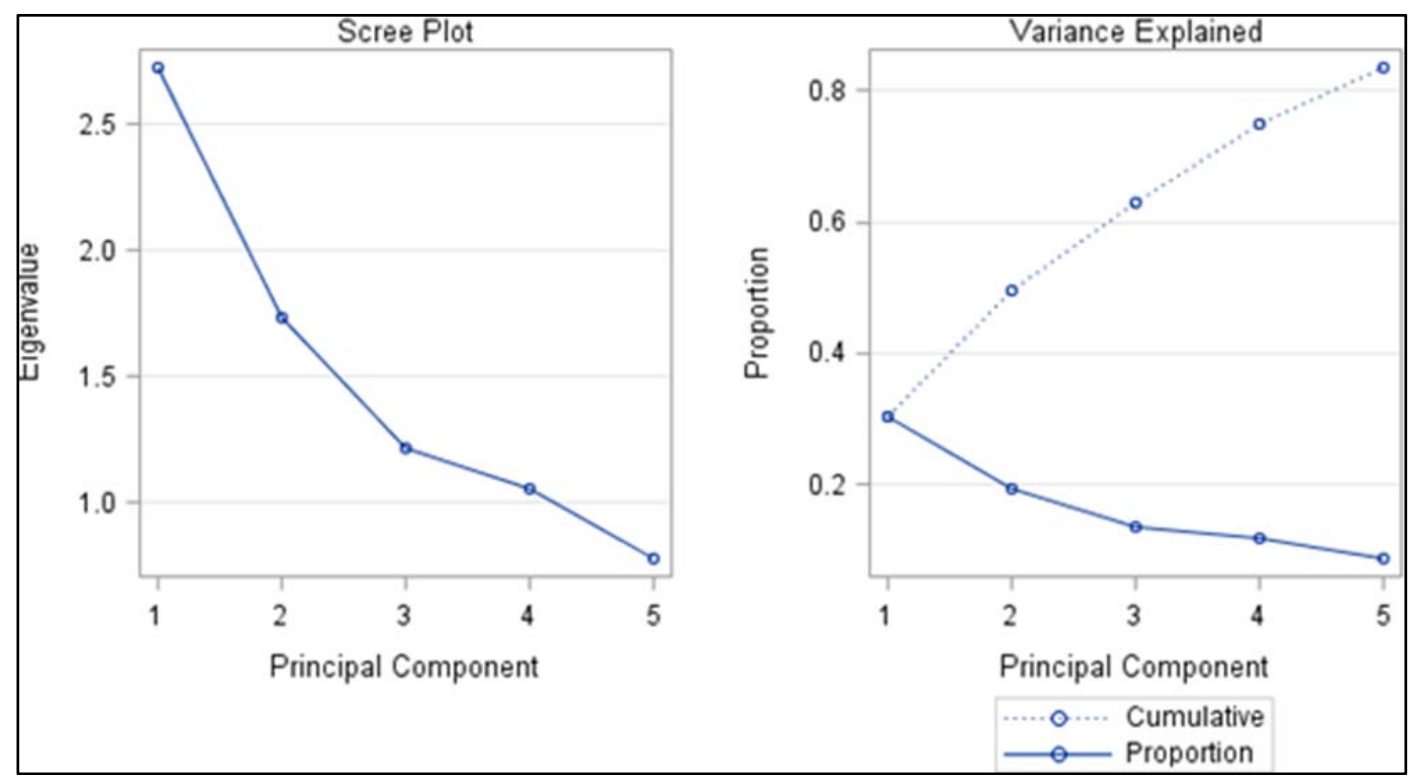

Figure 4.8 Scree plot from the SAS $\subset$ output for PCA\#1

Table 4.3 Variable weights in PCA \#1

\begin{tabular}{lrrrr}
\hline \multirow{1}{*}{\multicolumn{1}{c}{ Variable }} & \multicolumn{4}{c}{ Principal Component Number } \\
\cline { 2 - 5 } & $\mathbf{1}$ & $\mathbf{2}$ & $\mathbf{3}$ & \multicolumn{1}{c}{$\mathbf{4}$} \\
\hline AteBfastAlone $\sim$ & -0.4176 & -0.1958 & -0.2971 & 0.4494 \\
BfastwHH $\sim$ & 0.4602 & 0.1697 & 0.1686 & -0.4509 \\
AteLuOthers $\sim$ & 0.1848 & -0.5349 & 0.2262 & 0.1258 \\
PrepLu & -0.0256 & 0.5634 & 0.0337 & 0.3935 \\
LuComp & -0.2441 & 0.5221 & 0.2749 & -0.0462 \\
AteDinHHMem $\sim$ & 0.4246 & 0.1591 & -0.4123 & 0.1612 \\
DinOthActNone $\sim$ & -0.1774 & 0.1433 & -0.5879 & -0.3229 \\
AteDinAlone $\sim$ & -0.4559 & -0.0136 & 0.4125 & -0.1857 \\
GroceryShop $\sim$ & 0.3161 & 0.1032 & 0.2637 & 0.5072 \\
\hline
\end{tabular}


Table 4.4 Correlation matrix for variables in PCA \#1

\begin{tabular}{|c|c|c|c|c|c|c|c|c|c|}
\hline & 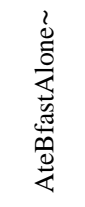 & 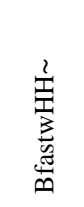 & 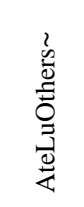 & 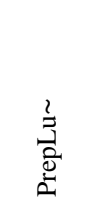 & 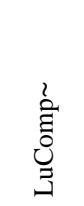 & 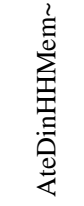 & 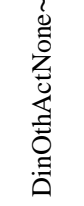 & 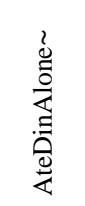 & 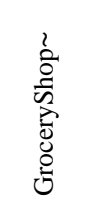 \\
\hline AteBfastAlone & 1 & -0.75 & -0.12 & -0.05 & 0.01 & -0.26 & 0.12 & 0.30 & -0.27 \\
\hline BfastwHH & -0.75 & 1 & 0.03 & -0.03 & -0.11 & 0.40 & -0.16 & -0.37 & 0.25 \\
\hline AteLuOthers & -0.12 & 0.03 & 1 & -0.30 & -0.42 & -0.09 & -0.26 & -0.21 & 0.13 \\
\hline PrepLu & -0.05 & -0.03 & -0.30 & 1 & 0.40 & 0.07 & 0.08 & -0.05 & 0.19 \\
\hline LuComp & 0.01 & -0.11 & -0.42 & 0.40 & 1 & -0.21 & 0.03 & 0.31 & -0.12 \\
\hline AteDinHHMem & -0.26 & 0.40 & -0.09 & 0.07 & -0.21 & 1 & -0.10 & -0.68 & 0.24 \\
\hline DinOthActNone & 0.12 & -0.16 & -0.26 & 0.08 & 0.03 & -0.10 & 1 & 0.01 & -0.25 \\
\hline AteDinAlone & 0.30 & -0.37 & -0.21 & -0.05 & 0.31 & -0.68 & 0.01 & 1 & -0.28 \\
\hline GroceryShop & -0.27 & 0.25 & 0.13 & 0.19 & -0.12 & 0.24 & -0.25 & -0.28 & 1 \\
\hline
\end{tabular}

Within each principal components analysis, respondents will have a unique value for every principal component. Each principal component integrates the effect of all of the variables used in the PCA. Specifically in PCA\#1, the first principal component (PC1) has four variables with the largest coefficients; eating breakfast alone (-0.4176), eating breakfast with other household members (0.4602), eating dinner alone (-0.4559), and eating dinner with other household members (0.4246). These four variables have the most dominant influence on the value of PC1, thus each respondent's value for PC1 shows their tendency for eating breakfast and dinner alone or with other household members. For example, a subject who had a propensity to eat breakfast and dinner alone would have a low value for PC1, and a subject who had a propensity to eat breakfast and dinner with a household member would have a high value for PC1.

For principal component 2 (PC2), the variables with the highest coefficients were eating lunch with others (-0.5349), preparing lunch (0.5634), and eating lunch while working on a computer (0.5221). Therefore, the value of PC2 for each subject reveals their lunch tendencies, specifically if they prepared their meal, ate with others, or ate while working 
on a computer. For example, a female who may work from home, and is able to make her lunch from scratch in her kitchen, as well as continue working on her computer while she eats, would have a high value for PC2.

Three variables had the highest coefficients for principal component 3 (PC3); eating dinner with other household members (-0.4123), not having other activities occurring during dinner (-0.5879), and eating dinner alone (-0.4125). Hence, PC3 reflects the respondent's habits related to the dinner meal: the extent to which she did not engage in other activities during the meal, and if she ate dinner alone or with others in her household.

Lastly, principal component 4 (PC4) reveals if each subject ate breakfast alone (0.4494) or with other household members (-0.4509), in addition to the frequency of which she went grocery shopping (0.5072), as their coefficients were the greatest out of the variables included in the analysis. Similar to PC1, PC4 indicates behavior related to breakfast, but also incorporates shopping frequency as the predominant determinant of the subject's value for PC4.

\section{Principal Components Analysis \#2}

Twelve variables were used to generate Group \#2 of principal components. In Group \#2, five principal components have an eigenvalue of 1 or more and combined they explain around $71 \%$ of the variance, lower than the proportion of variance explained by four principal components in Group \#1 (see Table 4.5). This is evidenced by the scree plot (Figure 4.9) which displays the proportion of variance explained by each eigenvalue and the cumulative proportion of variance explained by 5 principal components (71\%). Table 
4.6 shows each variable used in PCA\#2 and its weight, or influence, on each specific principal component. Additionally, the correlation matrix is included, Table 4.7, displaying the amount of correlation between the variables included in the analysis.

Table 4.5 Eigenvalues of the correlation matrix for PCA \#2

\begin{tabular}{crccc}
\hline $\begin{array}{c}\text { Principal } \\
\text { Component }\end{array}$ & Eigenvalue & Difference & Proportion & Cumulative \\
\hline 1 & 2.8144 & 1.0313 & 0.2345 & 0.2345 \\
2 & 1.7831 & 0.2802 & 0.1486 & 0.3831 \\
3 & 1.5029 & 0.1973 & 0.1252 & 0.5084 \\
4 & 1.3056 & 0.2131 & 0.1088 & 0.6172 \\
5 & 1.0925 & & 0.0910 & $\mathbf{0 . 7 0 8 2}$ \\
\hline
\end{tabular}

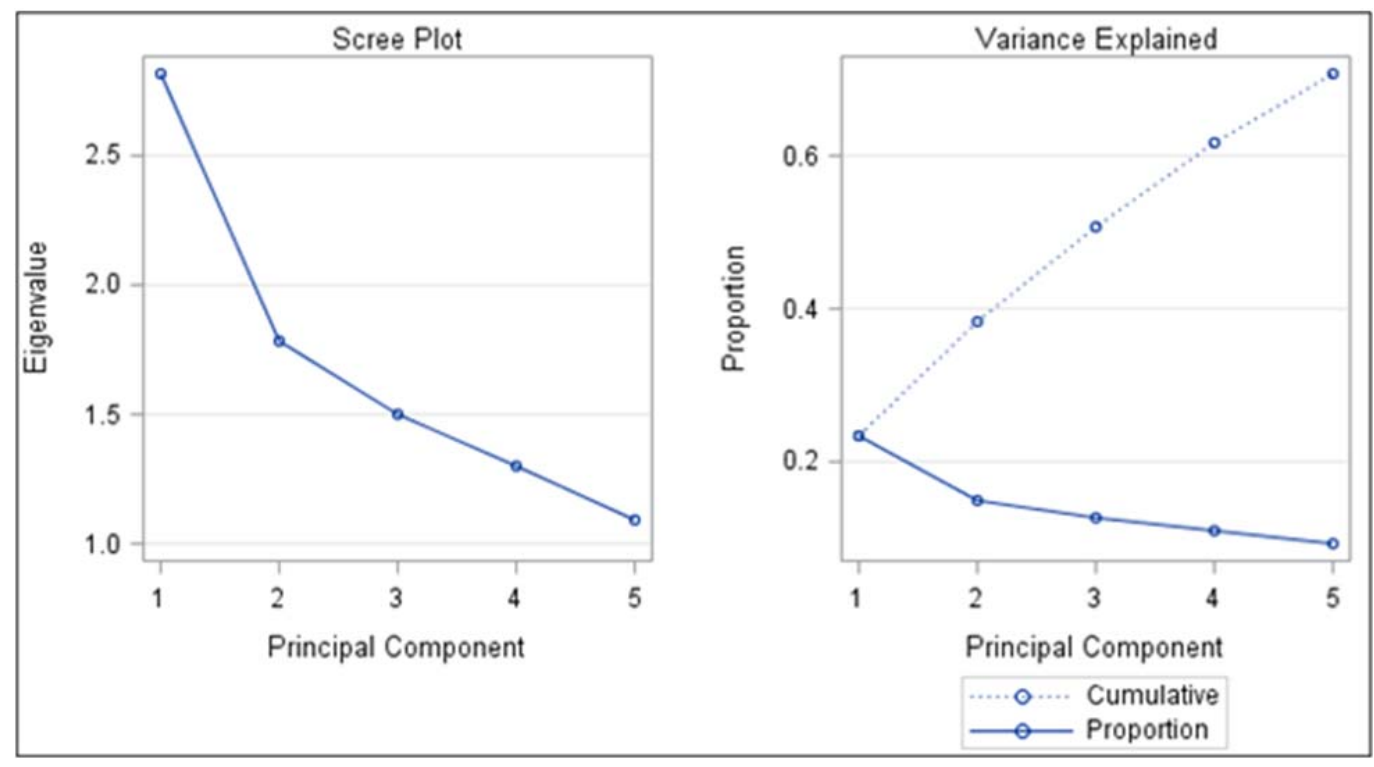

Figure 4.9 Scree plot from the SAS $\odot$ output for PCA\#2 
Table 4.6 Variable weights in PCA \#2

\begin{tabular}{lrrrrr}
\hline \multirow{2}{*}{\multicolumn{1}{c}{ Variable }} & \multicolumn{5}{c}{ Principal Component Number } \\
\cline { 2 - 6 } & $\mathbf{1}$ & $\mathbf{2}$ & $\mathbf{3}$ & \multicolumn{1}{c}{$\mathbf{4}$} & \multicolumn{1}{c}{$\mathbf{5}$} \\
\hline DidNotEatBfast $\sim$ & 0.0707 & -0.1957 & 0.5560 & 0.2149 & -0.2867 \\
AteBfastAlone $\sim$ & 0.3983 & -0.0688 & -0.3132 & -0.4879 & 0.1574 \\
BfastwHH $\sim$ & -0.4512 & 0.1090 & 0.0351 & 0.3270 & -0.1091 \\
DidNotEatLu $\sim$ & 0.1644 & -0.1508 & 0.4219 & -0.2675 & -0.2661 \\
AteLuOthers $\sim$ & -0.1708 & -0.5224 & -0.0945 & 0.1045 & 0.3696 \\
PrepLu & -0.0047 & 0.5646 & 0.0205 & 0.0332 & 0.3159 \\
LuComp $\sim$ & 0.2204 & 0.4960 & 0.2486 & 0.1629 & 0.1331 \\
DidNotEatDin $\sim$ & 0.1371 & -0.1167 & -0.3090 & 0.5262 & 0.0209 \\
AteDinHHMem $\sim$ & -0.4369 & 0.1726 & -0.0309 & -0.0309 & -0.2840 \\
DinOthActNone $\sim$ & 0.1590 & 0.1950 & -0.3932 & 0.1473 & -0.5001 \\
AteDinAlone $\sim$ & 0.4463 & -0.0063 & 0.2420 & 0.0924 & 0.1695 \\
GroceryShop $\sim$ & -0.3064 & 0.0570 & 0.1812 & -0.0953 & 0.4430 \\
\hline
\end{tabular}

Table 4.7 Correlation matrix for variables in PCA \#2

\begin{tabular}{|c|c|c|c|c|c|c|c|c|c|c|c|c|}
\hline & 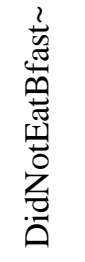 & 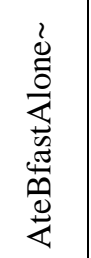 & 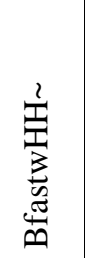 & 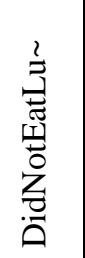 & 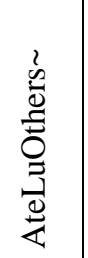 & 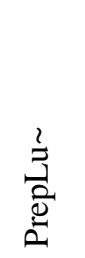 & 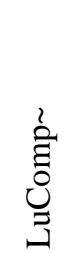 & 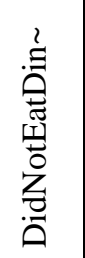 & 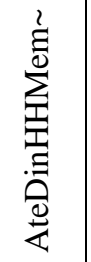 & 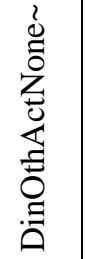 & 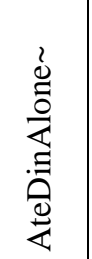 & 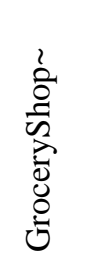 \\
\hline DidNotEatBfast & 1 & -0.31 & -0.20 & 0.27 & 0.06 & -0.11 & 0.04 & -0.07 & -0.17 & -0.07 & 0.12 & -0.05 \\
\hline AteBfastAlone & -0.31 & 1 & -0.75 & 0.16 & -0.12 & -0.05 & 0.01 & 0.07 & -0.26 & 0.12 & 0.30 & -0.27 \\
\hline BfastwHH & -0.20 & -0.75 & 1 & -0.19 & 0.03 & -0.03 & -0.11 & -0.01 & 0.40 & -0.16 & -0.37 & 0.25 \\
\hline DidNotEatLu & 0.27 & 0.16 & -0.19 & 1 & -0.18 & -0.17 & 0.01 & 0.00 & -0.06 & -0.14 & 0.20 & 0.00 \\
\hline AteLuOthers & 0.06 & -0.12 & 0.03 & -0.18 & 1 & -0.30 & -0.42 & 0.03 & -0.09 & -0.26 & -0.21 & 0.13 \\
\hline PrepLu & -0.11 & -0.05 & -0.03 & -0.17 & -0.30 & 1 & 0.40 & -0.03 & 0.07 & 0.08 & -0.05 & 0.19 \\
\hline LuComp & 0.04 & 0.01 & -0.11 & 0.01 & -0.42 & 0.40 & 1 & -0.03 & -0.21 & 0.03 & 0.31 & -0.12 \\
\hline DidNotEatDin & -0.07 & 0.07 & -0.01 & 0.00 & 0.03 & -0.03 & -0.03 & 1 & -0.43 & 0.16 & -0.04 & -0.13 \\
\hline AteDinHHMem & -0.17 & -0.26 & 0.40 & -0.06 & -0.09 & 0.07 & -0.21 & -0.43 & 1 & -0.10 & -0.68 & 0.24 \\
\hline DinOthActNone & -0.07 & 0.12 & -0.16 & -0.14 & -0.26 & 0.08 & 0.03 & 0.16 & -0.10 & 1 & 0.01 & -0.25 \\
\hline AteDinAlone & 0.12 & 0.30 & -0.37 & 0.20 & -0.21 & -0.05 & 0.31 & -0.04 & -0.68 & 0.01 & 1 & -0.28 \\
\hline GroceryShop & -0.05 & -0.27 & 0.25 & 0.00 & 0.13 & 0.19 & -0.12 & -0.13 & 0.24 & -0.25 & -0.28 & \\
\hline
\end{tabular}

For PCA\#2, the first principal component was influenced the most by 3 variables: eating breakfast with other household members (-0.4512), eating dinner with other household members (-0.4369), or eating dinner alone (0.4463). Therefore this principal component reflects each subject's propensity to eat breakfast with other individuals in her household, in addition to eating dinner alone or with other household members. Principal component 
2 (PC2) reveals the respondent's lunch tendencies, particularly if she ate with others (-0.5224), prepared the meal herself (0.5646), as well if she continued to work on her computer while eating (0.4960). Thus, a woman who often dines with her girlfriends during lunch or prepares lunch by herself would have a high value for PC2.

Only two variables were notably influential on the third principal component (PC3); skipping the breakfast meal (0.5560), and skipping lunch (0.4219). A woman who waits until later in the day to eat her first meal, for example, would have a high value for this principal component.

For principal component 4 (PC4), the variables with the highest coefficients were eating breakfast alone (-0.4879) and skipping the dinner meal (0.5262). Respondents with a high value for PC4 perhaps don't place their eating experience as a high priority, given they likely eat breakfast solo and skip the dinner meal all together. Principal component 5 (PC5) reflects the extent to which the respondent frequently did not have other activities occurring during dinner (-0.5001), and if she went grocery shopping often (0.4430). A woman who is fond of enjoying dinner without distractions and grocery shops multiple times during the week would have a high value for PC5.

\section{Principal Components Analysis \#3}

Eleven variables were used to generate Group \#3 of principal components. In Group \#3, four principal components have an eigenvalue of 1 or more and combined they explain around $67 \%$ of the variance (see Table 4.8), lower than the proportion of variance explained by Groups 1 and 2. This is evidenced by the scree plot (Figure 4.10) which displays the proportion of variance explained by each eigenvalue and the cumulative proportion of variance explained by 4 principal components (67\%). Table 4.9 shows each 
variable used in PCA\#3 and its influence, on each specific principal component.

Additionally, the correlation matrix is included, as Table 4.10, displaying the amount of correlation between the variables included in the analysis.

Table 4.8 Eigenvalues of the correlation matrix for PCA \#3

\begin{tabular}{ccccc}
\hline $\begin{array}{c}\text { Principal } \\
\text { Component }\end{array}$ & Eigenvalue & Difference & Proportion & Cumulative \\
\hline 1 & 2.4538 & 0.6322 & 0.2231 & 0.2231 \\
2 & 1.8214 & 0.1854 & 0.1656 & 0.3887 \\
3 & 1.6360 & 0.2164 & 0.1487 & 0.5374 \\
4 & 1.4196 & 0.5485 & 0.1291 & $\mathbf{0 . 6 6 6 4}$ \\
5 & 0.8710 & & 0.0792 & 0.7456 \\
\hline
\end{tabular}

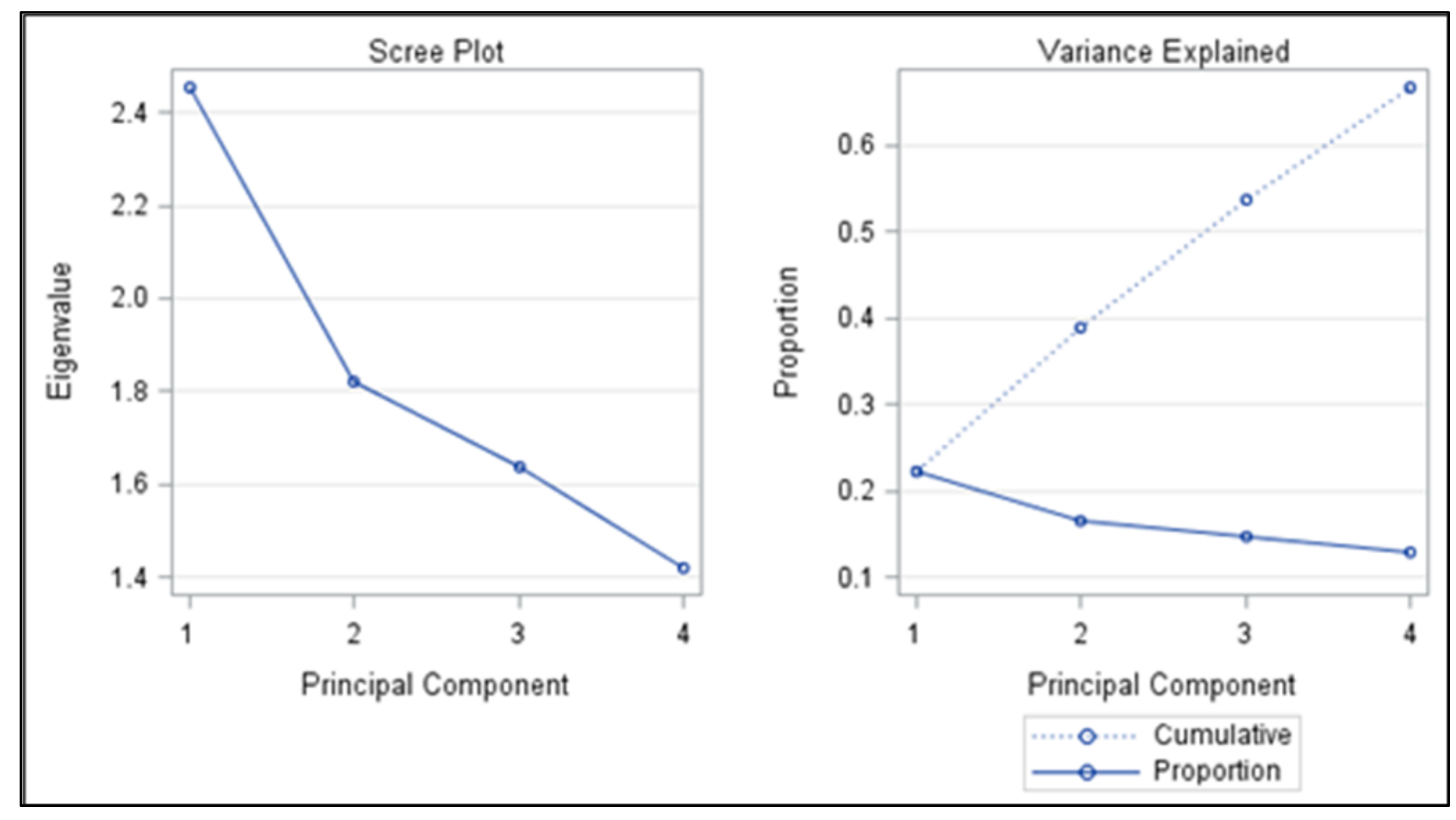

Figure 4.10 Scree plot from the SAS output for PCA\#3 
Table 4.9 Variable weights in PCA \#3

\begin{tabular}{lrrrrr}
\hline \multirow{2}{*}{ Variable } & \multicolumn{5}{c}{ Principal Component Number } \\
\cline { 2 - 6 } & \multicolumn{1}{c}{$\mathbf{1}$} & $\mathbf{2}$ & \multicolumn{1}{c}{$\mathbf{3}$} & \multicolumn{1}{c}{$\mathbf{4}$} & \multicolumn{1}{c}{$\mathbf{5}$} \\
\hline AteBfastAlone $\sim$ & -0.4086 & -0.1975 & -0.4062 & 0.1615 & -0.3055 \\
BfastwHH $\sim$ & 0.4734 & 0.1359 & 0.3825 & 0.0382 & 0.1393 \\
AteLuOther $\sim$ s & 0.2311 & -0.3635 & -0.2331 & -0.4554 & 0.2420 \\
PrepLu $\sim$ & -0.0881 & 0.6185 & -0.1015 & -0.0247 & 0.0694 \\
LuComp $\sim$ & -0.2798 & 0.4529 & 0.1451 & -0.0251 & -0.2437 \\
D19fLuDrive $\sim$ & 0.0884 & -0.3335 & 0.3522 & 0.4622 & -0.2937 \\
AteDinHHMem $\sim$ & 0.4138 & 0.1394 & -0.0352 & 0.4069 & -0.1939 \\
PurchasedDinne $\sim$ & -0.1800 & -0.1619 & 0.5294 & -0.3212 & -0.0424 \\
SomeElsePrepDin $\sim$ & 0.3036 & -0.0518 & -0.4207 & 0.2012 & 0.0021 \\
DinOthActNone $\sim$ & -0.2309 & 0.0236 & 0.0380 & 0.4137 & 0.7951 \\
GroceryShop $\sim$ & 0.3356 & 0.2502 & -0.1379 & -0.2644 & -0.0812 \\
\hline
\end{tabular}

Table 4.10 Correlation matrix for variables in PCA \#3

\begin{tabular}{|c|c|c|c|c|c|c|c|c|c|c|c|}
\hline & 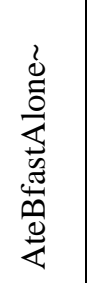 & 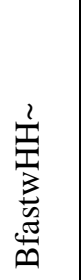 & 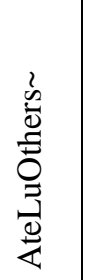 & 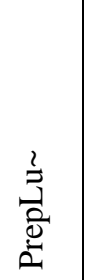 & 忌 & 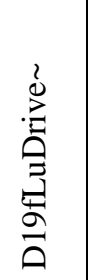 & 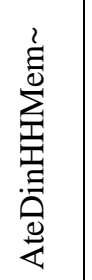 & 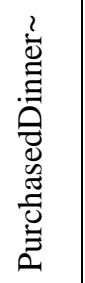 & 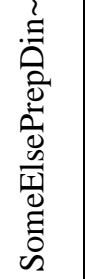 & 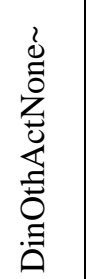 & 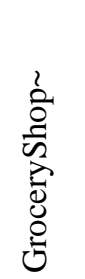 \\
\hline AteBfastAlone & 1 & -0.75 & -0.12 & -0.05 & 0.01 & -0.02 & -0.26 & -0.12 & -0.02 & 0.12 & -0.27 \\
\hline BfastwHH & -0.75 & 1 & 0.03 & -0.03 & -0.11 & 0.19 & 0.40 & -0.01 & 0.11 & -0.16 & 0.25 \\
\hline AteLuOthers & -0.12 & 0.03 & 1 & -0.30 & -0.42 & -0.14 & -0.09 & 0.00 & 0.25 & -0.26 & 0.13 \\
\hline PrepLu & -0.05 & -0.03 & -0.30 & 1 & 0.40 & -0.37 & 0.07 & -0.16 & -0.10 & 0.08 & 0.19 \\
\hline LuComp & 0.01 & -0.11 & -0.42 & 0.40 & 1 & -0.18 & -0.21 & 0.12 & -0.14 & 0.03 & -0.12 \\
\hline D19fLuDrive & -0.02 & 0.19 & -0.14 & -0.37 & -0.18 & 1 & 0.20 & 0.16 & 0.01 & 0.07 & -0.19 \\
\hline AteDinHHMem & -0.26 & 0.40 & -0.09 & 0.07 & -0.21 & 0.20 & 1 & -0.32 & 0.30 & -0.10 & 0.24 \\
\hline PurchasedDinner & -0.12 & -0.01 & 0.00 & -0.16 & 0.12 & 0.16 & -0.32 & 1 & -0.42 & -0.02 & -0.13 \\
\hline SomeElsePrepDin & -0.02 & 0.11 & 0.25 & -0.10 & -0.14 & 0.01 & 0.30 & -0.42 & 1 & -0.07 & 0.17 \\
\hline DinOthActNone & 0.12 & -0.16 & -0.26 & 0.08 & 0.03 & 0.07 & -0.10 & -0.02 & -0.07 & 1 & -0.25 \\
\hline GroceryShop & -0.27 & 0.25 & 0.13 & 0.19 & -0.12 & -0.19 & 0.24 & -0.13 & 0.17 & -0.25 & \\
\hline
\end{tabular}

In PCA\#3, the most influential variables on the first principal component (PC1) are

related to the social aspect of the eating situation. They include eating breakfast alone (-0.4086), eating breakfast with other household members (0.4734), and eating dinner with other household members (0.4138). Consequently, a female who typically eats breakfast and dinner with her family would have a high value for this component. For principal component 2 (PC2), variables related to the lunch meal were markedly 
influential: preparing lunch (0.6185) and working on a computer while eating lunch (0.4529). As an example, a busy "working woman” who tends to make her lunch quickly, later eating it at her desk while she continues working on her laptop, would have a high value for PC2.

Principal component 3 (PC3) shows the extent to which each subject ate breakfast alone (-0.4062), purchased dinner (0.5294), or had someone else make dinner for her (-0.4207). These variables could each indicate the degree to which respondents were pressed for time. For instance, a woman who ate breakfast alone while driving to work, and either purchased a carry-out meal or had dinner made for her by someone else, appears to utilize her time for things that do not pertain to food. This type of participant would have a high value for this component.

Tendencies related mostly to the lunch meal, and another habit related to dinner, were influential for principal component 4 (PC4). The dominant variables were eating lunch with others (-0.4554), eating lunch while driving (0.4622), eating lunch with household members (0.4069), and not having other activities occurring during dinner (0.4137). A stay-at-home mother who usually eats dinner at home with her children, or eats lunch while she is running errands in the car, for example, would have a high value for PC4.

Finally, for principal component 5 (PC 5) the only variable with influential power was not having other activities occurring during the dinner meal (0.7951). Respondents who had a high value for PC5 most likely did not engage in the behaviors represented by the other variables in the analysis. They tended to not have any distractions occurring during dinner. 


\section{Principal Components Analysis \#4}

In the group of principal components formulated using five demographic variables, two components have an eigenvalue of 1 or more: combined they explain around $58 \%$ of the

Table 4.11 Eigenvalues of the correlation matrix for PCA \#4

\begin{tabular}{|r|r|r|r|r|}
\hline \multicolumn{5}{|c|}{ Eigenvalues of the Correlation Matrix } \\
\hline & Eigenvalue & Difference & Proportion & Cumulative \\
\hline 1 & 1.7857 & 0.6606 & 0.3571 & 0.3571 \\
\hline 2 & 1.1251 & 0.1538 & 0.2250 & $\mathbf{0 . 5 8 2 2}$ \\
\hline 3 & 0.9713 & 0.1206 & 0.1943 & 0.7764 \\
\hline 4 & 0.8507 & 0.5835 & 0.1701 & 0.9466 \\
\hline 5 & 0.2672 & & .0534 & 1.0000 \\
\hline
\end{tabular}

variance (see Table 4.11), and were the only components used to generate Cluster Analysis \#4 (CA\#4). Less variation is explained using these variables than by the combination of eigenvalues in the first three analyses. The scree plot in Figure 4.11 displays the proportion of variance explained by each eigenvalue and the cumulative proportion of variance explained by two principal components (58\%). Table 4.12 shows each variable used in PCA\#4 and its influence on each specific principal component. Additionally, the correlation matrix is included, Table 4.13, displaying the amount of correlation between the variables included in the analysis.

Table 4.12 Variable weights in PCA \#4

\begin{tabular}{lcc}
\hline \multirow{2}{*}{ Variable } & \multicolumn{2}{c}{ Principal Component } \\
\cline { 2 - 3 } & $\mathbf{1}$ & $\mathbf{2}$ \\
\hline F02Age & 0.6359 & -0.1572 \\
F03Marrital & 0.6690 & 0.2094 \\
F04Ethnic & -0.0890 & 0.6357 \\
F05Ed & -0.3643 & -0.2108 \\
F08HHsize & -0.0868 & 0.6949 \\
\hline
\end{tabular}


Table 4.13 Correlation matrix for variables in PCA \#4

\begin{tabular}{|c|c|c|c|c|c|}
\hline \multirow{2}{*}{\multicolumn{5}{|c|}{ 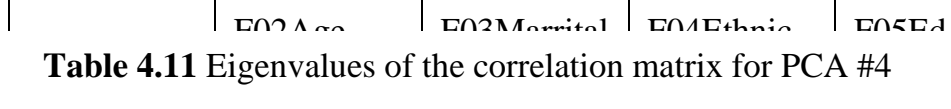 }} & гnouப́ \\
\hline & & & & & 391 \\
\hline \multicolumn{5}{|c|}{ Eigenvalues of the Correlation Matrix } & 292 \\
\hline & Eigenvalue & Difference & Proportion & Cumulative & 852 \\
\hline 1 & 1.7857 & 0.6606 & 0.3571 & 0.3571 & 226 \\
\hline 2 & 1.1251 & 0.1538 & 0.2250 & 0.5822 & 1 \\
\hline 3 & 0.9713 & 0.1206 & 0.1943 & 0.7764 & \\
\hline 4 & 0.8507 & 0.5835 & 0.1701 & 0.9466 & \\
\hline 5 & 0.2672 & & .0534 & 1.0000 & \\
\hline
\end{tabular}

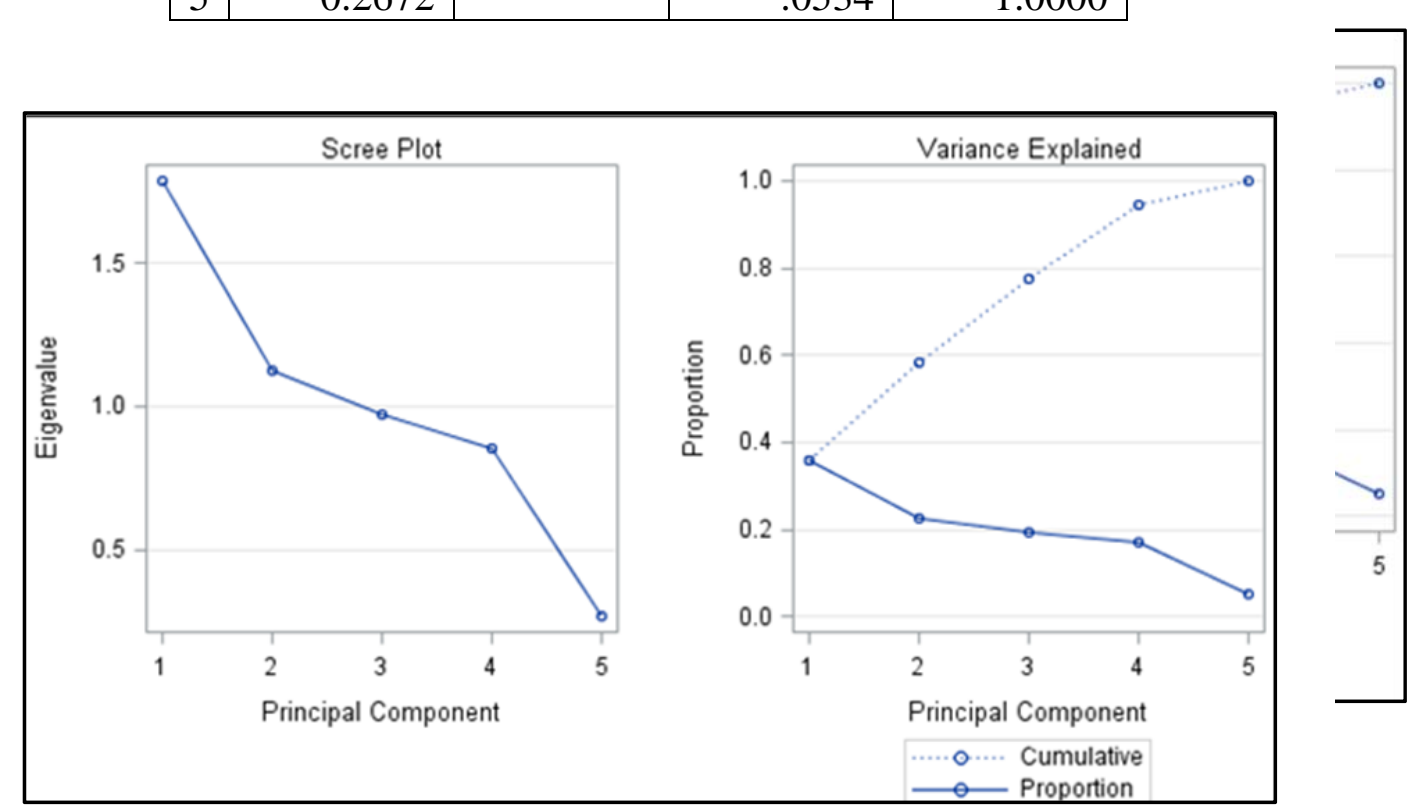

Figure 4.11 Scree plot from the SAS output for PCA\#4

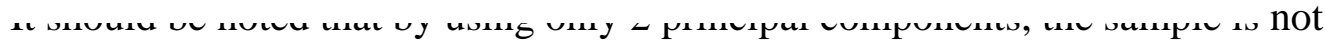

differentiated to the same extent in comparison with using 4 or 5 principal components, as was generated with the first three analyses. This supports the idea that by using factors other than demographic characteristics, an alternative segmentation pattern can potentially be achieved. 
For PCA\#4, the dominant variables for the first principal component (PC1) are age (0.6359) and marital status (0.6690). Therefore respondents who had similar values for PC1 most likely are close in age and have the same marital status. This is understandable, as age and marital status can be very influential on lifestyle choices.

For the second principal component (PC2), ethnicity (0.6357) and household size (0.6949) were the most influential variables. Although four ethnicity choices were included in the Final Survey, the ethnicities included in the population were only White/Caucasian (coded “1” in for data analysis purposes) or Hispanic/Latino (coded “4”). The females who had similar values for PC2, reflective of their tendencies, most likely shared similar ethnicities and the number of people living in their household.

\section{Cluster Analysis: Methods and Results}

Commonly applied in marketing for segmentation purposes (Punj and Stewart, 1983) cluster analysis is a classification procedure that assembles observations into groups, in which the variance amongst the observations grouped together is minimized and the variance between different groups is maximized (Ketchen and Shook, 1996). In order to decipher the quality of a cluster solution and its explanatory power for a set of observations, the researcher must assess multiple aspects of the analysis output (Ketchen and Shook, 1996). Using the principal components from PCA \#1, PCA \#2, PCA \#3, and PCA \#4, each succeeding cluster analysis was evaluated in order to determine the solution that best captured the multidimensionality of the sample population. 
The judgment of the researcher is an integral part of the evaluation of a cluster analysis, an aspect of the analysis that has been criticized in the past (Ketchen and Shook, 1996). Therefore this emphasizes the importance of the researchers' decision when determining the appropriate number of clusters that best explain the data set (Everitt, 1979). For each cluster analysis in the study at hand, the cluster history included in the SASC output was examined. Specifically, the R-square value associated with each set of cluster groupings was assessed, indicating the percentage of variation explained by each set of cluster groups. The higher the R-square value, the more consideration a set of clusters received for being the most appropriate number of clusters for the solution. The cubic clustering criterion (CCC) was also included in the SAS $($ ) output. Peaks in the CCC plot, associated with a specific number of clusters, were also used as an indication for the best number of clusters to use for the solution.

Cluster Analysis \#1

Cluster Analysis \#1 was performed using Group\# 1 of principal components. The cluster history displays the R-square value corresponding with each level of clusters. In this case, 4 clusters explain just over $47 \%$ of the variation in the data set, indicated by the Rsquare value. The cubic clustering criterion further supports the notion that 4 is an appropriate number of clusters, with a (local) peak occurring in the plot with the point associated with 4 clusters (see Table 4.14 and Figure 4.12). 
Table 4.14 Cluster history for CA\#1

\begin{tabular}{|c|c|c|c|c|c|c|c|c|c|c|}
\hline \multicolumn{11}{|c|}{ Cluster History } \\
\hline $\begin{array}{r}\begin{array}{r}\text { Number } \\
\text { of } \\
\text { Clusters }\end{array} \\
\end{array}$ & \multicolumn{2}{|c|}{ Clusters Joined } & \multirow{2}{*}{ Freq } & \multirow{2}{*}{$\begin{array}{r}\begin{array}{r}\text { Semipartial } \\
\text { R-Square }\end{array} \\
0.0226\end{array}$} & \multirow{2}{*}{$\begin{array}{r}\text { R-Square } \\
.789\end{array}$} & \multirow{2}{*}{$\begin{array}{r}\text { Approximate } \\
\text { Expected } \\
\text { R-Square } \\
\end{array}$} & \multirow{2}{*}{$\begin{array}{r}\begin{array}{r}\text { Cubic } \\
\text { Clustering } \\
\text { Criterion }\end{array} \\
\end{array}$} & \multirow{2}{*}{$\begin{array}{r}\begin{array}{r}\text { Pseudo F } \\
\text { Statistic }\end{array} \\
14.6\end{array}$} & \multirow{2}{*}{\begin{tabular}{|r|r}
$\begin{array}{r}\text { Pseudo } \\
\text { t-Squared }\end{array}$ \\
2.3
\end{tabular}} & \multirow[t]{2}{*}{ Tie } \\
\hline 11 & CL15 & 13 & & & & & & & & \\
\hline 10 & 11 & CL17 & 6 & 0.0233 & .766 & .789 & -1.4 & 14.6 & 4.8 & \\
\hline 9 & CL13 & CL29 & 11 & 0.0244 & .742 & .766 & -1.4 & 14.7 & 5.8 & \\
\hline 8 & CL12 & CL18 & 10 & 0.0292 & .712 & .739 & -1.4 & 14.9 & 4.8 & \\
\hline 7 & CL14 & $\mathrm{CL} 26$ & 11 & 0.0379 & .675 & .708 & -1.6 & 14.9 & 9.1 & \\
\hline 6 & CL19 & CL8 & 15 & 0.0523 & .622 & .669 & -2.1 & 14.5 & 7.4 & \\
\hline 5 & CL9 & CL16 & 14 & 0.0750 & .547 & .620 & -3.1 & 13.6 & 12.2 & \\
\hline 4 & CL7 & CL10 & 17 & 0.0765 & .471 & .515 & -1.7 & 13.6 & 9.7 & \\
\hline 3 & CL11 & CL6 & 19 & 0.1233 & .348 & .385 & -1.3 & 12.5 & 11.3 & \\
\hline 2 & $\mathrm{CL} 3$ & CL4 & 36 & 0.1683 & .179 & .222 & -1.6 & 10.5 & 11.4 & \\
\hline 1 & $\mathrm{CL} 2$ & CL5 & 50 & 0.1793 & .000 & .000 & 0.00 & . & 10.5 & \\
\hline
\end{tabular}

Out of the four clusters that were created in CA \#1, three were fairly close in size $(17,14$, and 15 participants accordingly), with the remaining cluster containing only four participants (see Panel a of Figure 4.14, which displays the distribution of participants amongst the clusters). By this segmentation scheme, it is probable that the three clusters of comparable sizes contained participants whose behavior was relatively similar in relation to the "food time" variables used to form the principal components and resulting cluster analysis. On the other hand, the behavior of the subjects in the last cluster was likely difficult to classify or distinguish based on the "food time" variables. It is possible these subjects were essentially outliers in the data set. 


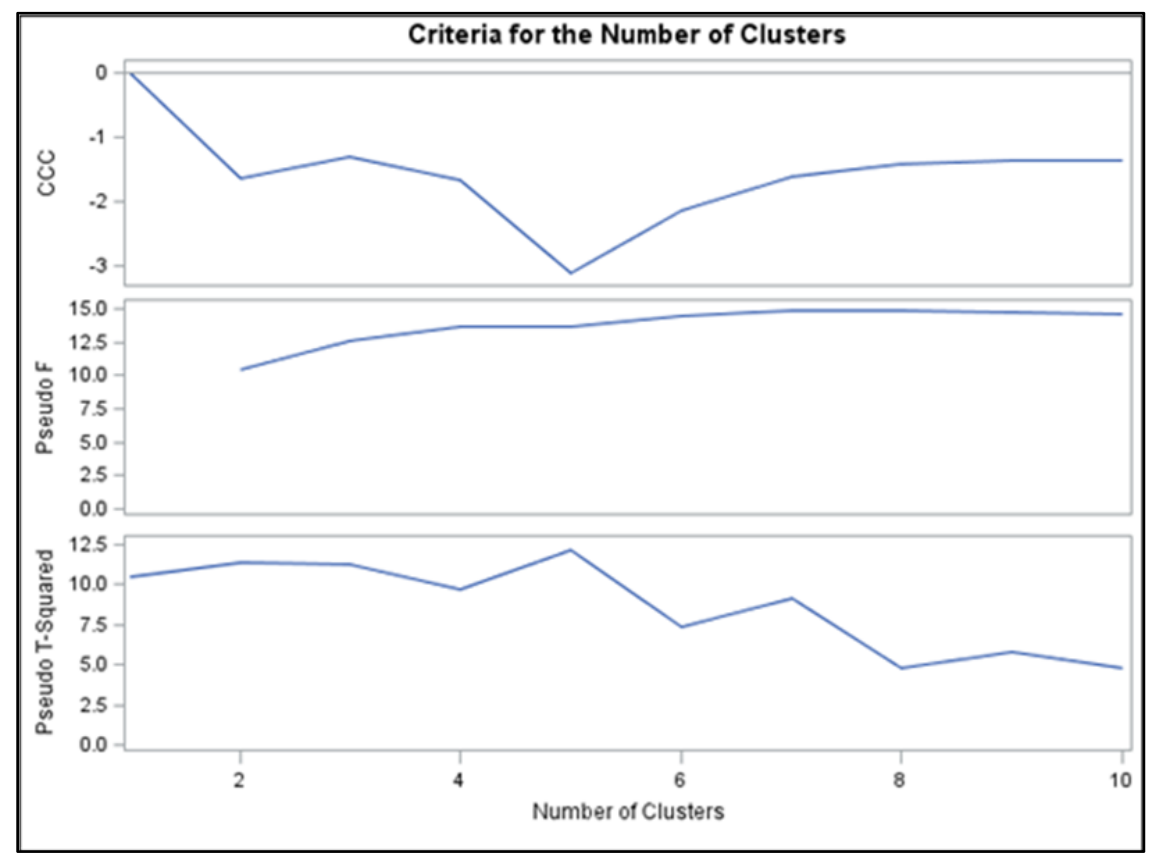

Figure 4.12 Cubic Clustering Criterion (CCC) plot for CA \#1

Cluster Analysis \# 2

Table 4.15 and Figure 4.13 show the output for Cluster Analysis \#2, performed using

Group\# 2 of principal components. The cluster history displays the R-square value

Table 4.15 Cluster history for CA\#2

\begin{tabular}{|c|c|c|c|c|c|c|c|c|c|c|}
\hline \multicolumn{11}{|c|}{ Cluster History } \\
\hline $\begin{array}{r}\begin{array}{r}\text { Number } \\
\text { of }\end{array} \\
\text { Clusters }\end{array}$ & \multicolumn{2}{|c|}{ Clusters Joined } & \multirow{2}{*}{ 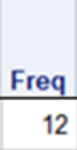 } & \multirow{2}{*}{$\begin{array}{r}\begin{array}{r}\text { Semipartial } \\
\text { R-Square }\end{array} \\
0.0237\end{array}$} & \multirow{2}{*}{$\begin{array}{r}\text { R-Square } \\
.734\end{array}$} & \multirow[t]{2}{*}{$\begin{array}{r}\text { Approximate } \\
\text { Expected } \\
\text { R-Square } \\
\end{array}$} & \multirow{2}{*}{$\begin{array}{r}\begin{array}{r}\text { Cubic } \\
\text { Clustering } \\
\text { Criterion }\end{array} \\
\end{array}$} & \multirow{2}{*}{$\begin{array}{r}\begin{array}{r}\text { Pseudo F } \\
\text { Statistic }\end{array} \\
10.8\end{array}$} & \multirow{2}{*}{$\begin{array}{r}\begin{array}{r}\text { Pseudo } \\
\text { t-Squared }\end{array} \\
4.2\end{array}$} & \multirow{2}{*}{ Tie } \\
\hline 11 & CL19 & CL13 & & & & & & & & \\
\hline 10 & CL14 & CL36 & 9 & 0.0303 & .704 & .733 & -1.7 & 10.6 & 5.2 & \\
\hline 9 & CL22 & CL18 & 8 & 0.0340 & .670 & .708 & -2.0 & 10.4 & 6.5 & \\
\hline 8 & $\mathrm{CL} 20$ & CL16 & 9 & 0.0362 & .634 & .678 & -2.3 & 10.4 & 6.6 & \\
\hline 7 & CL12 & CL15 & 6 & 0.0509 & .583 & .644 & -3.0 & 10.0 & 3.3 & \\
\hline 6 & CL23 & CL11 & 17 & 0.0610 & .522 & .603 & -3.8 & 9.6 & 9.7 & \\
\hline 5 & CL9 & 26 & 9 & 0.0720 & .450 & .526 & -3.2 & 9.2 & 7.7 & \\
\hline 4 & CL6 & CL10 & 26 & 0.0936 & .357 & .435 & -3.0 & 8.5 & 10.0 & \\
\hline 3 & CL8 & CL5 & 18 & 0.0973 & .259 & .324 & -2.5 & 8.2 & 7.3 & \\
\hline 2 & $\mathrm{CL} 3$ & CL4 & 44 & 0.1236 & .136 & .187 & -2.3 & 7.5 & 8.3 & \\
\hline 1 & $\mathrm{CL} 7$ & $\mathrm{CL} 2$ & 50 & 0.1356 & .000 & .000 & 0.00 & . & 7.5 & \\
\hline
\end{tabular}


corresponding with each level of clusters, with $26 \%$ of the variation in the data set explained by 3 clusters. The cubic clustering criterion also supports the notion that 3 is an appropriate number of clusters for this analysis, with a peak occurring in the plot with the point associated with 3 clusters (see Table 4.15 and Figure 4.13). This percentage of variation explained in CA \#2 is much less compared to CA \#1, in addition to the fact there are a smaller number of clusters. This draws attention to the variables used to form the principal components in CA \#2, which had three more variables compared to the principal components in CA \#1. Perhaps using more variables is detrimental in the sense that it complicates the segmentation process. It is conceivable that categorizing the sample is more challenging when there are additional variables to take into consideration.

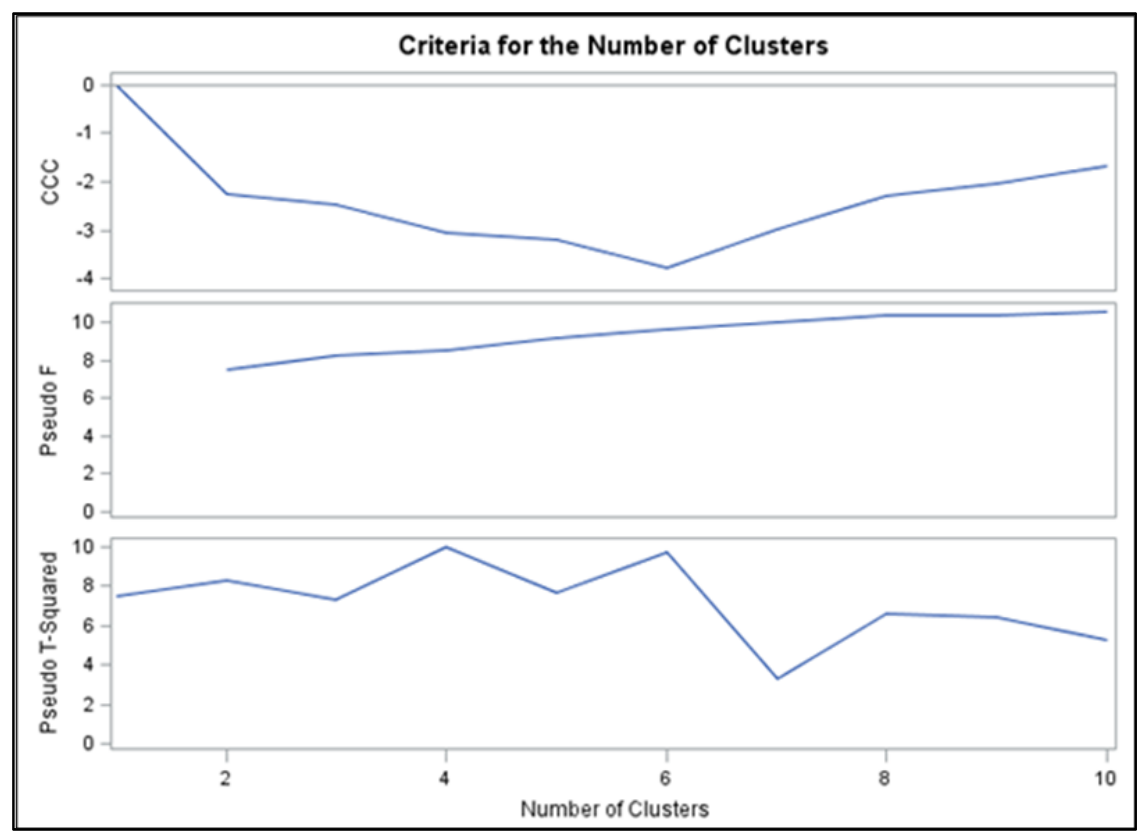

Figure 4.13 Cubic Clustering Criterion (CCC) plot for CA \#2 
The distribution of the three clusters formed in the second cluster analysis is very curious, particularly in relation to the clusters formed in CA \#1 (see Figure 4.14). While three of the clusters in CA \#1 were proportionally similar to one another, with the fourth cluster markedly smaller, the three clusters formed in CA \#2 were very different in size (18, 26, and 6 participants accordingly). The composition of each cluster in CA \#2 is even more

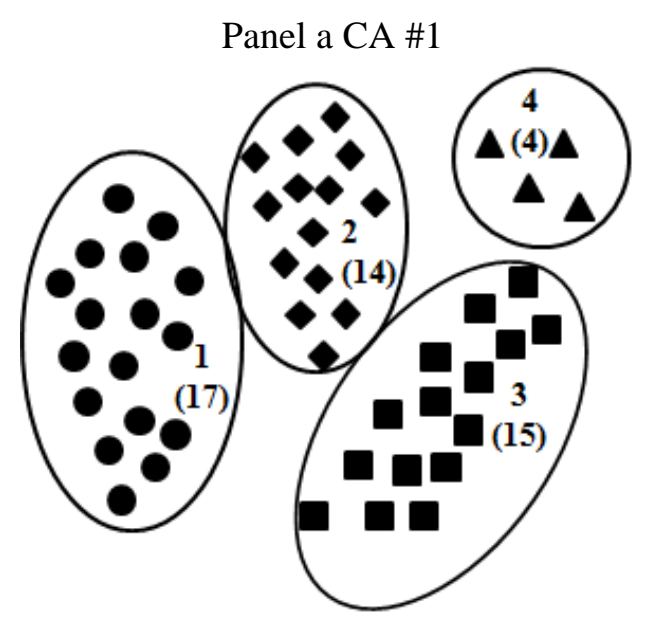

Panel b CA\#2

Panel c CA \#3
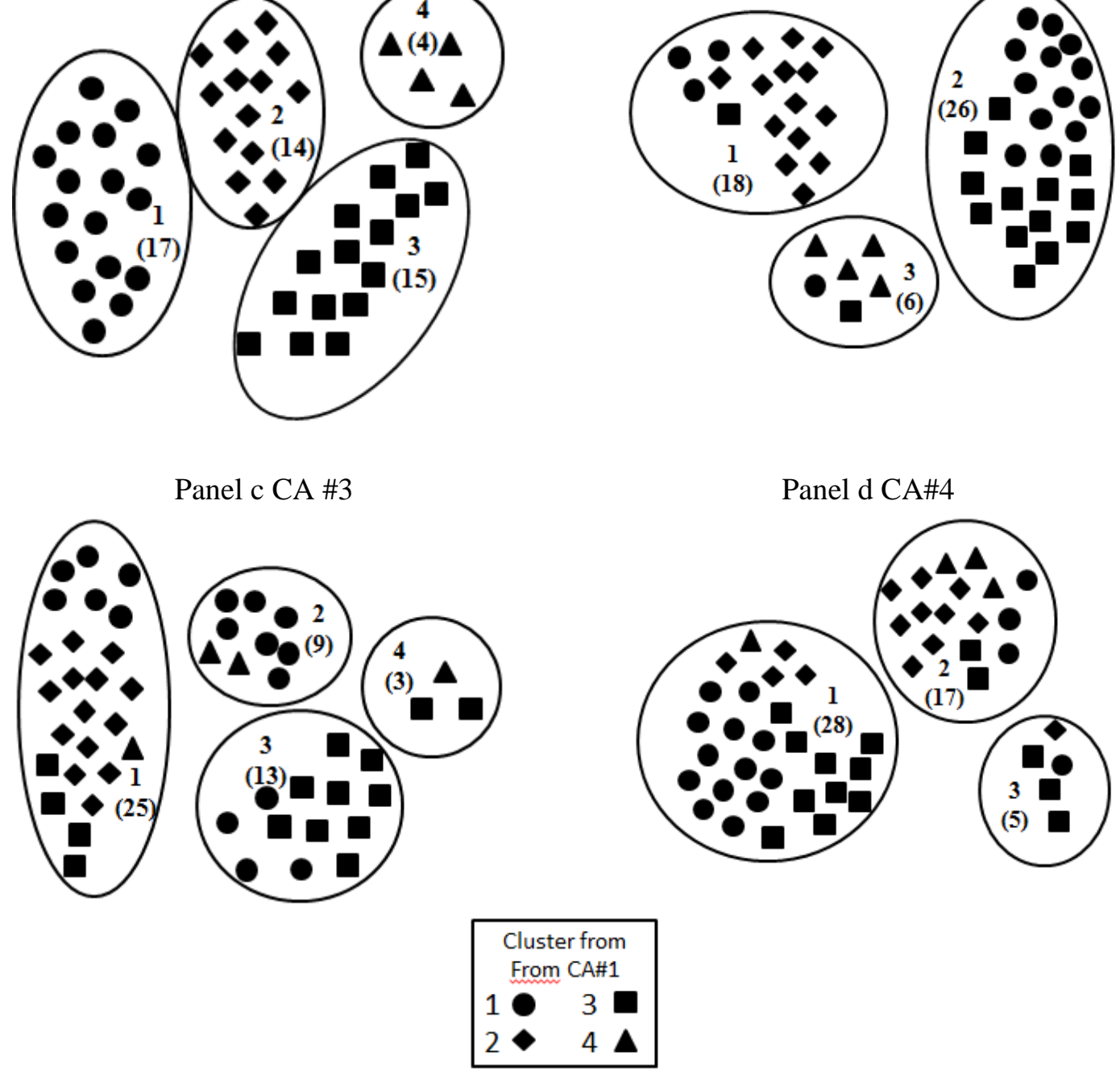

Panel d CA\#4

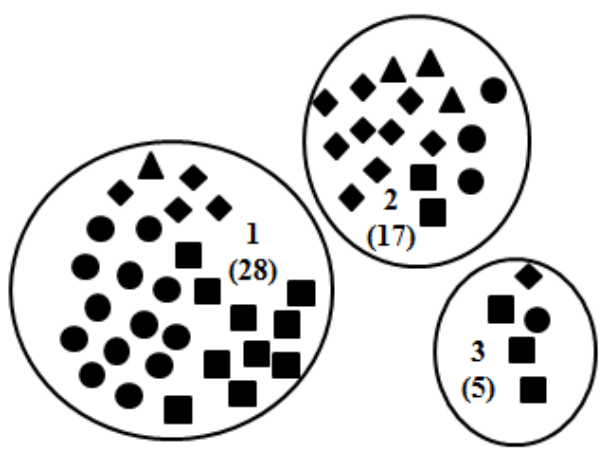

Figure 4.14 Clustering of the sample: CA \#1, CA \#2, CA \#3, and CA \#4 
intriguing. The majority of the first cluster (containing 18 subjects) was comprised of participants who were grouped in the second cluster in CA \#1. On the other hand, the second cluster in CA \#2 was made up almost equally of participants grouped in the first and third clusters in CA \#1. Finally, the majority of the third cluster in CA \#2 contains most of the same participants grouped in the fourth cluster in CA \#1 (the outliers, as it seems), with a few additional subjects also included. While the cluster formations of the two analyses are certainly different, many of the same individuals were repeatedly classified together in both analyses.

The primary difference between PCA\#1 and PCA\#2 was the inclusion of variables indicating the percent of days that meals were skipped. These additional variables most likely increased the variation in the data and clearly had an effect on the outcome. In this case, the results of the ANOVA and Chi-Squared tests help to determine whether this alternative clustering is more or less meaningful than CA \#1.

\section{Cluster Analysis \# 3}

Below is the output for Cluster Analysis \#3, performed using Group\# 3 of principal components. The cluster history displays the R-square value corresponding with each level of clusters. In this case, 4 clusters explain nearly $46 \%$ of the variation in the data set, indicated by the R-square value, which is again notably less compared to the percentage of variation explained by the cluster groups in CA \#1. Additionally, the cubic clustering criterion in CA \#3 indicates that 4 is an appropriate number of clusters, with a peak occurring in the plot with the point associated with 4 clusters (see Table 4.16 and Figure 4.15). 
Table 4.16 Cluster history for CA\#3

\begin{tabular}{|c|c|c|c|c|c|c|c|c|c|c|}
\hline \multicolumn{11}{|c|}{ Cluster History } \\
\hline $\begin{array}{r}\text { Number } \\
\text { of } \\
\text { Clusters }\end{array}$ & \multicolumn{2}{|c|}{ Clusters Joined } & \multirow{2}{*}{$\frac{\text { Freq }}{6}$} & \multirow{2}{*}{$\begin{array}{r}\begin{array}{r}\text { Semipartial } \\
\text { R-Square }\end{array} \\
0.0200\end{array}$} & \multirow{2}{*}{$\begin{array}{r}\text { R-Square } \\
.787\end{array}$} & \multirow{2}{*}{$\begin{array}{r}\text { Approximate } \\
\text { Expected } \\
\text { R-Square } \\
\end{array}$} & \multirow{2}{*}{$\begin{array}{r}\text { Cubic } \\
\text { Clustering } \\
\text { Criterion } \\
\end{array}$} & \multirow{2}{*}{$\begin{array}{r}\text { Pseudo F } \\
\text { Statistic } \\
14.4\end{array}$} & \multirow{2}{*}{$\begin{array}{r}\begin{array}{r}\text { Pseudo } \\
\text { t-Squared }\end{array} \\
4.3\end{array}$} & \multirow{2}{*}{ Tie } \\
\hline 11 & 13 & CL18 & & & & & & & & \\
\hline 10 & CL26 & 39 & 3 & 0.0205 & .767 & .789 & -1.3 & 14.6 & 4.3 & \\
\hline 9 & CL14 & CL19 & 11 & 0.0247 & .742 & .766 & -1.3 & 14.7 & 5.5 & \\
\hline 8 & $\mathrm{CL} 24$ & $\mathrm{CL} 11$ & 9 & 0.0250 & .717 & .739 & -1.2 & 15.2 & 3.6 & \\
\hline 7 & CL15 & $\mathrm{CL23}$ & 8 & 0.0487 & .668 & .708 & -1.9 & 14.4 & 8.7 & \\
\hline 6 & CL13 & CL9 & 18 & 0.0568 & .611 & .669 & -2.6 & 13.9 & 9.2 & \\
\hline 5 & CL21 & $\mathrm{CL} 7$ & 13 & 0.0686 & .543 & .620 & -3.3 & 13.4 & 7.9 & \\
\hline 4 & CL12 & CL6 & 25 & 0.0880 & .455 & .515 & -2.2 & 12.8 & 10.4 & \\
\hline 3 & CL8 & CL10 & 12 & 0.1321 & .323 & .385 & -2.1 & 11.2 & 13.4 & \\
\hline 2 & CL5 & $\mathrm{CL} 3$ & 25 & 0.1393 & .183 & .222 & -1.5 & 10.8 & 8.1 & \\
\hline 1 & CL4 & $\mathrm{CL} 2$ & 50 & 0.1835 & .000 & .000 & 0.00 & $\cdot$ & 10.8 & \\
\hline
\end{tabular}

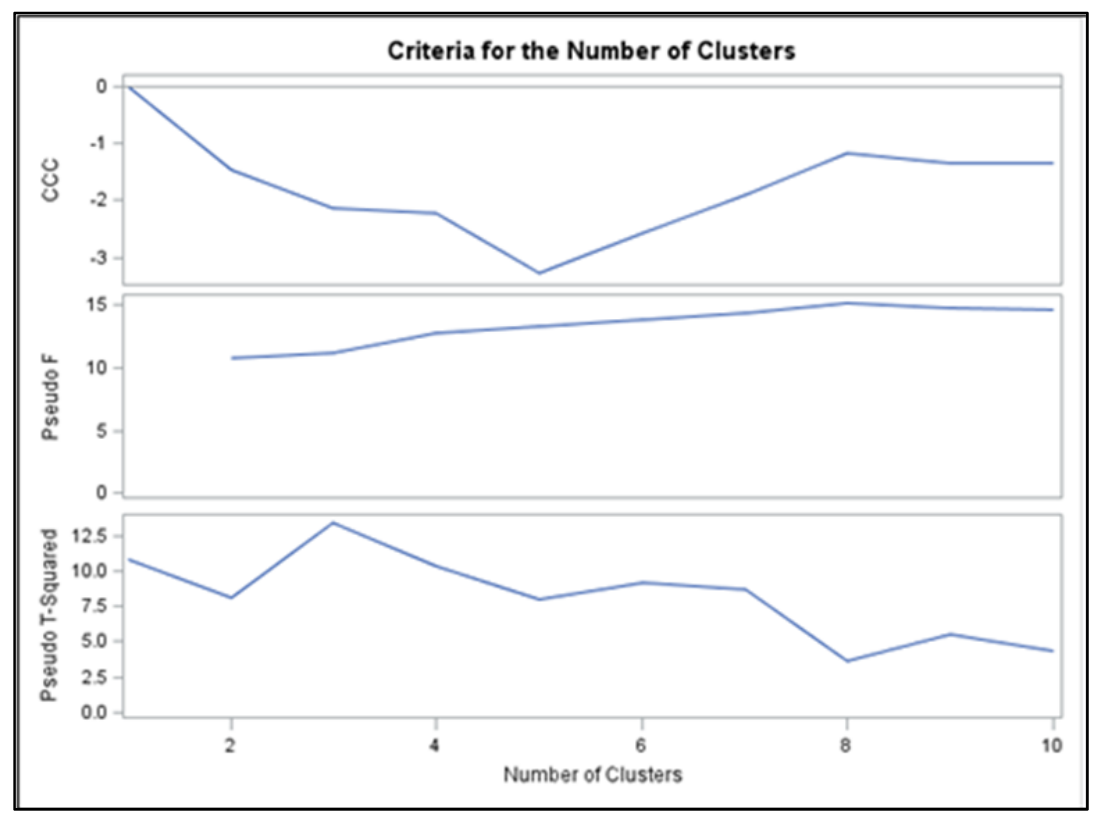

Figure 4.15 Cubic Clustering Criterion (CCC) plot for CA \#3

The cluster groups in CA \#3 vary quite a bit in size (25, 9, 13, and 3 participants), and here again, the distribution of participants in the four clusters in CA \#3 is very interesting when compared with CA \#1 (see Figure 4.14). The bulk of the participants grouped in the first cluster in CA \#3 were classified in the second cluster in CA \#1. However, the 
majority of the remaining participants appear to be the same subjects that were grouped in the first and third clusters in CA \#1. Lastly the fourth cluster in CA \#3 only contained three participants, one of which was in the fourth, or outlier, cluster in CA \#1.

PCA \#3 included all of the variables included in PCA \#1, with three additional variables that would tend to indicate time pressure (eating lunch while driving, purchasing dinner, and having dinner prepared by someone else). These "time pressure" variables account for the alternative clusters, either by creating meaningful distinctions among respondents or by increasing the variation in the data.

Cluster Analysis \# 4

Below is the output for Cluster Analysis \#4 (CA \#4), performed using the set of principal components formulated using solely demographic variables. The cluster history displays the R-square value corresponding with each level of clusters. In this case, 3 clusters explain nearly $72 \%$ of the variation in the data set, indicated by the R-square value. The Cubic Clustering Criterion also suggests 3 is an appropriate number of clusters, with a peak occurring in the plot with the point associated with 3 clusters (see Table 4.17 and Figure 4.16).

An R-square value of .721 presumably implies that the set of variables used in CA \#4 amply capture the variation of the data. However this is questionable due to the fact that only two principal components were used in this last approach. By only using two principal components, both of which were formed using purely demographic characteristics, it is likely there is less variation in the data to explain. On the other hand, the principal components used in Groups \#1, \#2, and \#3, derived using variables related 
Table 4.17 Cluster history for CA\#4

\begin{tabular}{|c|c|c|c|c|c|c|c|c|c|c|}
\hline \multicolumn{11}{|c|}{ Cluster History } \\
\hline $\begin{array}{r}\text { Number } \\
\text { of } \\
\text { Clusters }\end{array}$ & \multicolumn{2}{|c|}{ Clusters Joined } & \multirow{2}{*}{$\frac{\text { Freq }}{8}$} & \multirow{2}{*}{$\begin{array}{r}\begin{array}{r}\text { Semipartial } \\
\text { R-Square }\end{array} \\
0.0087\end{array}$} & \multirow{2}{*}{$\begin{array}{r}\text { R-Square } \\
.949\end{array}$} & \multirow{2}{*}{$\begin{array}{r}\begin{array}{r}\text { Approximate } \\
\text { Expected } \\
\text { R-Square }\end{array} \\
\end{array}$} & \multirow{2}{*}{$\begin{array}{r}\begin{array}{r}\text { Cubic } \\
\text { Clustering } \\
\text { Criterion }\end{array} \\
\end{array}$} & \multirow{2}{*}{$\begin{array}{r}\begin{array}{r}\text { Pseudo F } \\
\text { Statistic }\end{array} \\
72.2\end{array}$} & \multirow{2}{*}{$\begin{array}{r}\begin{array}{r}\text { Pseudo } \\
\text { t-Squared }\end{array} \\
13.6\end{array}$} & \multirow{2}{*}{ Tie } \\
\hline 11 & CL30 & CL16 & & & & & & & & \\
\hline 10 & CL34 & CL29 & 4 & 0.0089 & .940 & .935 & 0.60 & 69.5 & 16.2 & \\
\hline 9 & CL13 & CL42 & 13 & 0.0147 & .925 & .924 & 0.14 & 63.4 & 16.4 & \\
\hline 8 & CL11 & CL14 & 15 & 0.0164 & .909 & .910 & -.09 & 59.8 & 10.3 & \\
\hline 7 & CL12 & 8 & 9 & 0.0167 & .892 & .892 & 0.04 & 59.3 & 7.9 & \\
\hline 6 & CL17 & $\mathrm{CL} 22$ & 8 & 0.0193 & .873 & .867 & 0.37 & 60.4 & 24.9 & \\
\hline 5 & CL10 & 24 & 5 & 0.0291 & .844 & .833 & 0.61 & 60.7 & 8.7 & \\
\hline 4 & CL6 & CL7 & 17 & 0.0529 & .791 & .780 & 0.46 & 57.9 & 14.3 & \\
\hline 3 & CL8 & CL9 & 28 & 0.0699 & .721 & .693 & 1.06 & 60.7 & 29.5 & \\
\hline 2 & CL5 & $\mathrm{CL} 3$ & 33 & 0.3210 & .400 & .402 & -.05 & 32.0 & 58.3 & \\
\hline 1 & CL4 & $\mathrm{CL} 2$ & 50 & 0.3998 & .000 & .000 & 0.00 & $\sigma^{\circ}$ & 32.0 & \\
\hline
\end{tabular}

to time allocation and contextual factors $(9,12$, and 11 variables accordingly), likely produce a more complex data set. The similarities and differences between each study participant, specifically related to these "food time” variables, have a much greater chance of being widespread and multilayered compared to the similarities and differences related to demographic variables. Therefore, while the proportion of variance explained for Group \#4 is higher compared to the other three groups, it doesn’t necessarily imply the cluster analysis using demographic information is superior. 


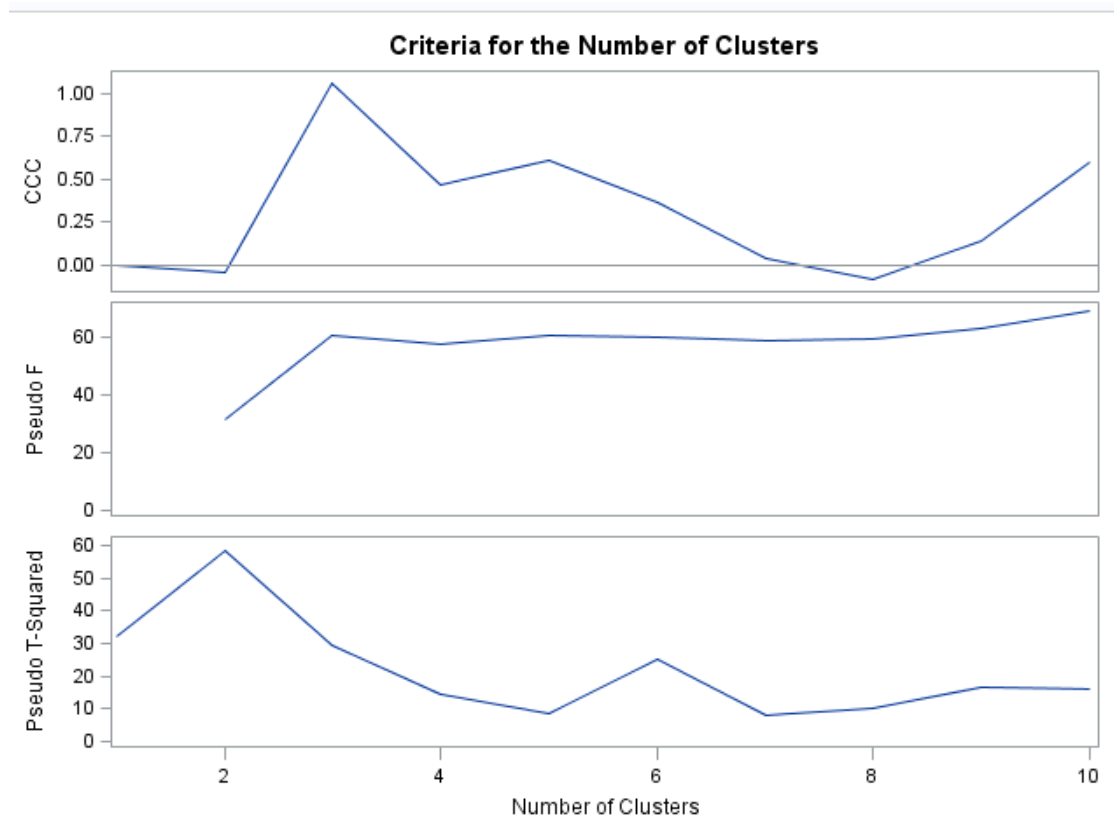

Figure 4.16 Cubic Clustering Criterion (CCC) plot for CA \#4

The first cluster in CA \#4 contains the majority of the sample with 28 participants, followed by 17 in the second cluster and only 5 in the remaining cluster group (see Figure 4.14). Compared with CA \#1's distribution, most of the participants classified in the first cluster are again grouped in the first cluster in CA \#4; although a fair amount of participants from the third cluster, along with a few individuals from the first and fourth clusters in CA \#1, are also in the first cluster in CA \#4. The second cluster in CA \#4 contains participants from each cluster grouping in CA \#1, in almost equal amounts. Finally, the fourth cluster in CA \#4 only contains 5 participants, the majority of which were in the third cluster in CA \#1. The variables used to form the principal components in CA \#4 pertained to solely demographic characteristics, unlike the other three analyses which used "food time" variables; thus it is understandable that the bulk of the study 
participants were grouped together in CA \#4, as the sample population did not differ a great deal in terms of demographic characteristics.

\section{Choosing the Most Effective Analysis: Methods and Results}

ANOVA and Chi-Square tests were conducted in order to verify the reliability and validity of each set of principal components and resulting cluster analysis. Statistical tests assess validity by measuring external variables that are theoretically related to the clusters, but were not used to define clusters (Ketchen and Shook, 1996). For the study at hand, ANOVA tests were used to assess the variance between the clusters and within each cluster group, along with evaluating the data to determine if the null hypothesis was true. The null hypothesis predicted that, for a given variable, no statistically differences would be found between different clusters. On the contrary, the alternative hypothesis proposed that differences would be found between two or more clusters. Rejecting the null hypothesis signified that the manner in which the clusters were grouped together (similar within each cluster) resulted in truly unique groups of clusters, different from one another relative to the variables tested in the study. For categorical variables, Chi-Square tests were conducted to test the null hypothesis that there is no difference in the distribution of responses among the clusters. Again, rejecting the null suggests that the clusters differ meaningfully.

Next, the proportion of variance explained by each cluster analysis (discussed in detail during the first half of Chapter IV), along with the number of significant differences found in the ANOVA and Chi-Square tests were compared amongst the cluster analyses. This evaluation was performed in an effort to find the cluster analysis which provided an interpretation of the data with the greatest amount of depth, different than would be 
achieved using only demographic variables. Table 4.18 below displays the total number of significant differences found for each cluster analysis. A complete chart listing all of the variables in the data set and the results of the significance tests is included in Appendix C.

Table 4.18 Number of significant differences found for each cluster analysis

\begin{tabular}{|c|c|c|c|c|c|}
\hline \multirow[t]{2}{*}{ Topic Area } & \multirow{2}{*}{$\begin{array}{c}\text { Total } \\
\text { Number of } \\
\text { Variables }\end{array}$} & \multicolumn{4}{|c|}{$\begin{array}{c}\text { Number of Significant Differences for } \\
\text { For PCA/CA }\end{array}$} \\
\hline & & $\# 1$ & $\# 2$ & \#3 & $\# 4$ \\
\hline Grocery Shopping & 19 & 6 & 4 & 5 & 3 \\
\hline Meal Planning and Preparation & 40 & 5 & 2 & 7 & 3 \\
\hline Food Choices & 17 & 5 & 3 & 4 & 4 \\
\hline Consumption Atmosphere & 53 & 14 & 10 & 12 & 11 \\
\hline Cooking Proclivity & 30 & 5 & 4 & 6 & 5 \\
\hline Demographics & 9 & 1 & & 1 & 7 \\
\hline Other & 2 & 2 & & 1 & 1 \\
\hline Total & 170 & 38 & 23 & 36 & 34 \\
\hline
\end{tabular}

When assessing significant differences or similarities among the four cluster analyses, the test results were intriguing (see Table 4.18 and Appendix C). CA \#1 had the most statistically significant differences (38), followed by CA \#3, CA\#4, and CA \#2 (36, 34, and 23 accordingly). Having the highest number of significant differences implies that CA \#1 is the superior analysis due to the fact this suggests the four clusters were truly different from one another. More specifically, it may be inferred that the behavior of the participants within each cluster was similar regarding a particular variable being tested, whereas it differed from the behavior of participants in other clusters (regarding the same variable being tested). 
Table 4.19 Variables for which statistically significant differences were found in at least two cluster analyses

\begin{tabular}{|c|c|c|}
\hline Grocery Shopping & $\begin{array}{l}\text { Meal Planning and } \\
\text { Preparation }\end{array}$ & Food Choices \\
\hline $\begin{array}{l}\text { GroceryShop } \\
\text { GrocShopChild } \\
\text { GrocShopHowLAvg } \\
\text { I05aConvLoc } \\
\text { I05dPrepFood }\end{array}$ & $\begin{array}{l}\text { PurchasedDinner } \\
\text { SOElsePreparBfast } \\
\text { UseCookBk }\end{array}$ & $\begin{array}{l}\text { DinNutriAvg } \\
\text { DinTastyAvg } \\
\text { DinWFreshIngAvg } \\
\text { I06dPack }\end{array}$ \\
\hline Consumption Atmosphere & Cooking Proclivity & Demographics \\
\hline $\begin{array}{l}\text { AteBfastAlone } \\
\text { AteDinAlone } \\
\text { AteDinHHMem }\end{array}$ & $\begin{array}{l}\text { I09bEatMeal } \\
\text { I09fCookLots } \\
\text { I11dPrepHealth }\end{array}$ & $\begin{array}{l}\text { F03Marital } \\
\text { F09Children }\end{array}$ \\
\hline $\begin{array}{l}\text { AteDinOthers } \\
\text { BfastwHH } \\
\text { D10eBrComp } \\
\text { D10fBrDrive } \\
\text { DinOthActHHMem } \\
\text { DinOthActWork } \\
\text { LuPurchFastFood } \\
\text { LuPurchVendor }\end{array}$ & LuPurchEnjoy & $\frac{\text { Other }}{\text { I10Health }}$ \\
\hline
\end{tabular}

Table 4.19 displays the variables in each topic area in which two or more analyses resulted in statistically significantly different means among the resulting clusters. In other words, a statistically significant difference was found between one or more cluster groups within the specific cluster analysis for at least two of the cluster analyses. With the exception of I10Health from the Initial Survey and the variables F03Marital and F09Children from the Final Survey, all of the variables in Table 4.19 are "food time" 
variables and measure the behavioral and contextual information gathered from participants during the study. It has been mentioned this information is rarely collected, particularly when compared to the amount of demographic information that is often collected. However the abundance of significant differences found with the "food time" variables supports the notion that unique variables such as these are indeed effective tools for segmentation.

Cluster Analysis \#1 (CA \#1) was chosen as the key analysis to be used in a comparison with the set of clusters derived from demographic variables (CA \#4). The proportion of variance explained by the principal components used to generate CA \#1 was the most at 74\% (compared to CA \#3 which explained 67\% of the variance). CA \#1 also resulted in the largest number of significant differences compared to the other analyses. More importantly, the topic areas had many significant differences, for all of the four analyses, indicating these areas are useful for segmentation purposes. For each cluster analysis, the topic area with the most significant differences implies this lifestyle characteristic differs amongst the clusters and therefore, can be valuable for segmentation. Topic areas encompassed the "food time" variables and many of the significant differences for these variables occurred with CA \#1, CA \#2, and CA\#3. Conversely, CA \#4 had seven significant variables that were associated with questions concerning demographic information, four of which were used in its initial principal components analysis. Hence, the large number of significant differences, 34, and the high explanatory power (72\%) of this cluster analysis is somewhat misleading. The results of the validity tests revealed that by using factors other than demographic characteristics, a different segmentation scheme can potentially be achieved. 
Table 4.20 lists the "food time” variables (arranged by topic area) with significant differences between the clusters for CA \#1 and/or Demographic CA. By far, the topic area with the most significant variables was Consumption Atmosphere, with 14 significant variables out of 53 variables in this category. This indicates the behavior of the participants within each cluster in CA \#1 and/or CA \#4 was different when compared to other clusters within the same analysis. Many of the Consumption Atmosphere variables were associated with various activities that occurred simultaneously while participants ate each meal during the study. Grocery shopping, meal planning and preparation, food choices, and cooking proclivity had a similar number of variables that were significant $(6,5,5$, and 5 accordingly), although the total number of variables in each topic area varied. 
Table 4.20 "Food time” variables with statistically significant differences among clusters from final model and demographic model

Table 4.20, Panel a Grocery Shopping

\begin{tabular}{|c|c|c|c|c|c|c|c|c|c|c|}
\hline \multirow[t]{2}{*}{ Variable } & \multirow{2}{*}{$\begin{array}{c}\text { Entire } \\
\text { Sample } \\
\mathrm{n}=50\end{array}$} & \multicolumn{4}{|c|}{ Final Model Cluster \# } & \multirow{2}{*}{$\begin{array}{c}\mathrm{P}- \\
\text { value }\end{array}$} & \multicolumn{3}{|c|}{$\begin{array}{l}\text { Demographic Model } \\
\text { Cluster \# }\end{array}$} & \multirow{2}{*}{$\begin{array}{l}\mathrm{P}- \\
\text { value }\end{array}$} \\
\hline & & 1 & 2 & 3 & 4 & & 1 & 2 & 3 & \\
\hline \multicolumn{11}{|l|}{ I01GrShare } \\
\hline Almost none & $6 \%$ & $12 \%$ & $0 \%$ & $7 \%$ & $0 \%$ & 0.08 & $0 \%$ & $12 \%$ & $20 \%$ & 0.27 \\
\hline Less than half & $6 \%$ & $6 \%$ & $0 \%$ & $7 \%$ & $25 \%$ & & $4 \%$ & $12 \%$ & $0 \%$ & \\
\hline More than half & $16 \%$ & $6 \%$ & $7 \%$ & $40 \%$ & $0 \%$ & & $21 \%$ & $50 \%$ & $20 \%$ & \\
\hline All or nearly all & $72 \%$ & $76 \%$ & $93 \%$ & $47 \%$ & $75 \%$ & & $75 \%$ & $71 \%$ & $60 \%$ & \\
\hline \multicolumn{11}{|l|}{ I05aConvLoc } \\
\hline Average & 1.04 & 1.18 & 1.50 & 0.86 & -0.50 & 0.01 & 1.11 & 1.00 & 0.80 & 0.83 \\
\hline $\mathrm{n}$ & 50 & 17 & 14 & 14 & 4 & & 28 & 16 & 5 & \\
\hline \multicolumn{11}{|l|}{ I05dPrepFood } \\
\hline Average & -0.17 & -0.20 & 0.57 & -0.85 & -0.50 & 0.05 & -0.81 & 0.64 & 0.67 & 0.00 \\
\hline $\mathrm{n}$ & 50 & 15 & 14 & 13 & 4 & & 26 & 17 & 3 & \\
\hline \multicolumn{11}{|l|}{ GroceryShop * } \\
\hline Average & 0.34 & 0.43 & 0.25 & 0.40 & 0.09 & 0.03 & 0.34 & 0.36 & 0.25 & 0.71 \\
\hline $\mathrm{n}$ & 49 & 17 & 14 & 15 & 4 & & 28 & 17 & 5 & \\
\hline \multicolumn{11}{|l|}{ BringList } \\
\hline Average & 0.38 & 0.38 & 0.15 & 0.50 & 1.00 & 0.02 & 0.45 & 0.30 & 0.25 & 0.42 \\
\hline $\mathrm{n}$ & 44 & 15 & 13 & 14 & 2 & & 24 & 16 & 4 & \\
\hline \multicolumn{11}{|l|}{ GrocShopHowLAvg } \\
\hline Average & 25.67 & 22.21 & 22.77 & 26.90 & 62.00 & 0.00 & 24.97 & 27.05 & 24.37 & 0.91 \\
\hline $\mathrm{n}$ & 44 & 15 & 13 & 14 & 2 & & 24 & 16 & 4 & \\
\hline \multicolumn{11}{|l|}{ GrocShopChild } \\
\hline Average & 0.14 & 0.20 & 0.04 & 0.18 & 0.00 & 0.53 & 0.15 & 0.00 & 0.63 & 0.00 \\
\hline $\mathrm{n}$ & 44 & 15 & 13 & 14 & 2 & & 24 & 16 & 4 & \\
\hline \multicolumn{11}{|l|}{ GrocShopFam } \\
\hline Average & 0.08 & 0.07 & 0.08 & 0.04 & 0.00 & 0.13 & 0.00 & 0.22 & 0.00 & 0.03 \\
\hline $\mathrm{n}$ & 43 & 15 & 13 & 14 & 2 & & 24 & 16 & 4 & \\
\hline
\end{tabular}

$\mathrm{X}$ indicates that there were no responses for the question among respondents in the cluster noted. * indicates that the variable was used in PCA \#1

Table 4.20, Panel b Meal Planning and Preparation

\begin{tabular}{|c|c|c|c|c|c|c|c|c|c|c|}
\hline \multirow{2}{*}{ Variable } & \multirow{2}{*}{$\begin{array}{c}\text { Entire } \\
\text { Sample } \\
\mathrm{n}=50\end{array}$} & \multicolumn{4}{|c|}{ Final Model Cluster \# } & \multirow{2}{*}{$\begin{array}{l}\mathrm{P}- \\
\text { value }\end{array}$} & \multicolumn{3}{|c|}{$\begin{array}{l}\text { Demographic Model } \\
\text { Cluster \# }\end{array}$} & \multirow{2}{*}{$\begin{array}{c}\mathrm{P}- \\
\text { value }\end{array}$} \\
\hline & & 1 & 2 & 3 & 4 & & 1 & 2 & 3 & \\
\hline \multicolumn{11}{|c|}{$\begin{array}{l}\text { SOElsePreparBfast } \\
\end{array}$} \\
\hline Average & 0.08 & 0.05 & 0.04 & 0.18 & 0.04 & 0.01 & 0.10 & 0.05 & 0.10 & 0.48 \\
\hline $\mathrm{n}$ & 49 & 17 & 13 & 15 & 4 & & 27 & 17 & 5 & \\
\hline \multicolumn{11}{|l|}{ BrPrepMic } \\
\hline Average & 0.12 & 0.14 & 0.03 & 0.08 & 0.43 & 0.04 & 0.09 & 0.15 & 0.15 & 0.71 \\
\hline $\mathrm{n}$ & 47 & 16 & 13 & 14 & 4 & & 25 & 17 & 5 & \\
\hline \multicolumn{11}{|l|}{ PrepScAvgBr } \\
\hline Average & 3.75 & 3.24 & 3.78 & 4.24 & 4.08 & 0.10 & 3.61 & 3.88 & 4.25 & 0.57 \\
\hline
\end{tabular}




\begin{tabular}{|c|c|c|c|c|c|c|c|c|c|c|}
\hline \multirow{2}{*}{ Variable } & \multirow{2}{*}{$\begin{array}{c}\text { Entire } \\
\text { Sample } \\
n=50\end{array}$} & \multicolumn{4}{|c|}{ Final Model Cluster \# } & \multirow{2}{*}{$\begin{array}{c}\mathrm{P}- \\
\text { value }\end{array}$} & \multicolumn{3}{|c|}{$\begin{array}{c}\text { Demographic Model } \\
\text { Cluster \# }\end{array}$} & \multirow{2}{*}{$\begin{array}{l}\mathrm{P}- \\
\text { value }\end{array}$} \\
\hline & & 1 & 2 & 3 & 4 & & 1 & 2 & 3 & \\
\hline $\mathrm{n}$ & 32 & 11 & 9 & 9 & 3 & & 18 & 12 & 2 & \\
\hline BrFroz & & & & & & & & 9 & & \\
\hline Average & 0.04 & 0.00 & 0.14 & $0.00 *$ & & 0.31 & 0.00 & 0.00 & 0.25 & 0.08 \\
\hline $\mathrm{n}$ & 24 & 10 & 7 & 7 & & & 12 & 8 & 4 & \\
\hline \multicolumn{11}{|l|}{ LuPrepSc } \\
\hline Average & 0.75 & 0.71 & 0.85 & 0.84 & 0.28 & 0.09 & 0.75 & 0.70 & 0.91 & 0.63 \\
\hline $\mathrm{n}$ & 44 & 14 & 13 & 13 & 4 & & 22 & 17 & 5 & \\
\hline \multicolumn{11}{|c|}{ PurchasedDinner } \\
\hline Average & 0.25 & 0.17 & 0.35 & 0.25 & 0.25 & 0.09 & 0.25 & 0.28 & 0.19 & 0.69 \\
\hline $\mathrm{n}$ & 50 & 17 & 14 & 15 & 4 & & 28 & 17 & 5 & \\
\hline \multicolumn{11}{|l|}{ UseCookBk } \\
\hline Average & 0.10 & 0.17 & 0.00 & 0.07 & 0.33 & 0.11 & 0.18 & 0.00 & 0.00 & 0.06 \\
\hline $\mathrm{n}$ & 43 & 14 & 14 & 12 & 3 & & 23 & 16 & 4 & \\
\hline \multicolumn{11}{|c|}{ F01cMealPurch } \\
\hline Average & 0.59 & 0.53 & 0.50 & 0.62 & 1.00 & 0.92 & 0.77 & 0.12 & 1.67 & 0.09 \\
\hline $\mathrm{n}$ & 46 & 15 & 14 & 13 & 4 & & 26 & 17 & 3 & \\
\hline
\end{tabular}

Note:

$\mathrm{X}$ indicates that there were no responses for the question among respondents in the cluster noted.

* indicates that the variable was used in PCA \#1

Table 4.20, Panel c Food Choices

\begin{tabular}{|c|c|c|c|c|c|c|c|c|c|c|}
\hline \multirow[t]{2}{*}{ Variable } & \multirow{2}{*}{$\begin{array}{c}\text { Entire } \\
\text { Sample } \\
\mathrm{n}=50\end{array}$} & \multicolumn{4}{|c|}{ Final Model Cluster \# } & \multirow{2}{*}{$\begin{array}{c}\mathrm{P}- \\
\text { value }\end{array}$} & \multicolumn{3}{|c|}{$\begin{array}{c}\text { Demographic Model } \\
\text { Cluster \# } \\
\end{array}$} & \multirow{2}{*}{$\begin{array}{l}\mathrm{P}- \\
\text { value }\end{array}$} \\
\hline & & 1 & 2 & 3 & 4 & & 1 & 2 & 3 & \\
\hline \multicolumn{11}{|l|}{ I06cPrice } \\
\hline Average & 1.22 & 1.73 & 1.14 & 0.85 & 0.75 & 0.03 & 1.19 & 1.35 & 0.67 & 0.47 \\
\hline $\mathrm{n}$ & 50 & 15 & 14 & 13 & 4 & & 26 & 17 & 3 & \\
\hline \multicolumn{11}{|l|}{ I06dPack } \\
\hline Average & 0.13 & 0.33 & 0.36 & -0.23 & -0.25 & 0.41 & -0.19 & 0.59 & 0.33 & 0.07 \\
\hline $\mathrm{n}$ & 50 & 15 & 14 & 13 & 4 & & 26 & 17 & 3 & \\
\hline \multicolumn{11}{|c|}{ DinWFreshIngAvg } \\
\hline Average & 1.34 & 1.63 & 0.96 & 1.43 & 1.10 & 0.01 & 1.55 & 1.05 & 1.18 & 0.02 \\
\hline $\mathrm{n}$ & 50 & 17 & 14 & 15 & 4 & & 28 & 17 & 5 & \\
\hline \multicolumn{11}{|c|}{ DinNutriAvg } \\
\hline Average & 1.18 & 1.40 & 0.82 & 1.30 & 1.10 & 0.06 & 1.38 & 0.80 & 1.38 & 0.01 \\
\hline $\mathrm{n}$ & 50 & 17 & 14 & 15 & 4 & & 28 & 17 & 5 & \\
\hline \multicolumn{11}{|c|}{ DinInexAvg } \\
\hline Average & 0.89 & 1.24 & 0.95 & 0.67 & 0.09 & 0.04 & 1.08 & 0.80 & 1.38 & 0.14 \\
\hline $\mathrm{n}$ & 48 & 16 & 14 & 14 & 4 & & 27 & 17 & 4 & \\
\hline \multicolumn{11}{|c|}{ DinTastyAvg } \\
\hline Average & 1.67 & 1.80 & 1.47 & 1.73 & 1.68 & 0.05 & 1.81 & 1.47 & 1.57 & 0.00 \\
\hline $\mathrm{n}$ & 48 & 16 & 14 & 14 & 4 & & 27 & 17 & 4 & \\
\hline
\end{tabular}

Note:

$\mathrm{X}$ indicates that there were no responses for the question among respondents in the cluster noted.

* indicates that the variable was used in PCA \#1 
Table 4.20, Panel d Consumption Atmosphere

\begin{tabular}{|c|c|c|c|c|c|c|c|c|c|c|}
\hline \multirow[t]{2}{*}{ Variable } & \multirow{2}{*}{$\begin{array}{c}\text { Entire } \\
\text { Sample } \\
\mathrm{n}=50\end{array}$} & \multicolumn{4}{|c|}{ Final Model Cluster \# } & \multirow{2}{*}{$\begin{array}{l}\text { P- } \\
\text { value }\end{array}$} & \multicolumn{3}{|c|}{$\begin{array}{c}\text { Demographic Model } \\
\text { Cluster \# }\end{array}$} & \multirow{2}{*}{$\begin{array}{l}\text { P- } \\
\text { value }\end{array}$} \\
\hline & & 1 & 2 & 3 & 4 & & 1 & 2 & 3 & \\
\hline \multicolumn{11}{|c|}{$\overline{\text { AteBfastAlone } \sim *}$} \\
\hline Average & 0.56 & 0.82 & 0.61 & 0.22 & 0.55 & $<0.01$ & 0.54 & 0.62 & 0.46 & 0.57 \\
\hline $\mathrm{n}$ & 50 & 17 & 14 & 15 & 4 & & 28 & 17 & 5 & \\
\hline \multicolumn{11}{|l|}{ BfastwHH * } \\
\hline Average & 0.26 & 0.09 & 0.11 & 0.61 & 0.24 & $<0.01$ & 0.30 & 0.14 & 0.44 & 0.10 \\
\hline $\mathrm{n}$ & 50 & 17 & 14 & 15 & 4 & & 28 & 17 & 5 & \\
\hline \multicolumn{11}{|l|}{ BrComp } \\
\hline Average & 0.22 & 0.10 & 0.35 & 0.21 & 0.34 & 0.03 & 0.21 & 0.30 & 0.00 & 0.04 \\
\hline $\mathrm{n}$ & 49 & 17 & 13 & 15 & 4 & & 27 & 17 & 5 & \\
\hline \multicolumn{11}{|l|}{ BrDrive } \\
\hline Average & 0.09 & 0.02 & 0.01 & 0.20 & 0.37 & 0.00 & 0.12 & 0.06 & 0.12 & 0.56 \\
\hline $\mathrm{n}$ & 49 & 17 & 13 & 15 & 4 & & 27 & 17 & 5 & \\
\hline \multicolumn{11}{|l|}{ BrReady } \\
\hline Average & 0.16 & 0.10 & 0.27 & 0.12 & 0.20 & 0.19 & 0.09 & 0.23 & 0.28 & 0.05 \\
\hline $\mathrm{n}$ & 49 & 17 & 13 & 15 & 4 & & 27 & 17 & 5 & \\
\hline \multicolumn{11}{|c|}{ AteLuAlone } \\
\hline Average & 0.43 & 0.40 & 0.35 & 0.45 & 0.81 & 0.05 & 0.43 & 0.42 & 0.48 & 0.93 \\
\hline $\mathrm{n}$ & 50 & 17 & 14 & 15 & 4 & & 28 & 17 & 5 & \\
\hline \multicolumn{11}{|c|}{ LuPurchVendor } \\
\hline Average & 0.04 & 0.03 & 0.00 & 0.06 & 0.21 & 0.03 & 0.03 & 0.07 & 0.00 & 0.49 \\
\hline $\mathrm{n}$ & 42 & 13 & 13 & 13 & 3 & & 24 & 14 & 4 & \\
\hline \multicolumn{11}{|c|}{ LuPurchFastFood } \\
\hline Average & 0.17 & 0.16 & 0.13 & 0.15 & 0.44 & 0.42 & 0.26 & 0.03 & 0.05 & 0.05 \\
\hline $\mathrm{n}$ & 42 & 13 & 13 & 13 & 3 & & 24 & 14 & 4 & \\
\hline \multicolumn{11}{|l|}{ LuPhone } \\
\hline Average & 0.03 & 0.02 & 0.01 & 0.03 & 0.15 & 0.04 & 0.02 & 0.06 & 0.00 & 0.22 \\
\hline $\mathrm{n}$ & 50 & 17 & 14 & 15 & 4 & & 28 & 17 & 5 & \\
\hline \multicolumn{11}{|l|}{ LuMusic } \\
\hline Average & 0.05 & 0.01 & 0.06 & 0.70 & 0.04 & 0.35 & 0.02 & 0.09 & 0.03 & 0.10 \\
\hline $\mathrm{n}$ & 50 & 17 & 14 & 15 & 4 & & 28 & 17 & 5 & \\
\hline \multicolumn{11}{|l|}{ LuComp ** } \\
\hline Average & 0.20 & 0.07 & 0.35 & 0.20 & 0.22 & 0.03 & 0.17 & 0.26 & 0.20 & 0.56 \\
\hline $\mathrm{n}$ & 50 & 17 & 14 & 15 & 4 & & 28 & 17 & 5 & \\
\hline AteDinAlon & & & & & & & & & & \\
\hline Average & 0.20 & 0.13 & 0.48 & 0.05 & 0.13 & $<0.01$ & 0.16 & 0.27 & 0.20 & 0.28 \\
\hline $\mathrm{n}$ & 50 & 17 & 14 & 15 & 4 & & 28 & 17 & 5 & \\
\hline AteDinHHM & & & & & & & & & & \\
\hline Average & 0.57 & 0.72 & 0.18 & 0.76 & 0.59 & $<0.01$ & 0.70 & 0.33 & 0.67 & 0.00 \\
\hline $\mathrm{n}$ & 50 & 17 & 14 & 15 & 4 & & 28 & 17 & 5 & \\
\hline AteDinOther & & & & & & & & & & \\
\hline Average & 0.17 & 0.13 & 0.29 & 0.13 & 0.16 & 0.13 & 0.12 & 0.30 & 0.07 & 0.01 \\
\hline $\mathrm{n}$ & 50 & 17 & 14 & 15 & 4 & & 28 & 17 & 5 & \\
\hline DinOthActP & & & & & & & & & & \\
\hline Average & 0.03 & 0.02 & 0.07 & 0.02 & 0.00 & 0.59 & 0.00 & 0.07 & 0.05 & 0.10 \\
\hline $\mathrm{n}$ & 50 & 17 & 14 & 15 & 4 & & 28 & 17 & 5 & \\
\hline DinOthActC & & & & & & & & & & \\
\hline Average & 0.10 & 0.08 & 0.18 & 0.08 & 0.00 & 0.33 & 0.04 & 0.18 & 0.17 & 0.06 \\
\hline $\mathrm{n}$ & 50 & 17 & 14 & 15 & 4 & & 28 & 17 & 5 & \\
\hline DinOthActD & & & & & & & & & & \\
\hline Average & 0.02 & 0.00 & 0.01 & 0.02 & 0.13 & 0.04 & 0.02 & 0.02 & 0.03 & 0.93 \\
\hline $\mathrm{n}$ & 50 & 17 & 14 & 15 & 4 & & 28 & 17 & 5 & \\
\hline
\end{tabular}




\begin{tabular}{|c|c|c|c|c|c|c|c|c|c|c|}
\hline \multirow{2}{*}{ Variable } & \multirow{2}{*}{$\begin{array}{c}\text { Entire } \\
\text { Sample } \\
\mathrm{n}=50\end{array}$} & \multicolumn{4}{|c|}{ Final Model Cluster \# } & \multirow{2}{*}{$\begin{array}{l}\text { P- } \\
\text { value }\end{array}$} & \multicolumn{3}{|c|}{$\begin{array}{l}\text { Demographic Model } \\
\text { Cluster \# }\end{array}$} & \multirow{2}{*}{$\begin{array}{l}\mathrm{P}- \\
\text { value }\end{array}$} \\
\hline & & 1 & 2 & 3 & 4 & & 1 & 2 & 3 & \\
\hline \multicolumn{11}{|c|}{ DinOthActWork } \\
\hline Average & 0.03 & 0.01 & 0.08 & 0.00 & 0.00 & 0.01 & 0.01 & 0.07 & 0.00 & 0.02 \\
\hline $\mathrm{n}$ & 50 & 17 & 14 & 15 & 4 & & 28 & 17 & 5 & \\
\hline \multicolumn{11}{|c|}{ DinOthActFriend } \\
\hline Average & 0.20 & 0.14 & 0.29 & 0.19 & 0.13 & 0.42 & 28.00 & 17.00 & 5.00 & 0.01 \\
\hline $\mathrm{n}$ & 50 & 17 & 14 & 15 & 4 & & 0.125 & 0.342 & 0.1 & \\
\hline \multicolumn{11}{|c|}{ DinOthActHHMem } \\
\hline Average & 0.28 & 0.32 & 0.06 & 0.52 & 0.00 & $<0.01$ & 0.36 & 0.10 & 0.42 & 0.01 \\
\hline $\mathrm{n}$ & 50 & 17 & 14 & 15 & 4 & & 28 & 17 & 5 & \\
\hline \multicolumn{11}{|c|}{ DinOthActNone * } \\
\hline Average & 0.08 & 0.07 & 0.05 & 0.01 & 0.55 & $<0.01$ & 0.05 & 0.14 & 0.10 & 0.26 \\
\hline $\mathrm{n}$ & 50 & 17 & 14 & 15 & 4 & & 28 & 17 & 5 & \\
\hline
\end{tabular}

Table 4.20, Panel e Cooking Proclivity

\begin{tabular}{|c|c|c|c|c|c|c|c|c|c|c|}
\hline \multirow{2}{*}{ Variable } & \multirow{2}{*}{$\begin{array}{c}\text { Entire } \\
\text { Sample } \\
\mathrm{n}=50\end{array}$} & \multicolumn{4}{|c|}{ Final Model Cluster \# } & \multirow{2}{*}{$\begin{array}{l}\mathrm{P}- \\
\text { value }\end{array}$} & \multicolumn{3}{|c|}{$\begin{array}{c}\text { Demographic Model } \\
\text { Cluster \# } \\
\end{array}$} & \multirow{2}{*}{$\begin{array}{c}\mathrm{P}- \\
\text { value }\end{array}$} \\
\hline & & 1 & 2 & 3 & 4 & & 1 & 2 & 3 & \\
\hline \multicolumn{11}{|l|}{$\overline{\text { I09bEatMeal }}$} \\
\hline Average & 1.06 & 1.53 & 0.00 & 1.47 & 1.00 & 0.00 & 1.33 & 0.53 & 1.40 & 0.05 \\
\hline $\mathrm{n}$ & 50 & 17 & 13 & 15 & 4 & & 27 & 17 & 5 & \\
\hline \multicolumn{11}{|c|}{ I09dMomCook } \\
\hline Average & 0.15 & -0.20 & 0.50 & 0.14 & 0.25 & 0.56 & -0.26 & 0.53 & 1.67 & 0.01 \\
\hline $\mathrm{n}$ & 50 & 15 & 14 & 14 & 4 & & 27 & 17 & 3 & \\
\hline \multicolumn{11}{|l|}{ I09ePlanMeal } \\
\hline Average & 0.65 & 0.00 & 0.71 & 1.07 & 1.25 & 0.09 & 0.69 & 0.65 & 0.33 & 0.90 \\
\hline $\mathrm{n}$ & 50 & 14 & 14 & 14 & 4 & & 26 & 17 & 3 & \\
\hline \multicolumn{11}{|c|}{ I11dPrepHealth } \\
\hline Average & 1.59 & 1.60 & 1.15 & 1.93 & 1.75 & 0.04 & 0.81 & 0.49 & 1.33 & 0.79 \\
\hline $\mathrm{n}$ & 50 & 15 & 13 & 14 & 4 & & 26 & 17 & 3 & \\
\hline \multicolumn{11}{|c|}{ BrPurchEnjoy } \\
\hline Average & 0.15 & 0.36 & 0.00 & 0.11 & 0.00 & 0.10 & 0.33 & 0.00 & 0.00 & 0.04 \\
\hline $\mathrm{n}$ & 19 & 7 & 5 & 4 & 3 & & 9 & & 1 & \\
\hline \multicolumn{11}{|c|}{ LuPurchEnjoy } \\
\hline Average & 0.18 & 0.05 & 0.32 & 0.12 & 0.33 & 0.10 & 0.13 & 0.27 & 0.11 & 0.35 \\
\hline $\mathrm{n}$ & 42 & 13 & 13 & 13 & 3 & & 24 & 14 & 4 & \\
\hline \multicolumn{11}{|c|}{ PurchDinTime } \\
\hline Average & 0.12 & 0.00 & 0.22 & 0.06 & 0.50 & 0.05 & 0.16 & 0.11 & 0.00 & 0.58 \\
\hline $\mathrm{n}$ & 35 & 9 & 12 & 12 & 2 & & 20 & 11 & 4 & \\
\hline \multicolumn{11}{|l|}{ F14dPrepNec } \\
\hline Average & 1.14 & 1.14 & 1.00 & 1.25 & 1.25 & 0.95 & 1.43 & 0.56 & 2.00 & 0.01 \\
\hline $\mathrm{n}$ & 42 & 14 & 12 & 12 & 4 & & 23 & 16 & 3 & \\
\hline \multicolumn{11}{|c|}{ F14ePrepMore } \\
\hline Average & 1.02 & 0.93 & 1.38 & 0.92 & 0.50 & 0.48 & 0.76 & 1.25 & 2.00 & 0.10 \\
\hline $\mathrm{n}$ & 44 & 15 & 13 & 12 & 4 & & 25 & 16 & 3 & \\
\hline
\end{tabular}

Note:

$\mathrm{X}$ indicates that there were no responses for the question among respondents in the cluster noted.

* indicates that the variable was used in PCA \#1 


\section{Profiling Each Segment}

Using the results from the ANOVA and Chi-square tests with a 0.1 level of significance, each cluster in CA\# 1 was profiled. First, the series of graphs below provides a comparison between the demographics characteristics of respondents in each cluster. Then, the profile of each cluster, with a descriptive title based on its characteristics, is explained.

Figure 4.17 displays the demographic characteristics of the entire sample, and of each cluster, providing a visual comparison of the clusters to one another. It is valuable to recognize the demographic makeup of each segment, as this information might also make the profile of each consumer group easier to understand. For example, if a cluster is comprised of mostly working women, it is logical to infer that many of them might not cook often due to time-constraints. Thus, this gives additional support to the notion these female consumers might be more receptive to food products with convenience attributes. Additionally, the segment profiles below were derived from the information in Appendix C, which lists the variables used in each PCA/CA, and variables for which significant differences were found among resulting clusters. 
Figure 4.17 Demographic characteristics of entire sample, and by cluster
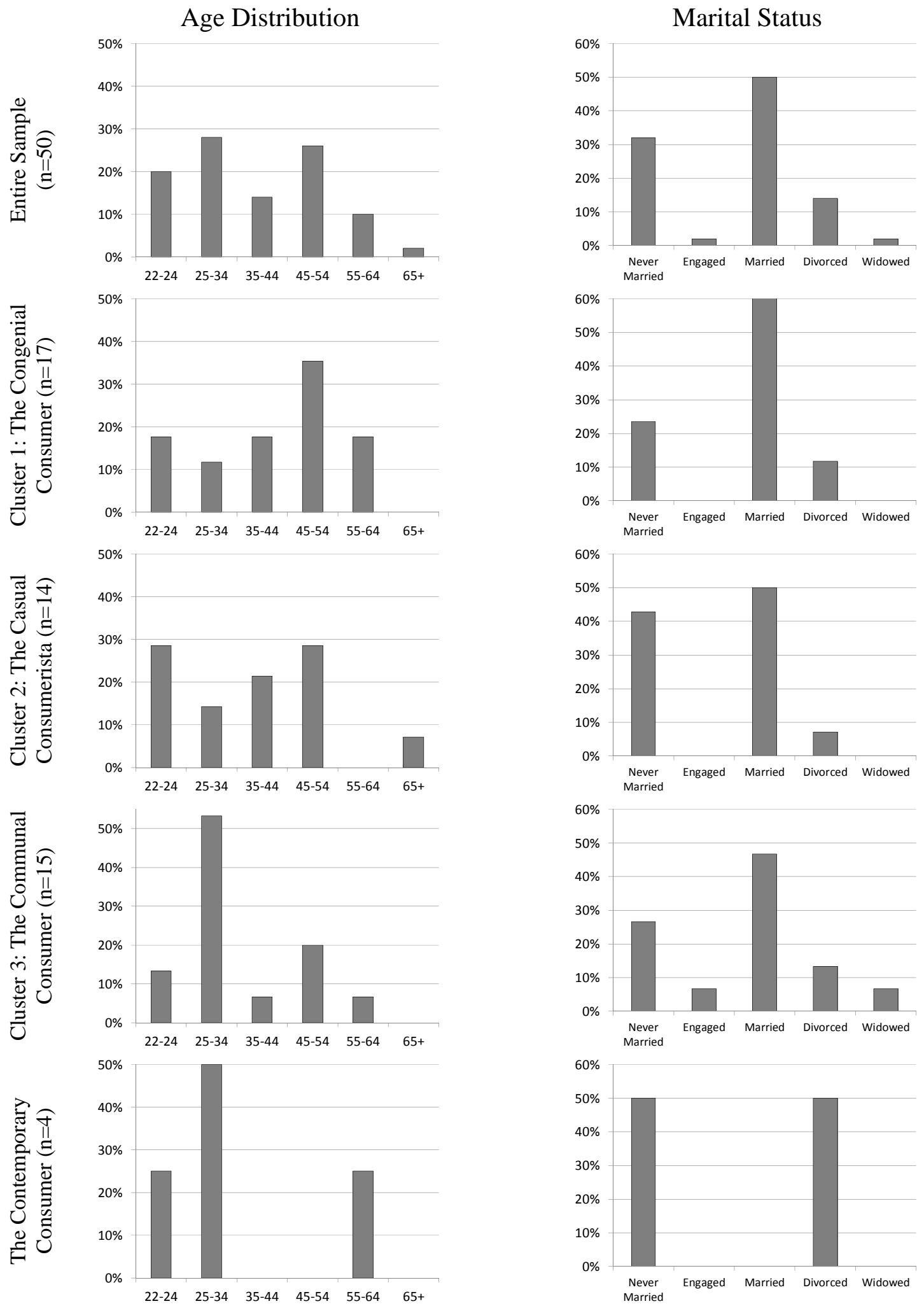
Figure 4.17 Demographic characteristics of entire sample, and by cluster, continued
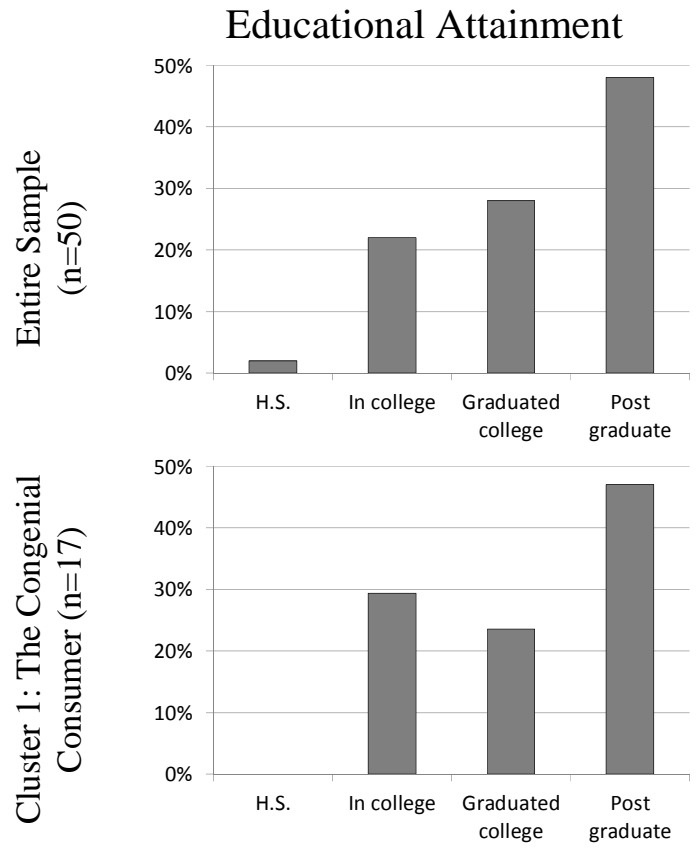

\section{Annual Household Income}
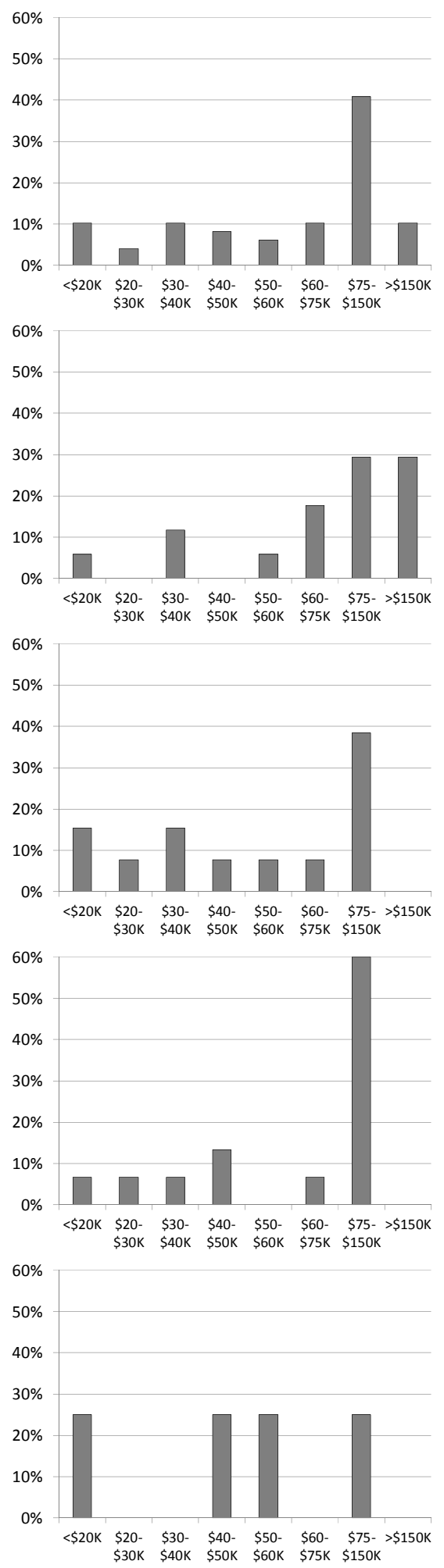
Figure 4.17 Demographic characteristics of entire sample, and by cluster, continued
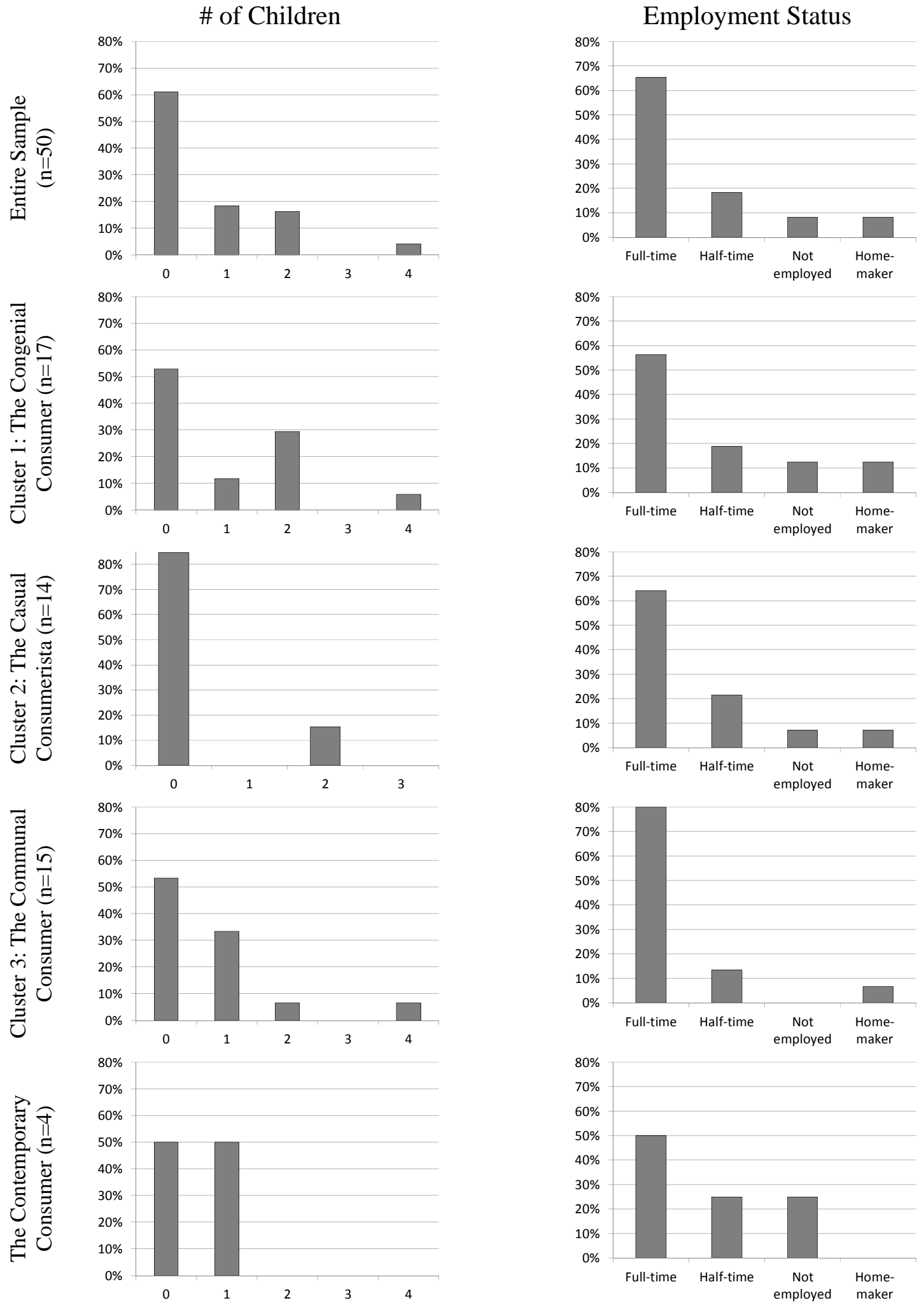


\section{Cluster \#1: The Congenial Consumer}

With a total of 17 women, Cluster \#1 is the largest consumer segment. Thirty-five percent are between the ages $45-54$ with the remainder of the cluster being distributed fairly evenly amongst the other age ranges. Many of the women in Cluster \#1 earn an annual household income that falls in the upper-income brackets. Thirty percent earn $\$ 150,000+$ each year, and 30\% earn between \$75,000 and \$149,000.

The women from the sample in Cluster \#1 were named "The Congenial Consumer," as this type of female shopper is often pressed for time (see variable I07bTime under Food Choices in Table 4.19) but she still manages to share meals with others frequently (see I09bEatMeal under Consumption Atmosphere). Compared to a purchased one, a meal that is homemade makes her feel healthier (see variable I11dPrepHealth under Cooking Proclivity), which is logical because compared to the other clusters, women in this segment purchased dinner the least amount of time during the week of study, $16.6 \%$ (see variable PurchasedDinner under Cooking Proclivity). They prefer a nutritious and savory homemade meal, while also keeping price as a high priority. This is evidenced by regularly describing their dinner meals as nutritious, as well as tasty, inexpensive, and made from fresh ingredients more often compared to the other segments (see variables DinWFreshIngAvg, DinNutriAvg, DinInexAvg, DinTastyAvg under Food Choices).

Although they prepared meals from scratch on a regular basis during the seven days, preparing lunch from scratch $71 \%$ and preparing dinner $51 \%$ of the time (see variables LuPrepSc and PrepDinFrScratch under Meal Planning and Preparation), this segment is the most likely to have someone else prepare dinner for them (32\% of the time). Further, 
she eats dinner with household members $72 \%$ of the time (see variables SomeElsePrepDin under Meal Planning and Preparation and AteDinHHMem under Consumption Atmosphere). Perhaps this can be attributed to the fact that $65 \%$ of the segment is married. They also went grocery shopping the most out of the four cluster groups, or $43 \%$ of the days during the week of data collection, and brought a shopping list 38\% of the time (see variable GroceryShop and BringList under Grocery Shopping). Finally, women in this segment seem to enjoy the eating experience. They took the longest amount of time to eat breakfast and lunch, 14 minutes and 21 minutes on average, and took the second longest amount of time to eat dinner, 24 minutes, on average, versus 27 minutes for the females in Cluster \#3 (see variables BrHowLong, AvgLuHowLong, and DinHowLongAvg under Consumption Atmosphere).

\section{Cluster \#2: The Casual Consumerista}

Overall, the range of ages is fairly widespread for the women in Cluster \#2, which includes 14 study participants. Specifically, approximately 29\% are between ages 45-54. Half of the females in Cluster \#2 are married and 42\% have never been married. A small portion, 7\%, is divorced. Similar to Cluster \#1, the women in this segment have obtained a high level of education. Fifty percent obtained a college degree and nearly $36 \%$ pursued more education after college.

The majority of Cluster $\# 2$ earns between $\$ 75,000$ and $\$ 149,000$ (38\%), with the remainder of the segment being fairly evenly distributed amongst other annual household income ranges. A large majority of this segment is employed full-time (64\%), and approximately $21 \%$ are employed half-time. Remaining respondents are either homemakers or not employed. 
The majority of the women in Cluster \#2 can be described as "casual” due to the fact their food-related tendencies fluctuate a great deal. For example, meals are either eaten alone, or shared with others, with almost equivalent regularity. During the week of study, these women ate lunch alone 35\% of the time (see variable AteLuAlone under Consumption Atmosphere in Table 4.19), while 49\% of the midday meals were eaten with others (see AteLuOthers under Consumption Atmosphere). Forty-two percent of this segment has never been married, which likely explains their propensity to spend dinner alone the most during the seven-day study (45\% of dinners) compared to other segments (see variable AteDinAlone under Consumption Atmosphere). On the other hand, this consumer still manages to eat dinner with other individuals who are not in their household more than women in other clusters, $29 \%$ of the time (see variable AteDinOthers under Consumption Atmosphere). Breakfast was typically eaten alone (60\% of the time, see variable AteBfastAlone under Consumption Atmosphere), while also engaging in other activities such as getting ready (27\% of the time), watching television (13\%), or using a computer (35\%, see variables D10hBrReady, D10bBrTV, and D10eBrComp under Consumption Atmosphere).

Sixty-five percent of the time they skipped dinner, because they did not have time (see variable DidNotEatNoTime under Food Choices). Conversely, they prepared lunch from scratch the most out of all of the segment groups, or $85 \%$ of the time (see variable LuPrepSc under Meal Planning and Preparation). They also prepared dinner $46 \%$ during the seven days (see variable PrepareDinner under Meal Planning and Preparation), cooking from scratch 69\% of the time they cooked (see variable PrepDinFrScratch under Meal Planning and Preparation). 
A store being in a convenient location is a very important factor for them when deciding where to shop for groceries (see variable I05aConvLoc under Grocery Shopping). During the seven days, they partook in this activity $25 \%$ of the time, and were the most likely to shop unaccompanied (see variables GroceryShop and GrocShopAlone under Grocery Shopping).

Cluster \#3: The Communal Consumer

Fifteen women from the sample population were categorized into Cluster \#3. Half are between the ages $25-34$, with another $21 \%$ being between the ages $45-54$. The majority of Cluster \#3 are either married (43\%) or have never been married (29\%). Different from other cluster groups, the highest level of educational attainment for $7 \%$ of the women in Cluster \#3 was obtaining a high school degree. Furthermore, half graduated from college and nearly 29\% pursed more education post-college. Sixty-four percent of Cluster \#3 earns between $\$ 75,000$ and $\$ 149,000$ (see Figure 4.29). Nearly $79 \%$ of this segment is employed full-time, and around 14\% are employed half-time.

The consumers in this segment appear to have food-related habits which are mostly communal in nature. They typically eat breakfast with household members, (61\%, see variable BfastwHH under Consumption Atmosphere in Table 4.19), share lunch with others $43 \%$ of the time (see variable AteLuOthers under Consumption Atmosphere), as well as eat dinner alone the least out of the four segments, only $5 \%$ out of the dinners that week (see variable AteDinAlone under Consumption Atmosphere).

Compared to purchasing a meal, cooking it at home makes her feel much healthier (see variable I11dPrepHealth under Consumption Atmosphere). This is understandable, as she prepared lunch 52\% of the seven-day time period (see variable PrepLu under Meal 
Planning and Preparation) and cooked dinner from scratch the most (83\%, see variable PrepDinFrScratch under Meal Planning and Preparation). Interestingly, someone else prepared breakfast for these women $18 \%$ of the time (see variable SOElsePreparBfast under Meal Planning and Preparation), which was the greatest proportion by far in the sample.

When purchasing lunch, $43 \%$ of the time they did so to save time (see variable LuPurchTime under Food Choices); and when purchasing dinner, they did so in order to avoid shopping and/or cooking 19\% of the time (see variable PurchDinAvoid under Food Choices). During dinner they often engaged with others, spending 19\% of dinner time with friends and 52\% with household members. The latter percentage unquestionably being the largest among the clusters (see variables DinOthActFriend and DinOthActHHMem under Consumption Atmosphere).

Lastly, women in this consumer segment shopped for groceries $40 \%$ of the seven-day duration bringing a list 50\% of the time, and spent 27 minutes, on average, to shop (see variables GroceryShop, BringList, and GrocShopHowLAvg under Grocery Shopping).

\section{Cluster \#4: The Contemporary Consumer}

While the number of women included in this consumer segment is extremely low (4), their demographic information is useful when interpreting their food-related tendencies and behaviors. Half of the women in Cluster \#4 are between the ages 25-34, with another $25 \%$ being between the ages $22-24$ and the remaining $25 \%$ being between the ages 55-64. All of the women have either never been married, or are divorced. Half of the women currently attend college, another $25 \%$ obtained a college degree, and the remaining 25\% pursued more education after college. The women in Cluster \#4 are evenly distributed 
amongst the following annual household income ranges: $\$ 75,000-\$ 149,000, \$ 50,000$ $\$ 59,999, \$ 40,000-\$ 49,999$, or less than $\$ 20,000$. Half of the women in Cluster $\# 4$ are employed full-time, and 25\% are employed half-time. The remaining 25\% are not employed.

The women in Cluster \#4 appear to multitask on a regular basis. The majority of women in this segment are very well-educated and $25 \%$ make an annual household income between $\$ 75,000-\$ 149,999$. It is likely these females are fairly career-oriented, as they ate lunch alone $81 \%$ of the study's duration (see variable AteLuAlone under Consumption Atmosphere in Table 4.19). Additionally, they ate lunch while sitting at their desk $21 \%$ of the time, worked on a computer $22 \%$, and/or or talked on the phone $15 \%$ of the time (see variables D19hLuDesk, LuComp, and LuPhone under Consumption Atmosphere). The latter is the most, by far, out of the four clusters.

They drove while eating breakfast $37 \%$ of the time during the seven-day period or used a computer (34\%, see variables D10fBrDrive and D10eBrComp under Consumption Atmosphere), and used a microwave to prepare their breakfast $43 \%$ of the time (see variable BrPrepMic under Meal Planning and Preparation). These tendencies imply this type of female consumer needs to eat the morning meal in a particularly efficient manner. Nonetheless, the women in this segment prioritize having good taste and high nutritional quality when it comes to dining. During the week of study, they described their meals as nutritious, tasty, and made with fresh ingredients the most often, compared to almost never describing them as inexpensive (see variables DinNutriAvg, DinTastyAvg, DinWFreshIngAvg, and DinInexAvg under Food Choices). While this cluster group 
rarely goes grocery shopping ( $9 \%$ of the study's duration), they take the most amount of time to shop by a wide margin, spending 62 minutes, on average, to make each trip (see variables GroceryShop and GrocShopHowLAvg under Grocery Shopping).

\section{Targeted Marketing Promotions Using the Four Consumer Segments}

Categorizing consumers into different segments is useful for targeting advertising and promotional tools. Ideally, marketing efforts are tailored for a segment to increase its effectiveness, thereby increasing the efficiency of marketing efforts. In order to demonstrate the usefulness of clustering consumers based on their food time and related behaviors, hypothetical avocado promotions designed for each consumer segment are described next.

\section{Cluster \#1: The Congenial Consumer}

The women in this segment are the most likely to have someone else prepare dinner for them (32\% of the time) and they also eat dinner with household members $72 \%$ of the time. Additionally, 65\% are married which might mean they are more apt to grill an avocado. Grilling is an unusual preparation technique for this fruit, but men are often associated with the grill, so their husbands could join them in preparing this innovative new dish. Figure 4.18 is an example of an advertisement designed to appeal to this segment. 


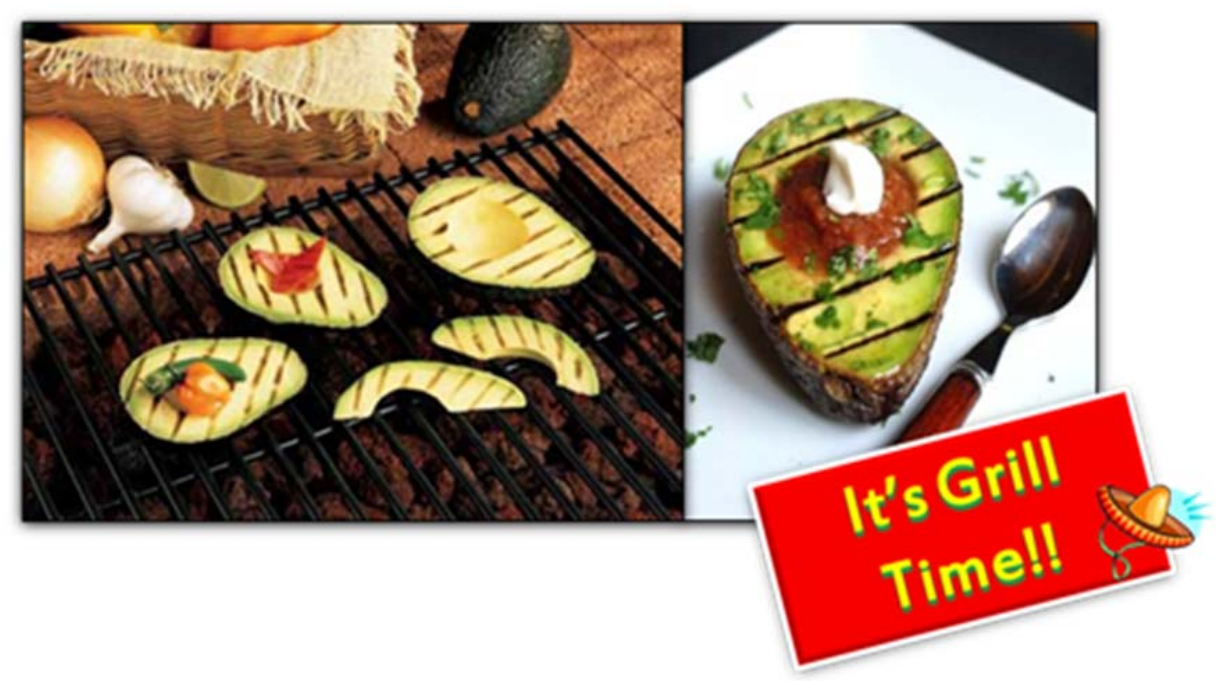

Figure 4.18 Advertisement for grilling avocados Sources: blog.americanfeast.com, California Avocado Commission

\section{Cluster \#2: The Casual Consumerista}

The women in Cluster \#2 have food tendencies that are extremely varied. Therefore, highlighting the numerous uses for avocados might appeal to this female consumer. While often eating alone, women in this cluster still manage to eat dinner with other individuals who are not in their household the most, 29\%, compared to the women in other clusters. When dining with others, guacamole is a popular dish to prepare and a guacamole kit might be especially enticing, as it already includes all of the necessary ingredients.

These women ate lunch alone 35\% of the time and prepared lunch from scratch the most compared to other segments (85\%). Therefore, when eating alone, these women might enjoy simply adding an avocado to a sandwich for the midday meal. Figure 4.19 is an example of an advertisement that might be appealing to this segment. 


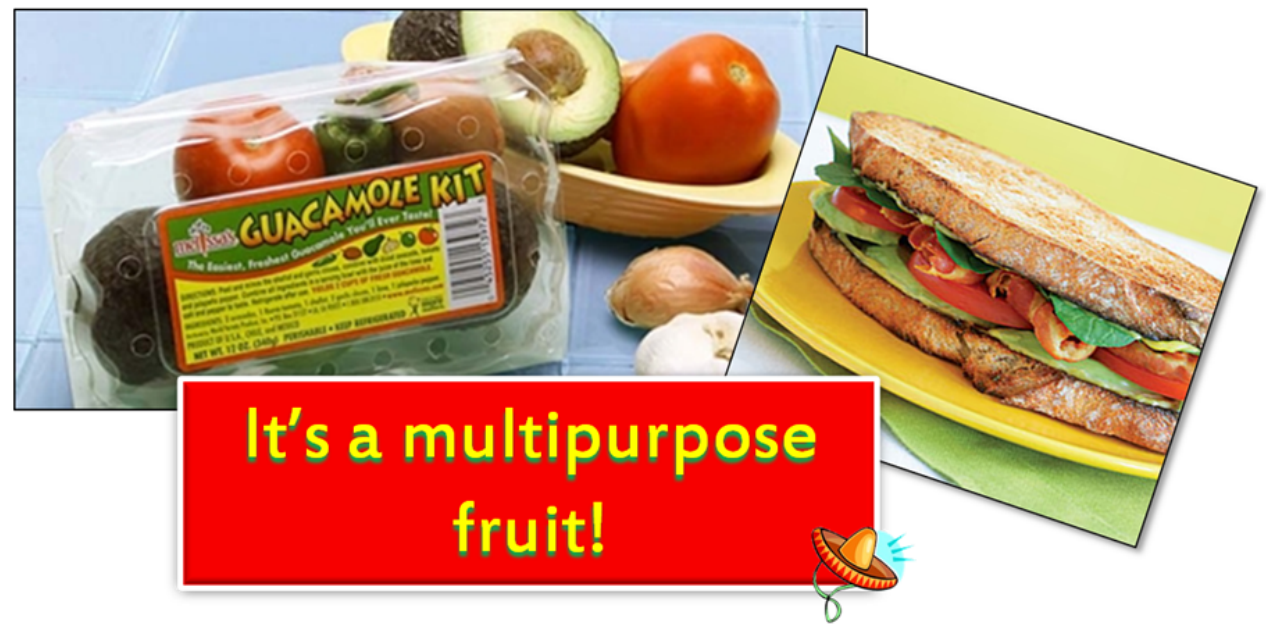

Figure 4.19 Advertisement for the multiple uses for avocados

Sources: www.melissas.com, www.finecooking.com

\section{Cluster \#3: The Communal Consumer}

The women in Cluster \#3 eat dinner alone the least out of the four segments, or 5\%, and compared to purchasing a meal, cooking it at home makes these consumers feel much healthier. In fact, they cooked dinner from scratch the most, 83\%, compared to the women in other clusters. Lastly, during the dinner meal they also engaged with other household members over half of the time. With that in mind, many families enjoy a weekly taco night in their home. This type of female consumer might be enticed to purchase an avocado in order to add a new ingredient to her existing taco recipe, impressing her family with the new addition to a meal they eat on a frequent basis. Figure 4.20 is an example of an advertisement encouraging shoppers to include avocados in their taco dishes. 

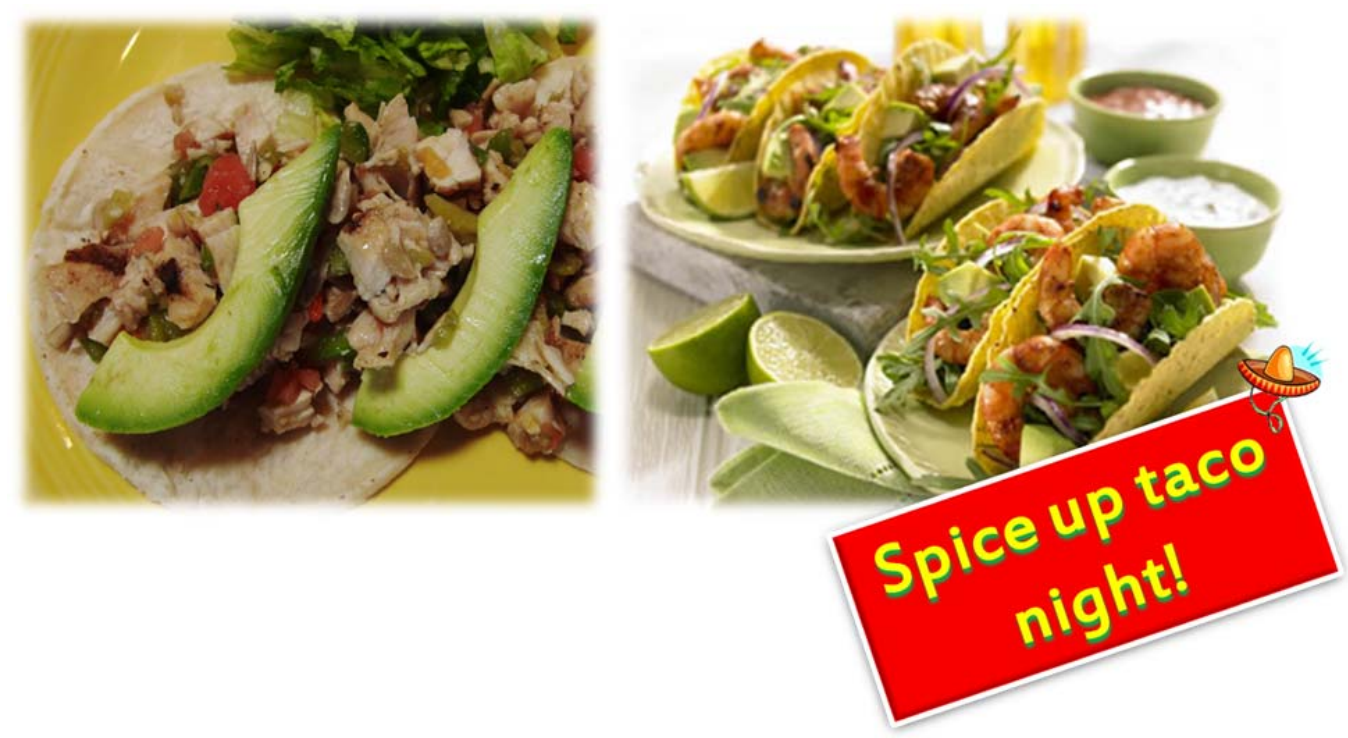

Figure 4.20 Advertisement encouraging consumers to use avocados in taco dishes

Source: 300besttacos.com, dietasfacilesyefectivas.co

\section{Cluster \#4: The Contemporary Consumer}

Females in Cluster \#4 appear to be career-oriented, and they often eat lunch alone while sitting at their desk, working on a computer, and/or talking on the phone. Additionally, they often drive while eating breakfast or use a computer, and they frequently use a microwave to prepare their breakfast. These tendencies imply these women often eat in a hurry and advertising the versatility of avocados might be particularly appealing to them. An avocado could be added to a salad, which she might take with her to work and eat while working at her desk. Furthermore, eating an avocado raw, with salt and pepper and a spoon is another option for efficient eating. Figure 4.21 is an advertisement promoting both of the aforementioned uses of avocados. 


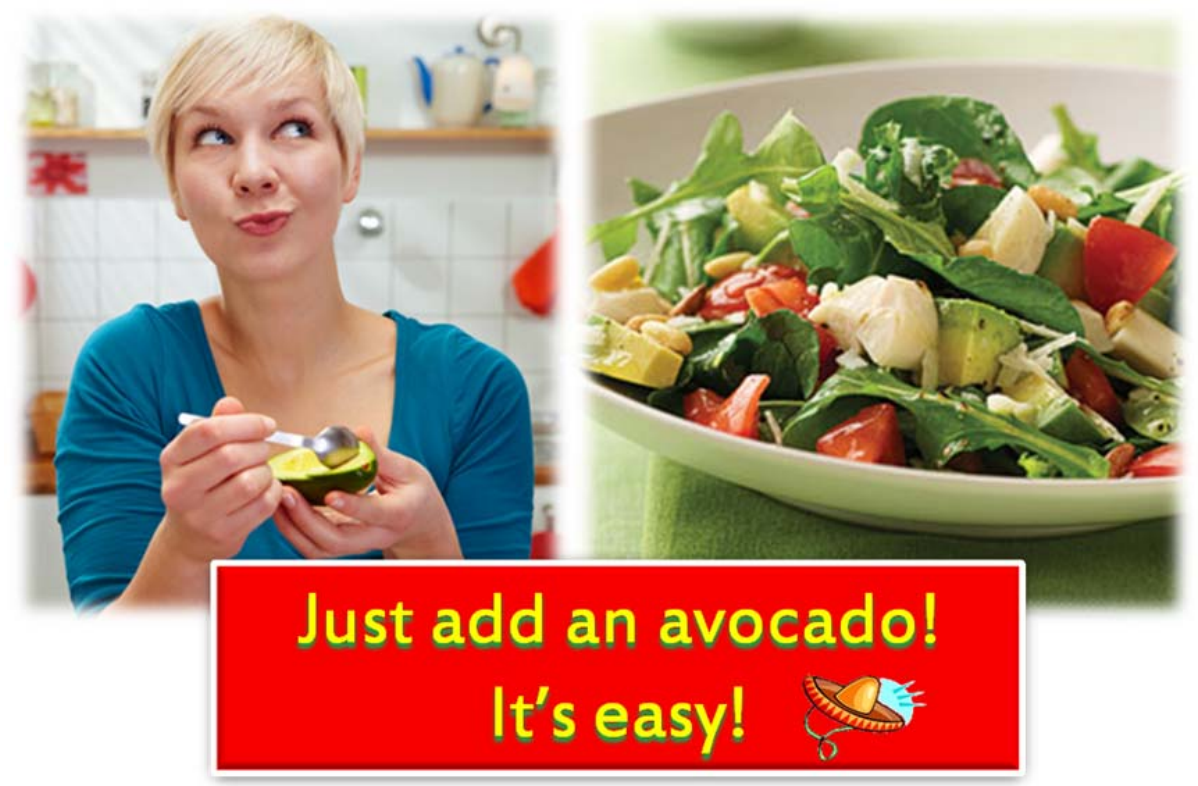

Figure 4.21 Advertisement for eating an avocado raw or adding it to a salad Sources: serendipity4molly.wordpress.com, www.myrecipes.com 


\section{Chapter V: Discussion}

This project studied women and their “food time,” obtaining information about food purchases, preparation, and consumption and using it to segment the female food consumer market. The goal was to demonstrate that a unique segmentation scheme may be achieved by using attitudinal and behavioral data describing the food context, compared to only using demographic information for segmentation purposes. This research approach was not commonly used in similar studies conducted in the past. Therefore, it could potentially provide more insight into the female food consumer.

In order to acquire information about eating habits, surveys were completed by a sample of 50 women for a seven-day time period. Specifically, the survey questions incorporated the amount of time spent purchasing and preparing food, the amount of time spent eating meals, the eating location and atmosphere, and if meals were eaten alone or with others. The study participants’ overall attitudes, behaviors, and preferences related to food, as well as information related to grocery shopping, and cooking was also included in the survey questions. The overall goal was to create an alternative segmentation scheme for the sample population using the attitudinal and contextual information from the surveys, in comparison with a segmentation scheme formed using only demographic characteristics.

The survey information was used to conduct three principal components analyses (PCAs) and successive cluster analyses (CAs) using attitudinal and behavioral variables created from the participants' responses. These three analyses were then compared with a PCA and a CA conducted using solely demographic variables. Next, ANOVA and Chi-square tests were performed in order to assess the differences among the clusters that were 
formed in each analysis. Cluster Analysis \#1 (CA \#1) was determined to be the superlative analysis due to the fact it appeared to capture the multidimensionality of the sample population the best out of the three analyses that used attitudinal and behavioral variables for segmentation (refer back to Choosing the Most Effective Analysis: Methods and Results in Chapter IV). CA \#1 was examined in contrast to CA \#4 (the cluster analysis conducted using only demographic attributes).

Notable findings highlight the importance of including "food time" information in the survey and analysis. Furthermore, the results support the notion that including these characteristics, instead of only demographic attributes, does indeed produce an alternative segmentation arrangement of a consumer market.

The comparison of CA\#1 and CA \#4 showed the study participants were categorized differently in each of the two analyses. Figure 5.1 displays the cluster groupings that were formed using both of these analyses with different shaped symbols indicating the cluster groups from CA \#1. CA \#4 clearly resulted in a different segmentation of consumers. Neither model is superior in a statistical sense. Instead, the differences between using "food time" variables and demographic variables for the two analyses, and the different segmentation schemes that resulted, were compared to one another using the results from the PCAs, CAs, ANOVA, and Chi-Square tests. 
The study suggests future possibilities for exploring the food-related tendencies of women. It recommends lifestyle characteristics as potentially valuable market segmentation tools. The data collected attests the role of "food time" allocation and the context of the eating situation as they relate to the purchase, preparation, and consumption of food are worthy of investigation. Additionally, the study suggests it can be beneficial to take these factors into consideration when attempting to profile consumers based their food preferences and patterns. A larger, more diverse sample would have undoubtedly led to more robust findings. However, the process pursued in the study is certainly recommendable for replication in similar larger-scale studies pursued in the future.

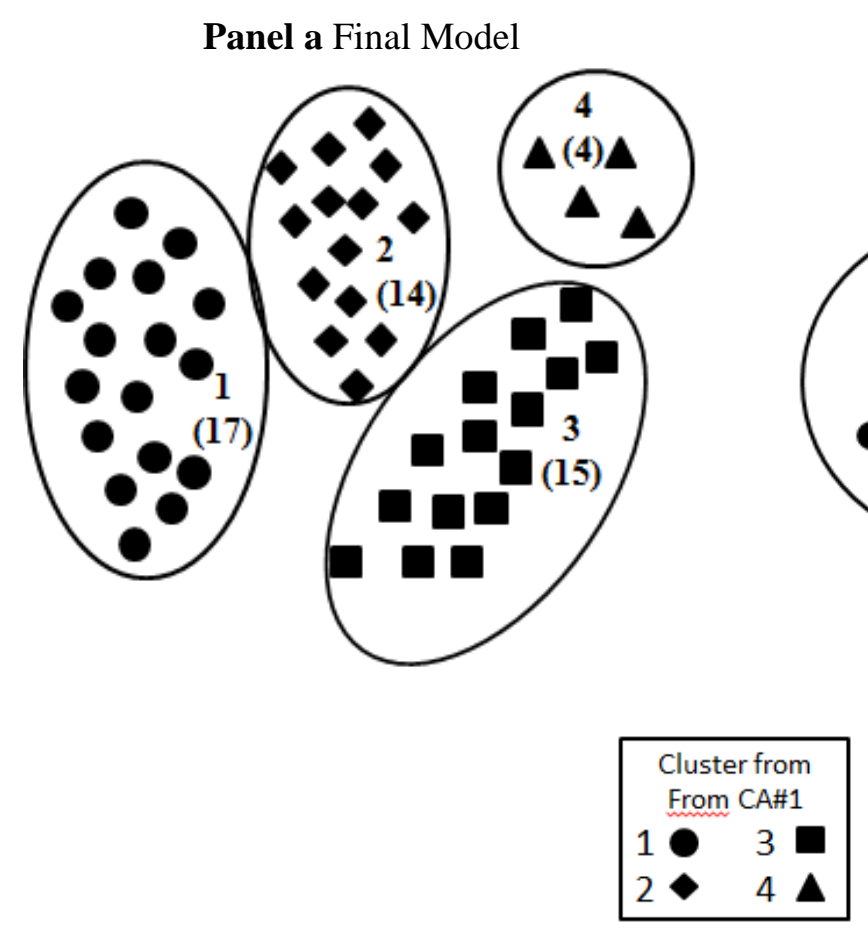

Panel b Demographic Model

Figure 5.1 Clustering of the sample: final model and demographic model 
This project, as well as additional research conducted in the future, may be used in a myriad of ways. It may be especially useful for segmenting a select market. For example, a retailer may wish to gain a better understanding of their customer base in a specific region or for a particular retail location. Studying a group of individuals who shop in the region or in the store location, using the process outlined in this project, may provide the management with distinctive information regarding their customers' food-related tendencies and preferences. Perhaps they might also design their marketing and promotional methods specifically targeting each consumer type (as exemplified in the avocado promotion described in Chapter IV).

The research process could be employed when developing and launching a new product. For example, if a manufacturer is promoting a ready-to-eat food item, they might direct advertising to consumers who value food items that require little to no preparation time, individuals who are easily identified by examining their "food time.” This is different than emphasizing product attributes such as a low price point or exceptional quality. This research process contributes to the pursuit for understanding the food choices of female food consumers, as well as all food consumers. Because the foundation of this method for marketing segmentation is comprised of the actual behavior performed by individuals, rather than behavior that is predicted to occur based on their demographic characteristics, it is an extremely comprehensive and in-depth approach to comprehending the multifaceted food-related tendencies of women. 


\section{BIBLIOGRAPHY}

Abbot, J.M., C. A. Thomson, J. Ranger-Moore, P. J. Teixeira, T. G. Lohnan, D. L. Taren, E. Cussler, S. B. Going, and L. B. Houtkooper. 2008. "Psychosocial and Behavioral Profile and Predictors of Self-Reported Energy Underreporting in Obese Middle-Aged Women.” Journal of the American Dietetic Association 108:114-119.

Allen, P. and C. Sachs. 2007. "Women and Food Chains. The Gendered Politics of Food.” International Journal of Sociology of Food and Agriculture 15:1-23.

Ares, G., and A. Gámbaro. 2007. "Influence of gender, age and motives underlying food choice on perceived healthiness and willingness to try functional foods." Appetite 49:148-158.

Barnett, R. C. 2004. "Women and Multiple Roles: Myths and Reality.” Harvard Review of Psychiatry 12:158-164.

Bava, C.M., S.R. Jaeger, and J. Park. 2008. "Constraints upon food provisioning practices in ‘busy’ women’s lives: Trade-offs which demand convenience.” Appetite 50: 486-498.

Beshara, M., A. Hutchinson, and C. Wilson. 2010. "Preparing meals under time stress. The experience of working mothers.” Appetite 55:695-700.

Bihan, H., K. Castetbon, C. Mejean, S. Peneau, L. Pelabon, F. Jellouli, H. Le Clesiau, and S. Hercberg. 2010. "Sociodemographic Factors and Attitudes toward Food Affordability and Health Are Associated with Fruit and Vegetable Consumption in a Low-Income French Population.” Journal of Nutrition 140:823-830.

Bittman, M., J. M. Rice, and J. Wajcman. 2004. “Appliances and their impact: the ownership of domestic technology and time spent on household work." The British Journal of Sociology 5:401-423.

Blake, C.E., C.A. Bisogni, J. Sobal, C.M. Devine, and M. Jastran. 2007. “Classifying foods in contexts: How adults categorize foods for different eating settings.” Appetite 49:500-510.

Brunner, T. A., K. van der Horst, and M. Siegrist. 2010. "Convenience food products. Drivers for consumption.” Appetite 55:498-506.

Buckley, M., C. Cowan, and M. McCarthy. 2007. "The convenience food market in Great Britain: Convenience food lifestyle (CFL) segments.” Appetite 49:600-617.

Candel, M. 2001. “Consumers' convenience orientation towards meal preparation: conceptualization and measurement.” Appetite 36:15-28. 
Centers for Disease Control and Prevention (CDC). 2011. "About BMI for Adults.” Atlanta, GA: Centers for Disease Control and Prevention. Retrieved May, 2012 from: http://www.cdc.gov/healthyweight/assessing/bmi/adult_bmi/index.html.

Cliff, N. 1988. "The Eigenvalues-Greater-Than-One Rule and the Reliability of Components.” Psychological Bulletin 103:276-279.

Deutsch, T. 2010. Building a Housewife's Paradise: Gender, Politics, and American Grocery Stores in the Twentieth Century. Chapel Hill, NC: University of North Carolina Press.

Engstrom, J. L., S. A. Paterson, A. Doherty, M. Trabulsi, and K. L. Speer. 2003. "Accuracy of Self-Reported Height and Weight in Women: An Integrative Review of the Literature.” Journal of Midwifery \& Women's Health 48:338-345.

Eshghi, A., Haughton, D., Legrand, P., Skaletsky, M., Woolford, S. 2011. "Identifying Groups: A Comparison of Methodologies.” Journal of Data Science 9:271-291.

Everitt, B.S., 1979. “Unresolved Problems in Cluster Analysis.” Biometrics 35:169-181.

Finch, H. 2005. "Comparison of Distance Measures in Cluster Analysis with Dichotomous Data.” Journal of Data Science 3:85-100.

Fisher, R. A. and F. Yatres. 1963. Statistical Tables for Biological, Agricultural, and Medical Research. New York, NY: Hafner Publishing Company.

Food Marketing Institute (FMI). 2011. U.S. Grocery Shopper Trends 2011. Arlington, VA.

Food Network. 2012. “About FoodNetwork.com.” New York, NY: The Home of Food Network. Retrieved June, 2012 from: http://www.foodnetwork.com/home/aboutfoodnetworkcom/index.html.

Freeman, A. and K. Poulin, 2000. "Developing a marketing geographic segmentation system using SAS software.” SUIG (SAS Users Group). Paper 229-28. Retrieved June, 2012 from: http://www2.sas.com/proceedings/sugi28/229-28.pdf.

Furst, T., M. Connors, C. A. Bisogni, J. Sobal, and L. W. Falk. 1996. "Food Choice: A Conceptual Model of the Process." Appetite 26:247-266.

Gehrt, K. C., and S. Shim. 1998. "A Shopping Orientation Segmentation of French Consumers: Implications for Catalog Marketing.” Journal of Interactive Marketing 12(4):34-46.

Glanz, K., G. Sorensen, and A. Farmer. 1996. "The Health Impact of Worksite Nutrition and Cholesterol Intervention Programs." American Journal of Health Promotion 10:453-470. 
Grier, S. A., and S. K. Kunnanyika. 2008. "The Context for Choice: Health Implications of Targeted Food and Beverage Marketing to African Americans.” American Journal of Public Health 98:1616-1629.

Griffin, J.M., A. B. Simon, E. Hulbert, J. Stevenson, J. P. Grill, S. Noorbaloochi, and M. R. Partin. 2011. "A comparison of small monetary incentives to convert survey non-respondents: a randomized control trial.” BMC Medical Research Methodology 11:81.

Guthrie, J.F., B.H. Lin, E. Frazao. 2002. "Role of Food Prepared Away from Home in the American Diet, 1977-78 versus 1994-1996: Changes and Consequences.” Journal of Nutrition Education and Behavior 34:140-150.

Harnack, L., M. Story, B. Martinson, D. Neumark-Sztainer, and J. Stang. 1998. “Guess who's cooking? The role of men in meal planning, shopping, and preparation in US families.” Journal of the American Dietetic Association 98:995-1000.

Harris, J. M., and R. Shiptsova. 2007. "Consumer Demand for Convenience Foods: Demographics and Expenditures.” Journal of Food Distribution Research 38:2236.

Hennessy, M. D., S. L. Volpe, M. D. Sammel, and S. Gennaro. 2010. "Skipping Meals and Less Walking Among African Americans Diagnosed With Preterm Labor." Journal of Nursing Scholarship 42:147-155.

Honkanen, P. and L. Frewer. 2009. "Russian consumers' motives for food choice.” Appetite 52:363-371.

Hopping, B. N., E. Erber, E. Mead, T. Sheehy, C. Roache and S. Sharma. 2010. "Socioeconomic indicators and frequency of traditional food, junk food, and fruit and vegetable consumption amongst Inuit adults in the Canadian Arctic.” Journal of Human Nutrition and Dietetics 23:51-58.

Hunter, W., S. McNaughton, D. Crawford, K. Ball. 2010. “Does food planning mediate the association between living arrangements and fruit and vegetable consumption among women aged 40 years and older?” Appetite 54:533-537.

Hussar, W.J., and T.M. Bailey. 2008. Projections of education statistics to 2017. Washington, DC: National Center for Education Statistics, Institute of Education Sciences, US Department of Education.

Hwang, H., B. Yang, Y. Takane. 2005. “A Simultaneous Approach to Constrained Multiple Correspondence Analysis and Cluster Analysis for Market Segmentation.” Asia Pacific Advances in Consumer Research 6:197-199.

Ketchen Jr., D. J. and C. L. Shook. 1996. "The Application of Cluster Analysis in Strategic Management Research: An Analysis and Critique.” Strategic Management Journal 17:441-458. 
Khattree, R. and D. N. Naik. 2000. Multivariate Data Reduction and Discrimination with SASC Software. Cary, NC: SAS Institute Inc.

King, S. C., Weber, A. J., Meiselman, H. L., and Lv, N. 2004. “The Effect of Meal Situation, Social Interaction, Physical Environment and Choice on Food Acceptability.” Food Quality and Preference 15:645-653.

Kornelis, M., E. van Herpen, I. van der Lans, and L. Aramyan. 2010. “Using non-food information to identify food-choice segment membership.” Food Quality and Preference 21:512-520.

Kuruvilla, S. J., and N. Joshi. 2010. "Influence of Demographics, Psychographics, Shopping Orientation, Mall Shopping Attitude and Purchase Patterns on Mall Patronage in India.” Journal of Retailing and Consumer Services 17:259-269.

Larson, M. G. 2008. "Statistical Primer for Cardiovascular Research: Analysis of Variance.” Circulation 117:115-121.

Lattimore, P., and N. Caswell. 2004. "Differential effects of active and passive stress on food intake in restrained and unrestrained eaters.” Appetite 42:167-173.

Lovegreen, S. 2005. Fashionable Food. Seven Decades of Food Fads. Chicago, IL: The University of Chicago Press.

Malhotra, N. K. 2010. Basic Marketing Research: A Decision-Making Approach, 3/e. Boston, MA: Pearson Learning Solutions.

Mancino, L. and C. Newman. 2007. Who Has Time To Cook? How Family Resources Influence Food Preparation. Washington, DC: United States Department of Agriculture.

Mediamark Research and Intelligence (MRI). 2010. New York, NY: GfK Mediamark Research \& Intelligence. Retrieved March, 2012 from: www.mriplus.com.

Meiselman, H. L., Johnson, J. L., Reeve, W. G., and Crouch, J. E. 2000. "Demonstrations of the Influence of the Eating Environment on Food Acceptance.” Appetite 35:231-237

Mendes, E. 2012. “Americans Spend \$151 a Week on Food; the High-Income, \$180.” Gallup Wellbeing. Retrieved May 2012 from:

http://www.gallup.com/poll/156416/americans-spend-151-week-food-highincome-180.aspx.

Messer, E. 2002. "From Hardtack to Home Fries. An Uncommon History of American Cooks and Meals.” Nutritional Anthropology 25:44-45.

Meyer, A. D., A. S. Tsui, and C. R. Hinings. 1993. "Configurational Approaches to Organizational Analysis.” The Academy of Management Journal 36:1175-1195. 
Michaelidou, N. 2012. “A typology of consumers’ variety-seeking disposition based on inherent needs.” Journal of Marketing Management 28:676-694.

Moag-Stahlberg, A. 2011. The State of Family Nutrition and Physical Activity: Are We Making Progress? American Dietetic Association. Retrieved June, 2012 from: www.eatright.org.

Moisio, R., E. J. Arnould, and L. L. Price, 2004. "Between Mothers and Markets: Constructing Family Identity through Home-made Food.” Journal of Consumer Culture 4:361-84.

Mortimer, G. and P. Clarke. 2011. "Supermarket consumers and gender differences relating to their perceived importance levels of store characteristics.” Journal of Retailing and Consumer Services 18:575-585.

Mosaic Research Consulting, LLC. 2011. "Social Media and Technology in the U.S. Foodservice Industry: Trends and Opportunities for an Emerging Market.” Rockville, Maryland: Packaged Facts.

National Center for Education Statistics. 2012. Digest of Education Statistics. Alexandria, VA: Education Publications Center. Retrieved June, 2012 from: http://nces.ed.gov/programs/digest/d11/tables/dt11_008.asp.

Oh, Y., A. Choi, and W. Woo. 2010. "U-BabSang: A Context-aware Food Recommendation System.” Journal of Supercomputing 54:61-81.

Okazaki, S. 2006. "What do we know about mobile Internet adopters? A cluster analysis.” Information \& Management 43:127-141.

Onwezen, M. C., and J. Bartels. 2011. "Which perceived characteristics make product innovations appealing to the consumer? A study on the acceptance of fruit innovations using cross-cultural consumer segmentation.” Appetite 57:50-58.

Onwezen, M. C., M. J. Reinders, I. A. van der Lans, S. J. Sijtsema, A. Jasiulewicz, M. Dolors Guardia, and L. Guerrero. 2012 “A cross-national consumer segmentation based on food benefits: The link with consumption situations and food perceptions." Food Quality and Preference 24:276-286.

Pachucki, M. A., P. F. Jacques, and N. A. Christakis. 2011. "Social Network Concordance in Food Choice Among Spouses, Friends, and Siblings.” American Journal of Public Health 101:2170-2177.

Park, J. L. and O. Capps, Jr. 1997. "Demand for Prepared Meals by U.S. Households.” American Journal of Agricultural Economics 79:814-824.

Pliner, P., R. Bell, E. S. Hirsch, and M. Kinchla. 2006. "Meal duration mediates the effect of 'social facilitation' on eating in humans.” Appetite 46:189-198. 
Prescott, J. and G. Bell. 1995. "Cross-cultural determinants of food acceptability: Recent research on sensory perceptions and preferences." Trends in Food Science and Technology 6:201-205.

Punj, G. and D. W. Stewart. 1983. “Cluster Analysis in Marketing Research: Review and Suggestions for Application.” Journal of Marketing Research 20:134-148.

Quinn, L., T. Hines, and D. Bennison. 2007. "Making sense of market segmentation: a fashion retailing case.” European Journal of Marketing 41:439-465.

Rao, C. R. 1964. "The Use and Interpretation of Principal Component Analysis in Applied Research.” Sankhyā: The Indian Journal of Statistics 26:329-358.

Redman, B.J. 1980. “The Impact of Women's Time Allocation on Expenditure for Meals Away from Home and Prepared Foods.” American Journal of Agricultural Economics 62:234-237.

Ravindra K. and D. Naik. 2000. Multivariate Data Reduction and Discrimination with SAS Software. Cary, NC: SAS Institute.

RetailWire LLC. 2012. “QR Code Update: Explosive Growth in Adoption.” Retrieved August, 2012 from: http://www.retailwire.com/tip/1249/qr-code-updateexplosive-growth-in-adoption\#form.

Rockett, H. R.H., M. Breitenbach, A. L. Frazier, J. Witschi, A. M. Wolf, A. E. Field, and G. A. Colditz. 1997. "Validation of a Youth/Adolescent Food Frequency Questionnaire.” Preventive Medicine 26:808-816.

Ronteltap, A., S. J. Sijtsema, H. Dagevos, and M. A. de Winter. 2012. “Construal levels of healthy eating. Exploring consumers' interpretation of health in the food context.” Appetite 59:333-340.

Rozin, P. and A. Fallon. 1980. "The psychological categorization of foods and non-foods: A preliminary taxonomy of food rejections.” Appetite 1:193-201.

SAS Institute Inc., 1983. SASC Technical Report A-108, Cubic Clustering Criterion. Cary, NC. SAS Institute Inc. Retrieved June, 2012 from: http://support.sas.com/documentation/onlinedoc/v82/techreport_a108.pdf.

SAS Institute Inc., 2008. SAS/STAT® 9.2 User’s Guide. Cary, NC: SAS Institute Inc. SAS Institute Inc., 2009. SAS OnlineDoc®, Version 8, Cary, NC: SAS Institute Inc. SAS Institute Inc., 2011. SAS/STAT® 9.3 User’s Guide. Cary, NC: SAS Institute Inc. Sealy, Y. M. 2010. “Parents’ Food Choices: Obesity Among Minority Parents and Children.” Journal of Community Health Nursing 27:1-11. 
Sharma, S. and A. Kumar. 2005. "Cluster Analysis and Factor Analysis. The Handbook of Market Research: Dos and Don'ts.” Thousand Oaks, CA: Sage Publications. Retrieved June, 2012 from: http://www.terry.uga.edu/ rgrover/chapter_18.pdf.

Shay, C. M., L. Van Horn, J. Stamler, A. R. Dyer, I. J. Brown, Q. Chan, K. Miura, L. Zhao, N. Okuda, M. L. Daviglus, and P. Elliott . 2012. "Food and nutrient intakes and their associations with lower BMI in middle-aged US adults: the International Study of Macro-/Micronutrients and Blood Pressure (INTERMAP).” American Journal of Clinical Nutrition 96:483-491.

Shlens, J. 2009. “A Tutorial on Principal Component Analysis.” Center for Neural Science, New York University, New York City, NY. Retrieved June, 2012 from: http://www.snl.salk.edu/ shlens/pca.pdf.

Sloan, A. E. 2011. “Top 10 Food Trends.” Food Technology 65: 24-41. Smith, S. M. and G. S. Albaum. 2005. Fundamentals of Marketing Research. Thousand Oaks, CA. Sage Publications.

Smith, S. and G. Albaum. 2005. Fundamentals of Marketing Research. Thousand Oaks, CA: SAGE Publications.

Soliah, L., J. Walter, and D. Antosh. 2006. "Quantifying the Impact of Food Preparation Skills Among College Women.” College Student Journal 40:729-739.

Solis, H. L. and K. Hall. 2011. Women in the Labor Force: A Databook. Report 1034. Washington, DC: U.S. Department of Labor, U.S. Bureau of Labor Statistics.

Stanton, William J. 1971. Fundamentals of Marketing. New York City, NY: McGrawHill.

SurveySwipe. 2012. “About SurveySwipe.” Seattle, WA: Survey Analytics LLC. Retrieved February, 2012 from: http://www.surveyswipe.com/application/surveyswipe/about.html.

Taylor, P., K. Parker, R. Fry, W. Wang, and E. Patten. 2011. “Women See Value and Benefits of College; Men Lag on Both Fronts, Survey Finds Social \& Demographic Trends.” Pew Social \& Demographic Trends, PEW Research Center: Washington, D.C.

Tomiyama A. J., T. Mann, and L. Comer. 2009. "Triggers of eating in everyday life.” Appetite 52:72-82.

Turrell, G., and A. M. Kavanagh. 2006. “Socio-economic pathways to diet: modelling the association between socio-economic position and food purchasing behaviour.” Public Health Nutrition 9:375-383.

U.S. Bureau of Labor Statistics. 2010a. American Time Use Survey. Washington, DC. Retrieved February, 2012 from: http://www.bls.gov/tus/. 
U.S. Bureau of Labor Statistics. 2010b. Annual Social and Economic Supplement, Current Population Survey. Washington, DC.

U.S. Bureau of Labor Statistics. 2011. Annual Social and Economic Supplement, Current Population Survey. Washington, DC.

U.S. Census Bureau. 2010. American Fact Finder. Washington, DC: U.S. Census Bureau.

U.S. Census Bureau. 2002a. Demographic Trends in the $20^{\text {th }}$ Century. Washington, DC:

U.S. Census Bureau. Retrieved February, 2012 from: http://www.census.gov/prod/2002pubs/censr-4.pdf.

U.S. Census Bureau. 2002b. Measuring America: The Decennial Censuses from 1790 to 2000. Washington, DC: U.S. Census Bureau. Retrieved February, 2012 from: http://www.census.gov/prod/2002pubs/pol02marv.pdf.

U.S. Department of Agriculture, Economic Research Service (USDA-ERS). 2011. Food CPI and Expenditures: Food Expenditure Tables. Retrieved May, 2012 from: http://www.ers.usda.gov/data-products/food-expenditures.aspx. Washington, DC.

Vereecken, C., M. Covents, and L. Maes. 2010. “Comparison of a food frequency questionnaire with an online dietary assessment tool for assessing preschool children’s dietary intake.” Journal of Human Nutrition and Dietetics 23:502-510.

Wrieden, W. L., A. S. Anderson, P. J. Longbottom, K. Valentine, M. Stead, M. Caraher, T. Lang, B. Gray, and E. Dowler. 2007. "The impact of a community-based food skills intervention on cooking confidence, food preparation methods and dietary choices-an exploratory trial.” Public Health Nutrition 10:203-211.

Zick, C. D., and R. B. Stevens. 2009. “Trends in Americans' food-related time use: 19752006.” Public Health Nutrition 13:1064-1072.

Zickuhr, K. 2012. "Three-quarters of smartphone owners use location-based services." Washington, DC: Pew Research Center, Internet \& American Life Project. 
APPENDIX A: Recruitment Flyer

\section{Participants are needed!!
Women and Their "Food Time"
GIIf(D) Master's Thesis Research}

- Wanted: women who will participate in a one-week study

- It's Easy to Participate!

- Complete surveys using SurveySwipe, a free smartphone application

- Complete 1 survey to begin, 2 surveys each day, and one final survey...All within a week!

- Each survey only takes a few minutes to complete!!

- Click here to sign up to download the app:

- http://foodtime.micropanel.com/a/join.do

- Or scan the QR code in the right hand corner above

- Why participate??

- Imagine... food products specially designed for your needs

- Imagine... food products designed to SAVE YOU TIME

- How much time do you spend cooking? Eating? Who do you cook for?

- Help product developers and marketers make food products that MAKE YOUR LIFE EASIER

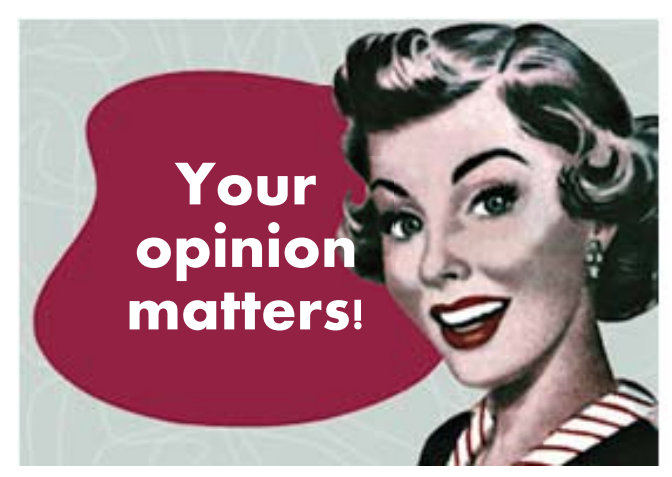

Questions: Contact garland.n.jaeger@gmail.com 
1. About what share of grocery shopping would you say you do for your household?

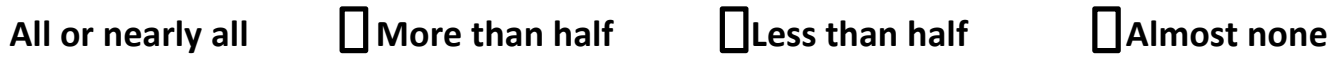

2. How many times a week, on average, would you say you go to the grocery store?
$\square 1$
$\square 2$
$\square 3$
$\square 4$
$\square 5+$

3. Please finish the phrase: "I find grocery shopping..."

$\begin{array}{ccccc}\begin{array}{c}\text { Very } \\ \text { Unpleasant }\end{array} & \begin{array}{c}\text { Somewhat } \\ \text { Unpleasant }\end{array} & \begin{array}{c}\text { Neither Pleasant } \\ \text { or Unpleasant }\end{array} & \begin{array}{c}\text { Somewhat } \\ \text { Pleasant }\end{array} & \begin{array}{c}\text { Very } \\ \text { Pleasant }\end{array} \\ \square & \square & \square & \square & \square\end{array}$

4. About what share of meal planning and preparation would you say you do for your household?

$\square$ Almost none $\square$ Less than half More than half $\square$ Almost or nearly all

5. For each of the factors listed, please indicate how important it is to you when deciding where to shop for groceries.

\begin{tabular}{|c|c|c|c|c|c|}
\hline & $\begin{array}{c}\text { Not at All } \\
\text { Important }\end{array}$ & $\begin{array}{c}\text { Not } \\
\text { Important }\end{array}$ & Neutral & $\begin{array}{c}\text { Somewhat } \\
\text { Important }\end{array}$ & $\begin{array}{c}\text { Very } \\
\text { Important }\end{array}$ \\
\hline Convenient location & 0 & 0 & 0 & 0 & 0 \\
\hline $\begin{array}{c}\text { Quality fruit and } \\
\text { vegetables }\end{array}$ & 0 & 0 & 0 & 0 & 0 \\
\hline $\begin{array}{c}\text { Quality meat and } \\
\text { seafood }\end{array}$ & 0 & 0 & 0 & 0 & 0 \\
\hline $\begin{array}{c}\text { Good selection of } \\
\text { tasty prepared foods }\end{array}$ & 0 & 0 & 0 & 0 & 0 \\
\hline $\begin{array}{c}\text { Wide selection of } \\
\text { products }\end{array}$ & 0 & 0 & 0 & 0 & 0 \\
\hline $\begin{array}{c}\text { Frequent money- } \\
\text { saving specials }\end{array}$ & 0 & 0 & 0 & 0 & 0 \\
\hline $\begin{array}{c}\text { Good selection of } \\
\text { organic, }\end{array}$ & 0 & 0 & 0 & & 0 \\
\hline $\begin{array}{c}\text { environmental and } \\
\text { green" products }\end{array}$ & & & & & \\
\hline
\end{tabular}

6. Please indicate how important each of the following attributes are when choosing the food you purchase and eat:

\begin{tabular}{|l|c|c|c|c|c|}
\hline & $\begin{array}{c}\text { Not at All } \\
\text { Important }\end{array}$ & $\begin{array}{c}\text { Not } \\
\text { Important }\end{array}$ & Neutral & $\begin{array}{c}\text { Somewhat } \\
\text { Important }\end{array}$ & $\begin{array}{c}\text { Very } \\
\text { Important }\end{array}$ \\
\hline
\end{tabular}




\begin{tabular}{|c|c|c|c|c|c|}
\hline Taste & 0 & 0 & 0 & 0 & 0 \\
\hline Nutrition & 0 & 0 & 0 & 0 & 0 \\
\hline Price & 0 & 0 & 0 & 0 & 0 \\
\hline $\begin{array}{c}\text { Functional product } \\
\text { packaging } \\
\text { (storability, able to } \\
\text { be eaten on-the-go, } \\
\text { etc.) }\end{array}$ & 0 & 0 & 0 & 0 & 0 \\
\hline Ease of preparation & 0 & 0 & 0 & 0 & 0 \\
\hline
\end{tabular}

7. How much, would you say, the following factors influence the purchase and preparation of the foods you eat?

\begin{tabular}{|c|c|c|c|c|c|}
\hline & Never & Rarely & Sometimes & Often & $\begin{array}{c}\text { Very } \\
\text { often }\end{array}$ \\
\hline Health & 0 & 0 & 0 & 0 & 0 \\
\hline Time & 0 & 0 & 0 & 0 & 0 \\
\hline Cost & 0 & 0 & 0 & 0 & 0 \\
\hline $\begin{array}{c}\text { The effort that goes into } \\
\text { planning and shopping }\end{array}$ & 0 & 0 & 0 & 0 & 0 \\
\hline
\end{tabular}

8. Would you consider purchasing fresh food such as fruits, vegetables, and meats using an online ordering system and home delivery service?

$\square$ Yes $\square$ No

9. Please indicate whether you agree or disagree with each statement below related to cooking, cooking tendencies or knowledge?

\begin{tabular}{|c|c|c|c|c|c|}
\hline & $\begin{array}{c}\text { Strongly } \\
\text { Disagree }\end{array}$ & $\begin{array}{c}\text { Somewhat } \\
\text { Disagree }\end{array}$ & $\begin{array}{c}\text { Neither } \\
\text { Agree nor } \\
\text { Disagree }\end{array}$ & $\begin{array}{c}\text { Somewhat } \\
\text { Agree }\end{array}$ & $\begin{array}{c}\text { Strongly } \\
\text { Agree }\end{array}$ \\
\hline $\begin{array}{c}\text { I enjoy the experience } \\
\text { of cooking a great } \\
\text { deal }\end{array}$ & 0 & 0 & 0 & 0 & 0 \\
\hline $\begin{array}{c}\text { I usually eat meals } \\
\text { with others }\end{array}$ & 0 & 0 & 0 & 0 & 0 \\
\hline $\begin{array}{c}\text { I am knowledgeable } \\
\text { about cooking }\end{array}$ & 0 & 0 & 0 & 0 & 0 \\
\hline $\begin{array}{c}\text { My mother taught me } \\
\text { how to cook }\end{array}$ & 0 & 0 & 0 & 0 & 0 \\
\hline $\begin{array}{c}\text { I typically plan my } \\
\text { meals in advance of } \\
\text { cooking them }\end{array}$ & 0 & 0 & 0 & 0 & 0 \\
\hline $\begin{array}{c}\text { I cook a lot } \\
\text { throughout the week }\end{array}$ & 0 & 0 & 0 & 0 & 0 \\
\hline $\begin{array}{c}\text { I enjoy entertainment } \\
\text { pertaining to cooking: }\end{array}$ & 0 & 0 & 0 & 0 \\
\hline
\end{tabular}


cooking shows, blogs, websites, etc.

10. How would you describe your overall health?

Could be a lot healthier

$\square$
Could be somewhat healthier
Healthy

enough
As healthy as it

could possibly be

11. Please indicate whether you agree or disagree with the following phrases about preparing a homemade meal. "Preparing a homemade meal..."

\begin{tabular}{|c|c|c|c|c|c|}
\hline & $\begin{array}{c}\text { Strongly } \\
\text { Disagree }\end{array}$ & $\begin{array}{c}\text { Somewhat } \\
\text { Disagree }\end{array}$ & $\begin{array}{c}\text { Neither } \\
\text { Agree nor } \\
\text { Disagree }\end{array}$ & $\begin{array}{c}\text { Somewhat } \\
\text { Agree }\end{array}$ & $\begin{array}{c}\text { Strongly } \\
\text { Agree }\end{array}$ \\
\hline $\begin{array}{c}\text {...is something I } \\
\text { enjoy doing. }\end{array}$ & 0 & 0 & 0 & 0 & 0 \\
\hline $\begin{array}{c}\text {...requires a lot of } \\
\text { effort and time. }\end{array}$ & 0 & 0 & 0 & 0 & 0 \\
\hline ...is expensive. & 0 & 0 & 0 & 0 & 0 \\
\hline $\begin{array}{c}\text {...makes me feel } \\
\text { healthier. }\end{array}$ & 0 & 0 & 0 & 0 & 0 \\
\hline $\begin{array}{c}\text {...is something I } \\
\text { prefer less } \\
\text { compared to } \\
\text { purchasing a meal. }\end{array}$ & 0 & 0 & 0 & 0 & 0 \\
\hline $\begin{array}{c}\text {...is something I } \\
\text { like to share with } \\
\text { others. }\end{array}$ & 0 & 0 & 0 & 0 & 0 \\
\hline
\end{tabular}


1. Did you eat your breakfast by yourself or with others this morning?

$\square$ I did not eat breakfast this morning (continue to Q10)

$\square$ I ate by myself (continue to Q3)

$\square$ I ate with others in my household (continue to Q2)

$\square$ I ate breakfast with others not in my household (continue to Q3)

2. Did everyone in your household eat the same breakfast dish? (continue to Q3)

$\square$ Yes $\square$ No

3. Did you purchase breakfast this morning or did you prepare breakfast?

$\square$ I prepared breakfast (continue to $\mathrm{Q} 4$ )

$\square$ I purchased breakfast (continue to Q6)

DSomeone else prepared breakfast for me (ex: household members, etc.)

(continue to Q8)

4. Please indicate which statement(s) correctly describe the way you prepared breakfast.

(Select all that apply)

$\square$ I made breakfast from scratch (continue to Q5)

$\square$ A portion of the breakfast I prepared was premade (continue to Q7)

$\square$ I prepared my breakfast with a microwave (continue to Q10)

Dother

5. How many ingredients did you use? (continue to $Q 10$ )

$\square 1 \quad \square 2 \quad \square 3 \quad \square 4 \quad \square 5+$

6. What is the most important reason why you purchased breakfast this morning? (for all question responses, continue to Q10)

口To save time

$\square$ To save money

$\square$ To avoid shopping and/or cooking

I enjoy the taste of the breakfast I purchase

$\square$ Other

7. Please select the phrases below that best describe the pre-made and/or on-the-go parts of your breakfast. (Select all that apply) (for all question responses, continue to Q8)

$\square$ It was a frozen meal. (Example: instant waffles)

$\square$ It was processed. Not part of the meal was made fresh. (Example: pop tarts)

$\square$ It required little preparation. (Example: oatmeal or cereal)

$\square$ It was a hand-held food item. (Example: smoothie, muffin,, etc.)

口 
It was a fresh fruit item. (Example: apple, banana, etc.)

8. Did you eat breakfast on-the-go this morning? (continue to Q10)

$\square$ Yes $\square$ No

9. Please indicate which phrases below best describe the reason you did not eat breakfast this morning. (Select all that apply) (for all question responses, continue to Q10)

$\square$ I don't like to eat breakfast.

II wasn't hungry.

I didn't have time.

I am trying to lose weight.

Dother

10. While eating breakfast, were any other activities occurring at the same time? (Select all activities that occurred) (for all question responses, continue to Q11)

$\square$ Talking on the phone
$\square$ Watching television
DReading
$\square$ Listening to music
$\square$ Using a computer or another digital device (iPad, etc.)
$\square$ Driving a car
$\square$ Riding public transportation
$\square$ Getting ready for work, school, etc.
$\square$ Helping other members in my household get ready
$\square$ Tasks related to childcare
$\square$ No other activities were taking place during breakfast
$\square$ Other

11. How long, would you say, did it take you to eat breakfast from beginning to end, in minutes, (excluding prep time)? (continue to Q12)

$\square$ **Drop-down choices ranged from 1-40+ in single minute increments

12. Did you eat lunch by yourself or with others today?

$\square$ I did not eat lunch today (continue to Q13)

$\square$ I ate lunch by myself (continue to Q14)

$\square$ I ate lunch with others (continue to Q14)

13. Please indicate which phrases below best describe the reason you did not eat lunch today. (Select all that apply) (for all question responses, continue to Q20)

$\square$ I don't like to eat lunch.

$\square$ I wasn't hungry.

$\square$ 
I didn't have time.

I am trying to lose weight.

Dother

14. Did you prepare lunch today or purchase lunch?

I prepared lunch. (Includes bringing your lunch from home) (continue to Q15)

I purchased lunch. (continue to Q18)

Dsomeone else prepared lunch for me. (Example: household member, etc.) (continue to Q15)

15. Please indicate which statement(s) correctly describe the way your lunch was prepared. (Select all that apply)

The lunch was prepared from scratch. (continue to Q16)

$\square$ A portion of the lunch was premade. (continue to Q17)

$\square$ A portion of the lunch was prepared using a microwave. (continue to Q17)

Dother $\square$ (continue to

16. How many ingredients did you use? (continue to Q20)

$\square_{1} \square_{2} \quad \square_{3} \square_{4} \quad \square_{5+}$

17. What is the most important reason you purchased lunch today? (for all question responses, continue to Q19)

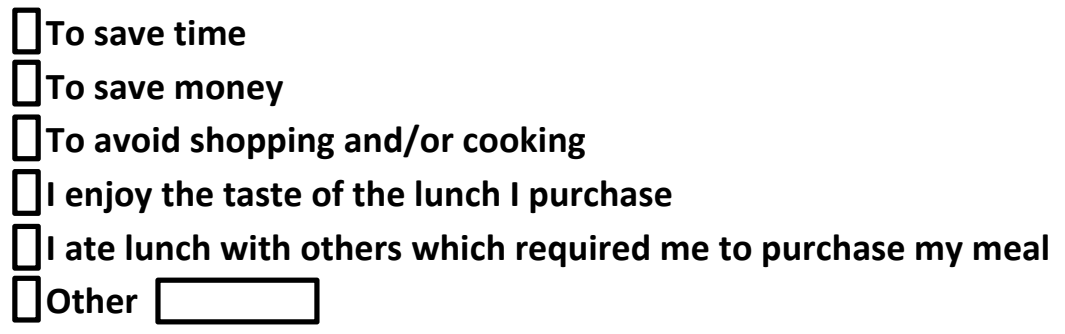

18. Please select a statement below that best describes the food establishment you purchased your lunch from. (for all question responses, continue to Q20)

$\square$ I purchased lunch from a prepared foods section of a grocery store.

II purchased lunch from a street side vendor/caterer.

$\square$ I ate lunch in a sit-down restaurant setting.

$\square$ I purchased lunch from a fast food establishment.

$\square$ I purchased lunch from a carry-out establishment.

19. While eating lunch, were any other activities occurring at the same time? (Select all activities that occurred) (for all question responses, continue to Q21)

$\square$ Talking on the phone
$\square$ Watching television
OReading
$\square$
$\square$ Listening to music 
Using a computer or another digital device (iPad, etc.)

Driving a car

$\square$ Riding public transportation

Dsitting at a desk, engaged in work-related tasks

$\square$ No other activities were taking place during lunch

Dother

20. How long, would you say, did it take you to eat lunch from beginning to end (in minutes)?

**Drop-down choices ranged from 1-59 in single minute increments, in addition to the following options:

1 hour 10 minutes

1 hour 15 minutes

1 hour 30 minutes

More than 1 hour 30 minutes 
1. Did you eat dinner by yourself or with others this evening?

$\square$ I did not eat dinner this evening (continue to Q2)

$\square$ I ate dinner by myself (continue to Q4)

$\square$ I ate dinner with others in my household (continue to Q3)

$\square$ I ate dinner with others not in my household (continue to Q4)

2. Please select the phrase below that best describes the reason you did not eat dinner. (for all question responses, continue to Q11)

$\square$ I don't like to eat dinner.

$\square$ I wasn't hungry.

I didn't have time.

I am trying to lose weight.

Dother

3. Did everyone in your household eat the same dishes? (continue to Q4)

$\square$ Yes $\square$ No

4. Did you prepare dinner this evening or did you purchase it?

II prepared dinner (continue to Q5)

DI purchased dinner (continue to Q8)

$\square$ Someone else prepared dinner for me (ex: household members, etc.) (continue to Q9)

5. Please indicate which statement(s) correctly describe the way you prepared dinner. (Select all that apply)

$\square$ I used a cookbook (if no other responses were selected, continue to Q9)

I made dinner from scratch (continue to $Q 6$ )

DSome of the dinner I prepared was premade (continue to Q7)

$\square$ I prepared dinner with a microwave (if no other responses were selected, continue to Q9)

Dother $\square$ (if no other responses were selected, continue

6. How many ingredients did you use? (continue to Q9)
$\square 1 \quad \square 2 \quad \square 3 \quad \square 4 \quad \square 5+$

7. Please select the statement(s) below that best describe the portion of your dinner that was pre-made. (Select all that apply) (for all question responses, continue to Q9)

DIt was a frozen meal.

DIt was a frozen item that required little preparation. (Example: steam in the bag frozen vegetables, etc.)

$\square$ 
It was a processed food item in a box. (Example: instant potatoes)

पit was a processed food item in a can. (Example: soup, canned fruit, canned vegetables, etc.)

पit was a processed food item in a jar. (Example: pasta sauce)

पit was a processed food item in a bag. (Example: tortillas)

8. What is the most important reason why you purchased dinner? (for all question responses, continue to Q10)

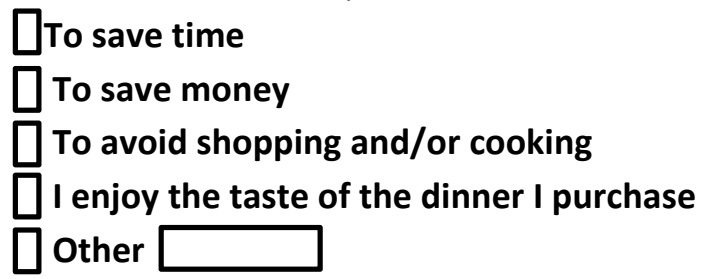

9. How well would you say the following phrases describe the meal you had for dinner? (for all question responses, continue to Q10)

\begin{tabular}{|c|c|c|c|c|c|}
\hline & $\begin{array}{c}\text { Very } \\
\text { Well }\end{array}$ & Well & Neutral & Bad & $\begin{array}{c}\text { Very } \\
\text { Bad }\end{array}$ \\
\hline Made from fresh ingredients & 0 & 0 & 0 & 0 & 0 \\
\hline Nutritious & 0 & 0 & 0 & 0 & 0 \\
\hline Inexpensive & 0 & 0 & 0 & 0 & 0 \\
\hline Tasty & 0 & 0 & 0 & 0 & 0 \\
\hline $\begin{array}{c}\text { Is made using a recipe or food } \\
\text { item I haven't tried before }\end{array}$ & 0 & 0 & 0 & 0 & 0 \\
\hline Easy-to-Prepare & 0 & 0 & 0 & 0 & 0 \\
\hline
\end{tabular}

10. While eating dinner, were any other activities occurring at the same time? (Select all activities that occurred) (for all question responses, continue to Q11)
$\square$ Talking on the phone
DWatching television
Reading
DListening to music
$\square$ Using a computer or another digital device (iPad, etc.)
DDriving a car
DEngaged in work-related tasks
$\square$ Visiting with friends
$\square$ Visiting with household members
No other activities were taking place during dinner
Dother

11. How long, would you say, did it take you to eat dinner from beginning to end (in minutes)? (for all question responses, continue to Q12)

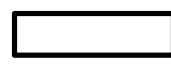


12. Did you go grocery shopping today?

$\square$ Yes (continue to Q13) पNo (survey terminates)

13. Did you bring a shopping list? (for all question responses, continue to Q14)

$\square$ Yes $\square$ No

14. How long, would you say, it took you to grocery shop from beginning to end (in minutes)? (continue to Q15)

**Drop-down choices ranged from 1-60 in single minute
increments, in addition to the following option:
1 hour 5 minutes
1 hour 10 minutes
1 hour 15 minutes
More than 1 hour 15 minutes

15. About how much did you spend at the grocery store today? (continue to Q16)

$\square * *$ Drop-down choices ranged from \$1-\$200+ in \$10 increments

16. Was anyone else with you while you were shopping (Select all that apply)?

$\square$ Child

Domestic Partner

Driend

Family member other than a partner or child

$\square$ No one else was with me while I was shopping.

Dother 
Final Survey

1. Please indicate how typical this week was for you in terms of the following:

\begin{tabular}{|c|c|c|c|c|c|}
\hline & $\begin{array}{c}\text { Not } \\
\text { Typical at } \\
\text { All }\end{array}$ & $\begin{array}{c}\text { Somewhat Not } \\
\text { Typical }\end{array}$ & Neutral & $\begin{array}{c}\text { Somewhat } \\
\text { Typical }\end{array}$ & $\begin{array}{c}\text { Very } \\
\text { Typical }\end{array}$ \\
\hline Money spent on groceries & 0 & 0 & 0 & 0 & 0 \\
\hline $\begin{array}{c}\text { Number of meals } \\
\text { prepared }\end{array}$ & 0 & 0 & 0 & 0 & 0 \\
\hline $\begin{array}{c}\text { Number of meals } \\
\text { purchased }\end{array}$ & 0 & 0 & 0 & 0 & 0 \\
\hline $\begin{array}{c}\text { Frequency of meals you } \\
\text { ate with others }\end{array}$ & 0 & 0 & 0 & 0 & 0 \\
\hline $\begin{array}{c}\text { Amount of effort that } \\
\text { went into cooking and } \\
\text { shopping }\end{array}$ & 0 & 0 & 0 & 0 & 0 \\
\hline
\end{tabular}

2. In which age range do you fall?
18-24
25-34
35-44
45-54
55-64
$\square 65+$

3. Please select your marital status below.

$\begin{array}{ccccc}\text { Never } & \text { Engaged } & \text { Married } & \text { Divorced } & \text { Widowed } \\ \text { Married } & \square & \square & \square & \square \\ \square & & \square & \end{array}$

4. Please select your race category below.
White/Caucasian
Black/African
$\square$
American Indian or Alaska Native
Asian
Hispanic/Latino
$\square$

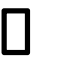
$\square$

5. Please select your level of education that has been completed below.
$\square$ Graduated college +
$\square$ Attended college
$\square$ Graduated high school
Did not graduate
$\square$ Post graduate
$\square$ No college
high school

6. In which income range does your household fall?

$\begin{array}{lll}\square \$ 150,000+ & \square \$ 75,000-\$ 149,000 & \square \$ 60,000-\$ 74,999 \\ \square \$ 50,000-\$ 59,999 & \square \$ 40,000-\$ 49,999 & \square \$ 30,000-\$ 39,999 \\ \square \$ 20,000-\$ 29,999 & \square \$<20,000 & \end{array}$

7. Please select your employment status below.
Employed
Employed
Not employed
full $\square^{\text {ime }}$
half ${ }^{\text {ime }}$
Homemaker 
8. How many people live in your household including yourself?

$\square_{1} \square_{2} \square_{3} \square_{4} \quad \square_{5} \square_{6+}$

9. How many children are in your household?

$\square_{1} \square_{2} \quad \square_{3} \quad \square_{4} \quad \square_{5+} \square_{\text {No children in household }}$

10. How many of them are under the age 18 ?

$\square_{1} \square_{2} \quad \square_{3} \quad \square_{4} \quad \square_{5+}$

11. Please enter your zip code.

12. Please enter how tall you are in feet below. Note: You will be asked to enter any remaining inches in the next question. (Example: If you are 5 feet, $\mathbf{4}$ inches tall only enter "5" below.)

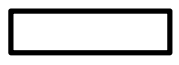

Please enter the remaining inches of your height below. (Example: If you are 5 feet, 4 inches tall enter "4" below.)

13. Please enter your weight below in pounds.

14. How well would you say the following phrases describe your perception of preparing a homemade meal compared to purchasing a meal?

\begin{tabular}{|c|c|c|c|c|c|}
\hline & $\begin{array}{c}\text { Describes Not } \\
\text { Well At All }\end{array}$ & $\begin{array}{c}\text { Does Not } \\
\text { Describe } \\
\text { Well }\end{array}$ & Neutral & $\begin{array}{c}\text { Describes } \\
\text { Somewhat } \\
\text { Well }\end{array}$ & $\begin{array}{c}\text { Describes } \\
\text { Very Well }\end{array}$ \\
\hline $\begin{array}{c}\text { Is something I } \\
\text { really enjoy doing. }\end{array}$ & 0 & 0 & 0 & 0 & 0 \\
\hline $\begin{array}{c}\text { It requires a lot of } \\
\text { effort and time. }\end{array}$ & 0 & 0 & 0 & 0 & 0 \\
\hline $\begin{array}{c}\text { It is important to } \\
\text { me. }\end{array}$ & 0 & 0 & 0 & 0 & 0 \\
\hline It is necessary. & 0 & 0 & 0 & 0 & 0 \\
\hline $\begin{array}{c}\text { It is something I } \\
\text { would like to do } \\
\text { more. }\end{array}$ & 0 & 0 & 0 & 0 & 0 \\
\hline
\end{tabular}


APPENDIX C: Significance Chart

\begin{tabular}{|c|c|c|c|c|c|c|}
\hline $\begin{array}{l}\text { Topic Area, and } \\
\text { Variable Name }\end{array}$ & Survey & $\begin{array}{c}\text { Analysis } \\
\text { Type }\end{array}$ & $\begin{array}{c}\text { PCA } \\
\# 1 \\
\end{array}$ & $\begin{array}{c}\text { PCA } \\
\# 2 \\
\end{array}$ & $\begin{array}{c}\text { PCA } \\
\# 3 \\
\end{array}$ & $\begin{array}{c}\text { PCA } \\
\# 4 \\
\end{array}$ \\
\hline \multicolumn{7}{|l|}{ Grocery Shopping } \\
\hline BringList $\sim$ & 7PM & ANOVA & $\mathrm{X}$ & & & \\
\hline F01a\$Gr & Final & ANOVA & & & $\mathrm{X}$ & \\
\hline GroceryShop & 7PM & ANOVA & $X$ & $\mathrm{X}$ & $\mathrm{X}$ & \\
\hline GrocShopAlone & 7PM & ANOVA & & & & \\
\hline GrocShopChild & 7PM & ANOVA & & & $\mathrm{X}$ & $\mathrm{X}$ \\
\hline GrocShopFam & 7PM & ANOVA & & & & $\mathrm{X}$ \\
\hline GrocShopFriend & 7PM & ANOVA & & & & \\
\hline GrocShopHowLAvg & 7PM & ANOVA & $\mathrm{X}$ & $\mathrm{X}$ & $\mathrm{X}$ & \\
\hline GrocShopPart & 7PM & ANOVA & & & & \\
\hline I01GrShare & Initial & Chi-Sq & $\mathrm{X}$ & & & \\
\hline I02GrNum & Initial & ANOVA & & & & \\
\hline I03GrPleasant & Initial & ANOVA & & & & \\
\hline I05aConvLoc & Initial & ANOVA & $\mathrm{X}$ & $\mathrm{X}$ & & \\
\hline I05bFrVeg & Initial & ANOVA & & & & \\
\hline I05cMeatSea & Initial & ANOVA & & & & \\
\hline I05dPrepFood & Initial & ANOVA & $\mathrm{X}$ & & $\mathrm{X}$ & $\mathrm{X}$ \\
\hline I05eSelection & Initial & ANOVA & & $\mathrm{X}$ & & \\
\hline I05fMoneySav & Initial & ANOVA & & & & \\
\hline I05gGreenSel & Initial & ANOVA & & & & \\
\hline \multicolumn{7}{|c|}{ Meal Planning and Preparation } \\
\hline AverNumIngr $\sim$ & 7PM & ANOVA & & & & \\
\hline BrFroz & 2PM & ANOVA & & & & $\mathrm{X}$ \\
\hline $\mathrm{BrHH} \sim$ & 2PM & ANOVA & & & & \\
\hline BrLitPrep & 2PM & ANOVA & & & & \\
\hline BrPrepMic & 2PM & ANOVA & $\mathrm{X}$ & & & \\
\hline BrPrepPremade & 2PM & ANOVA & & & & \\
\hline BrPrepSc & $2 \mathrm{PM}$ & ANOVA & & & & \\
\hline BrProc & 2PM & ANOVA & & & $\mathrm{X}$ & \\
\hline F01bMealPrep & Final & ANOVA & & & & \\
\hline F01cMealPurch & Final & ANOVA & & & & $X$ \\
\hline FreshF $\sim$ & 2PM & ANOVA & & & & \\
\hline FrozDinner & 7PM & ANOVA & & $\mathrm{X}$ & & \\
\hline I04MealShare & Initial & Chi-Sq & & & & \\
\hline I07aHealth & Initial & Chi-Sq & & & & \\
\hline I07bTime & Initial & Chi-Sq & & & & \\
\hline I07cCost & Initial & Chi-Sq & & & & \\
\hline I07dEffort & Initial & Chi-Sq & & & & \\
\hline ItemWLitPrep & 7PM & ANOVA & & & & \\
\hline LuPrepMic & 2PM & ANOVA & & & & \\
\hline LuPrepPremade & 2PM & ANOVA & & & $\mathrm{X}$ & \\
\hline LuPrepSc & $2 \mathrm{PM}$ & ANOVA & $\mathrm{X}$ & & & \\
\hline
\end{tabular}




\begin{tabular}{|c|c|c|c|c|c|c|}
\hline $\begin{array}{l}\text { Topic Area, and } \\
\text { Variable Name }\end{array}$ & Survey & $\begin{array}{l}\text { Analysis } \\
\text { Type }\end{array}$ & $\begin{array}{c}\text { PCA } \\
\# 1\end{array}$ & $\begin{array}{l}\text { PCA } \\
\# 2\end{array}$ & $\begin{array}{c}\text { PCA } \\
\# 3\end{array}$ & $\begin{array}{c}\text { PCA } \\
\# 4\end{array}$ \\
\hline PreparBfast $\sim$ & $2 \mathrm{PM}$ & ANOVA & & & & \\
\hline PrepareDinner & 7PM & ANOVA & & & & \\
\hline PrepDinFrScratch & 7PM & ANOVA & & & & \\
\hline PrepLu & 2PM & ANOVA & & & & \\
\hline PrepScAvgBrIng & 2PM & ANOVA & $\mathrm{X}$ & & & \\
\hline PrepScAvgLuIng & 2PM & ANOVA & & & & \\
\hline PrepWMicro & 7PM & ANOVA & & & & \\
\hline PrepWPremadePor & 7PM & ANOVA & & & & \\
\hline PurchasedDinner & 7PM & ANOVA & $\mathrm{X}$ & & $X$ & \\
\hline PurchBfast $\sim$ & 2PM & ANOVA & & & & \\
\hline PurchLu〜 & 2PM & ANOVA & & & $X$ & \\
\hline SOElsePreparBfast & $2 \mathrm{PM}$ & ANOVA & $\mathrm{X}$ & & $\mathrm{X}$ & \\
\hline SomeElsePrepDin & 7PM & ANOVA & & & $\mathrm{X}$ & \\
\hline SOPrepLu & 2PM & ANOVA & & & & \\
\hline UseCookBk & 7PM & ANOVA & & $\mathrm{X}$ & $\mathrm{X}$ & $\mathrm{X}$ \\
\hline UsedProcItemBag & 7PM & ANOVA & & & & \\
\hline UsedProcItemBox & 7PM & ANOVA & & & & \\
\hline UsedProcItemCan & 7PM & ANOVA & & & & \\
\hline UsedProcItemJar & 7PM & ANOVA & & & & \\
\hline \multicolumn{7}{|l|}{ Food Choices } \\
\hline BrDontL & 2PM & ANOVA & & & & \\
\hline BrNotH & 2PM & ANOVA & & & & \\
\hline DidNotEatNotH* & 7PM & ANOVA & & & & \\
\hline DidNotEatNoTime* & $7 \mathrm{PM}$ & ANOVA & & & & \\
\hline DinEasToPrepAvg & 7PM & ANOVA & & & & \\
\hline DinInexAvg & 7PM & ANOVA & $\mathrm{X}$ & & & \\
\hline DinNutriAvg & 7PM & ANOVA & $X$ & $X$ & $\mathrm{X}$ & $\mathrm{X}$ \\
\hline DinRecNewFAvg & 7PM & ANOVA & & & $\mathrm{X}$ & \\
\hline DinTastyAvg & 7PM & ANOVA & $\mathrm{X}$ & $\mathrm{X}$ & & $\mathrm{X}$ \\
\hline DinWFreshIngAvg & 7PM & ANOVA & $\mathrm{X}$ & $\mathrm{X}$ & $\mathrm{X}$ & $\mathrm{X}$ \\
\hline I06aNut & Initial & ANOVA & & & & \\
\hline I06aTaste & Initial & ANOVA & & & & \\
\hline I06cPrice & Initial & ANOVA & $\mathrm{X}$ & & & \\
\hline I06dPack & Initial & ANOVA & & & $\mathrm{X}$ & $\mathrm{X}$ \\
\hline I06ePrep & Initial & ANOVA & & & & \\
\hline NoLuNotHun* & $2 \mathrm{PM}$ & ANOVA & & & & \\
\hline NoLuTime* & 2PM & ANOVA & & & & \\
\hline \multicolumn{7}{|l|}{ Consumption Atmosphere } \\
\hline AteBfastAlone & 2PM & ANOVA & $\mathrm{X}$ & & $\mathrm{X}$ & \\
\hline AteDinAlone & 7PM & ANOVA & $\mathrm{X}$ & $\mathrm{X}$ & $\mathrm{X}$ & \\
\hline AteDinHHMem & 7PM & ANOVA & $X$ & $\mathrm{X}$ & $\mathrm{X}$ & $X$ \\
\hline AteDinOthers & 7PM & ANOVA & & $\mathrm{X}$ & $\mathrm{X}$ & $X$ \\
\hline
\end{tabular}




\begin{tabular}{|c|c|c|c|c|c|c|}
\hline $\begin{array}{l}\text { Topic Area, and } \\
\text { Variable Name }\end{array}$ & Survey & $\begin{array}{l}\text { Analysis } \\
\text { Type }\end{array}$ & $\begin{array}{c}\text { PCA } \\
\# 1\end{array}$ & $\begin{array}{c}\text { PCA } \\
\# 2\end{array}$ & $\begin{array}{c}\text { PCA } \\
\# 3\end{array}$ & $\begin{array}{c}\text { PCA } \\
\# 4\end{array}$ \\
\hline AteLuAlone & $2 \mathrm{PM}$ & ANOVA & $\mathrm{X}$ & & & \\
\hline AteLuOthers & 2PM & ANOVA & & & & \\
\hline AvgLuHowLong & $2 \mathrm{PM}$ & ANOVA & & & & \\
\hline BfastwHH & 2PM & ANOVA & $X$ & $\mathrm{X}$ & $\mathrm{X}$ & \\
\hline BfastwNotinHH & 2PM & ANOVA & & & & \\
\hline BrChild & 2PM & ANOVA & & & & $\mathrm{X}$ \\
\hline BrComp & 2PM & ANOVA & $\mathrm{X}$ & & & $\mathrm{X}$ \\
\hline BrDrive & $2 \mathrm{PM}$ & ANOVA & $\mathrm{X}$ & $X$ & $X$ & \\
\hline BrHelp & 2PM & ANOVA & & & & \\
\hline BrHHSameDish & 2PM & ANOVA & & & & \\
\hline BrHowLong & 2PM & ANOVA & & & & \\
\hline BrMusic & 2PM & ANOVA & & & & \\
\hline BrNoOther & $2 \mathrm{PM}$ & ANOVA & & & & \\
\hline BrOTG & 2PM & ANOVA & & & & \\
\hline BrPhone & 2PM & ANOVA & & & & \\
\hline BrPubTrans & 2PM & ANOVA & & & & \\
\hline BrRead & $2 \mathrm{PM}$ & ANOVA & & & & \\
\hline BrReady & 2PM & ANOVA & & & & $\mathrm{X}$ \\
\hline BrTV & $2 \mathrm{PM}$ & ANOVA & & & & \\
\hline DidNotEatBfast & $2 \mathrm{PM}$ & ANOVA & & & & \\
\hline DidNotEatDin & 7PM & ANOVA & & $X$ & & \\
\hline DidNotEatLu & 2PM & ANOVA & & & $\mathrm{X}$ & \\
\hline DinHowLongAvg & 7PM & ANOVA & & & & \\
\hline DinNotSameDish & 7PM & ANOVA & & & & \\
\hline DinOthActComp & 7PM & ANOVA & & & & $X$ \\
\hline DinOthActDrive & 7PM & ANOVA & $\mathrm{X}$ & & & \\
\hline DinOthActFriend & 7PM & ANOVA & & & & $\mathrm{X}$ \\
\hline DinOthActHHMem & 7PM & ANOVA & $\mathrm{X}$ & & & $\mathrm{X}$ \\
\hline DinOthActMusic & 7PM & ANOVA & & & & \\
\hline DinOthActNone & 7PM & ANOVA & $\mathrm{X}$ & & & \\
\hline DinOthActPhone & 7PM & ANOVA & & & & \\
\hline DinOthActRead & 7PM & ANOVA & & & & \\
\hline DinOthActTV & $7 \mathrm{PM}$ & ANOVA & & & & \\
\hline DinOthActWork & 7PM & ANOVA & $\mathrm{X}$ & & & $\mathrm{X}$ \\
\hline DinSameDish & 7PM & ANOVA & & & & \\
\hline F01dMealOth & Final & ANOVA & & & & \\
\hline LuComp & $2 \mathrm{PM}$ & ANOVA & $X$ & & & \\
\hline LuDesk & 2PM & ANOVA & & & $X$ & \\
\hline LuDrive & 2PM & ANOVA & & & $\mathrm{X}$ & \\
\hline LuMusic & 2PM & ANOVA & & & & $\mathrm{X}$ \\
\hline LuNoOth & 2PM & ANOVA & & & $\mathrm{X}$ & \\
\hline LuPhone & $2 \mathrm{PM}$ & ANOVA & $\mathrm{X}$ & & & \\
\hline LuPurchCarryO & 2PM & ANOVA & & $X$ & & \\
\hline LuPurchFastFood & 2PM & ANOVA & & $\mathrm{X}$ & $\mathrm{X}$ & $X$ \\
\hline
\end{tabular}




\begin{tabular}{|c|c|c|c|c|c|c|}
\hline $\begin{array}{l}\text { Topic Area, and } \\
\text { Variable Name }\end{array}$ & Survey & $\begin{array}{l}\text { Analysis } \\
\text { Type }\end{array}$ & $\begin{array}{c}\text { PCA } \\
\# 1\end{array}$ & $\begin{array}{c}\text { PCA } \\
\# 2\end{array}$ & $\begin{array}{c}\text { PCA } \\
\# 3\end{array}$ & $\begin{array}{c}\text { PCA } \\
\# 4\end{array}$ \\
\hline LuPurchPrepFoodsGroc & 2PM & ANOVA & & & & \\
\hline LuPurchSitDown & 2PM & ANOVA & & & & \\
\hline LuPurchVendor & 2PM & ANOVA & $\mathrm{X}$ & $\mathrm{X}$ & $\mathrm{X}$ & \\
\hline LuRead & 2PM & ANOVA & & $\mathrm{X}$ & & \\
\hline LuTV & 2PM & ANOVA & & & & \\
\hline \multicolumn{7}{|l|}{ Cooking Proclivity } \\
\hline BrPurchAvoid & 2PM & ANOVA & & & & \\
\hline BrPurchEnjoy & 2PM & ANOVA & & & & $X$ \\
\hline BrPurchTime & 2PM & ANOVA & & & & \\
\hline F01eEffort & Final & ANOVA & & & & \\
\hline F14aPrepEnjoy & Final & ANOVA & & & & \\
\hline F14bPrepEffort & Final & ANOVA & & & & \\
\hline F14cPrepImp & Final & ANOVA & & $\mathrm{X}$ & & \\
\hline F14dPrepNec & Final & ANOVA & & & & $\mathrm{X}$ \\
\hline F14ePrepMore & Final & ANOVA & & & & $\mathrm{X}$ \\
\hline I09aCookEnjoy & Initial & ANOVA & & & & \\
\hline I09bEatMeal & Initial & ANOVA & $X$ & $\mathrm{X}$ & $X$ & $X$ \\
\hline I09cKnowCook & Initial & ANOVA & & & & \\
\hline I09dMomCook & Initial & ANOVA & & & & $\mathrm{X}$ \\
\hline I09ePlanMeal & Initial & ANOVA & $\mathrm{X}$ & & & \\
\hline I09fCookLots & Initial & ANOVA & & $\mathrm{X}$ & $X$ & \\
\hline I09gCookEnt & Initial & ANOVA & & & & \\
\hline I11aPrepEnjoy & Initial & ANOVA & & & & \\
\hline I11aPrepEnjoy & Initial & ANOVA & & & & \\
\hline I11bPrepEffort & Initial & ANOVA & & & & \\
\hline I11cPrepExp & Initial & ANOVA & & & & \\
\hline I11dPrepHealth & Initial & ANOVA & $X$ & $\mathrm{X}$ & $\mathrm{X}$ & \\
\hline I11ePrepLess & Initial & ANOVA & & & & \\
\hline I11fPrepShare & Initial & ANOVA & & & & \\
\hline LuPurchAvoid & 2PM & ANOVA & & & $\mathrm{X}$ & \\
\hline LuPurchEnjoy & 2PM & ANOVA & $\mathrm{X}$ & & $\mathrm{X}$ & \\
\hline LuPurchReq & 2PM & ANOVA & & & $\mathrm{X}$ & \\
\hline LuPurchTime & 2PM & ANOVA & & & & \\
\hline PurchDinAvoid & 7PM & ANOVA & & & & \\
\hline PurchDinEnjoyTaste & 7PM & ANOVA & & & & \\
\hline PurchDinTime & 7PM & ANOVA & $\mathrm{X}$ & & & \\
\hline \multicolumn{7}{|l|}{ Demographics } \\
\hline F02Age & Final & Chi-Sq & & & & $\mathrm{X}$ \\
\hline F03Marrital & Final & Chi-Sq & $\mathrm{X}$ & & & $\mathrm{X}$ \\
\hline F04Ethnic & Final & Chi-Sq & & & & $\mathrm{X}$ \\
\hline F05Ed & Final & Chi-Sq & & & & \\
\hline F06Income & Final & Chi-Sq & & & & $X$ \\
\hline
\end{tabular}




\begin{tabular}{|c|c|c|c|c|c|c|}
\hline $\begin{array}{l}\text { Topic Area, and } \\
\text { Variable Name }\end{array}$ & Survey & $\begin{array}{c}\text { Analysis } \\
\text { Type }\end{array}$ & $\begin{array}{c}\text { PCA } \\
\# 1 \\
\end{array}$ & $\begin{array}{c}\text { PCA } \\
\# 2 \\
\end{array}$ & $\begin{array}{c}\text { PCA } \\
\# 3 \\
\end{array}$ & $\begin{array}{c}\text { PCA } \\
\# 4 \\
\end{array}$ \\
\hline F07Employ & Final & Chi-Sq & & & & $\mathrm{X}$ \\
\hline F08HHsize & Final & Chi-Sq & & & & $\mathrm{X}$ \\
\hline F09Children & Final & ANOVA & & & $\mathrm{X}$ & $\mathrm{X}$ \\
\hline FBMI & Final & ANOVA & & & & \\
\hline \multicolumn{7}{|l|}{ Other } \\
\hline I08Online & Initial & Chi-Sq & $\mathrm{X}$ & & & \\
\hline I10Health & Initial & Chi-Sq & $X$ & & $X$ & $X$ \\
\hline
\end{tabular}


APPENDIX D: Variable Sets

\begin{tabular}{|c|c|c|}
\hline \multicolumn{3}{|c|}{ Variable Set \#1 } \\
\hline Variable & $\begin{array}{c}\text { Corresponding } \\
\text { Survey Question } \\
\text { (Table 3.3) } \\
\end{array}$ & Survey \\
\hline $\begin{array}{c}\text { Ate Breakfast } \\
\text { Alone }\end{array}$ & AteBfastAlone & 2PM \\
\hline $\begin{array}{c}\text { Ate Breakfast } \\
\text { with } \\
\text { Household }\end{array}$ & BfastwHH & 2PM \\
\hline $\begin{array}{c}\text { Ate Lunch } \\
\text { with Others }\end{array}$ & AteLuOthers & 2PM \\
\hline $\begin{array}{l}\text { Prepared } \\
\text { Lunch }\end{array}$ & PrepLu & 2PM \\
\hline $\begin{array}{c}\text { Used a } \\
\text { Computer } \\
\text { While Eating } \\
\text { Lunch }\end{array}$ & LuComp & 2PM \\
\hline $\begin{array}{l}\text { Ate Dinner } \\
\text { with } \\
\text { Household }\end{array}$ & AteDinHHMem & 7PM \\
\hline $\begin{array}{l}\text { No Other } \\
\text { Activities } \\
\text { Were } \\
\text { Occuring } \\
\text { During } \\
\text { Dinner }\end{array}$ & DinOthActNone & 7PM \\
\hline $\begin{array}{c}\text { Ate Dinner } \\
\text { Alone }\end{array}$ & AteDinAlone & 7PM \\
\hline $\begin{array}{c}\text { Grocery } \\
\text { Shopping }\end{array}$ & GroceryShop & 7PM \\
\hline
\end{tabular}




\begin{tabular}{|c|c|c|}
\hline \multicolumn{3}{|c|}{ Variable Set \#2 } \\
\hline Variable & $\begin{array}{c}\text { Corresponding } \\
\text { Survey Question } \\
\text { (Table 3.3) }\end{array}$ & Survey \\
\hline $\begin{array}{c}\text { Did Not Eat } \\
\text { Breakfast }\end{array}$ & DidNotEatBfast & 2PM \\
\hline $\begin{array}{c}\text { Ate Breakfast } \\
\text { Alone } \\
\end{array}$ & AteBfastAlone & 2PM \\
\hline $\begin{array}{c}\text { Ate Breakfast } \\
\text { with } \\
\text { Household } \\
\end{array}$ & BfastwHH & 2PM \\
\hline $\begin{array}{c}\text { Did Not Eat } \\
\text { Lunch }\end{array}$ & DidNotEatLu & 2PM \\
\hline $\begin{array}{c}\text { Ate Lunch } \\
\text { with Others }\end{array}$ & AteLuOthers & 2PM \\
\hline $\begin{array}{c}\text { Prepared } \\
\text { Lunch }\end{array}$ & PrepLu & 2PM \\
\hline $\begin{array}{c}\text { Used a } \\
\text { Computer } \\
\text { While Eating } \\
\text { Lunch } \\
\end{array}$ & LuComp & 2PM \\
\hline $\begin{array}{l}\text { Did Not Eat } \\
\text { Dinner }\end{array}$ & DidNotEatDin & $7 \mathrm{PM}$ \\
\hline $\begin{array}{l}\text { Ate Dinner } \\
\text { with } \\
\text { Household }\end{array}$ & AteDinHHMem & 7PM \\
\hline $\begin{array}{l}\text { No Other } \\
\text { Activities } \\
\text { Were } \\
\text { Occuring } \\
\text { During } \\
\text { Dinner }\end{array}$ & DinOthActNone & 7PM \\
\hline $\begin{array}{l}\text { Ate Dinner } \\
\text { Alone }\end{array}$ & AteDinAlone & $7 \mathrm{PM}$ \\
\hline $\begin{array}{c}\text { Grocery } \\
\text { Shopping }\end{array}$ & GroceryShop & 7PM \\
\hline
\end{tabular}




\begin{tabular}{|c|c|c|}
\hline \multicolumn{3}{|c|}{ Variable Set \#3 } \\
\hline Variable & $\begin{array}{l}\text { Corresponding } \\
\text { Survey Question } \\
\text { (Table 3.3) }\end{array}$ & Survey \\
\hline $\begin{array}{l}\text { Ate Breakfast } \\
\text { Alone }\end{array}$ & AteBfastAlone & $2 \mathrm{PM}$ \\
\hline $\begin{array}{l}\text { Ate Breakfast } \\
\text { with } \\
\text { Household }\end{array}$ & BfastwHH & $2 \mathrm{PM}$ \\
\hline $\begin{array}{c}\text { Ate Lunch } \\
\text { with Others }\end{array}$ & AteLuOthers & 2PM \\
\hline $\begin{array}{l}\text { Prepared } \\
\text { Lunch }\end{array}$ & PrepLu & 2PM \\
\hline $\begin{array}{c}\text { Used a } \\
\text { Computer } \\
\text { While Eating } \\
\text { Lunch }\end{array}$ & LuComp $\sim$ & 2PM \\
\hline $\begin{array}{l}\text { Driving While } \\
\text { Eating Lunch }\end{array}$ & D19fLuDrive & 2PM \\
\hline $\begin{array}{l}\text { Ate Dinner } \\
\text { with } \\
\text { Household }\end{array}$ & AteDinHHMem & 7PM \\
\hline $\begin{array}{c}\text { Purchased } \\
\text { Dinner }\end{array}$ & PurchasedDinner & 7PM \\
\hline $\begin{array}{l}\text { Someone Else } \\
\text { Prepared } \\
\text { Dinner }\end{array}$ & SomeElsePrepDin & 7PM \\
\hline $\begin{array}{l}\text { No Other } \\
\text { Activities } \\
\text { Were } \\
\text { Occuring } \\
\text { During } \\
\text { Dinner }\end{array}$ & DinOthActNone & 7PM \\
\hline $\begin{array}{l}\text { Grocery } \\
\text { Shopping }\end{array}$ & GroceryShop & $7 \mathrm{PM}$ \\
\hline
\end{tabular}

